\title{
WestVirginiaUniversity
}

THE RESEARCH REPOSITORY @ WVU

Graduate Theses, Dissertations, and Problem Reports

2005

\section{Investigation of moisture sensitivity of hot mix asphalt concrete}

Anu Ganesan Viswanathan

West Virginia University

Follow this and additional works at: https://researchrepository.wvu.edu/etd

\section{Recommended Citation}

Viswanathan, Anu Ganesan, "Investigation of moisture sensitivity of hot mix asphalt concrete" (2005). Graduate Theses, Dissertations, and Problem Reports. 1664.

https://researchrepository.wvu.edu/etd/1664

This Thesis is protected by copyright and/or related rights. It has been brought to you by the The Research Repository @ WVU with permission from the rights-holder(s). You are free to use this Thesis in any way that is permitted by the copyright and related rights legislation that applies to your use. For other uses you must obtain permission from the rights-holder(s) directly, unless additional rights are indicated by a Creative Commons license in the record and/ or on the work itself. This Thesis has been accepted for inclusion in WVU Graduate Theses, Dissertations, and Problem Reports collection by an authorized administrator of The Research Repository @ WVU. For more information, please contact researchrepository@mail.wvu.edu. 


\title{
Investigation of Moisture Sensitivity of Hot Mix Asphalt Concrete
}

\author{
By \\ Anu Ganesan Viswanathan \\ Thesis submitted to the College of Engineering and Mineral Resources \\ at West Virginia University \\ in partial fulfillment of the requirements for the degree of \\ Master of Science \\ in \\ Civil Engineering \\ John P. Zaniewski, Ph.D., Chair \\ Ronald W. Eck, Ph.D. \\ Udaya B. Halabe, Ph.D. \\ Department of Civil and Environmental Engineering \\ Morgantown, West Virginia 26506 \\ 2005
}

$\underline{\text { Key Words }}$

Asphalt mix design, stripping potential, Marshall Stabilometer, laboratory conditioning, indirect tensile strength, tensile strength ratio and antistrip additives 


\section{ABSTRACT \\ Investigation of Moisture Sensitivity of Hot Mix Asphalt Concrete}

\section{Anu Ganesan Viswanathan}

The Superpave mix design procedure was implemented at the end of Strategic Highway Research Program (SHRP). Prior to implementing Superpave mix design method, WVDOH used Marshall mix design method. National standards for Marshall method do not require testing for potential moisture damage problems. However, Superpave method requires that mix designers evaluate potential moisture sensitivity problem using AASHTO T 283, "Resistance of Compacted Bituminous Mixture to Moisture Induced Damage". West Virginia, in compliance with national standards, requires the use of this test for development of Superpave mix designs.

The objective of this research project is to evaluate impact of change in AASHTO T 283 test method on Superpave mix designs in West Virginia. The Lottman test method and Tunnicliff and Root test method were combined into Modified Lottman test procedure and published as AASHTO T 283 in 1985 and revised in 1989. Research was done to establish how the Superpave compaction and conditioning method affect the test results. As a result of this research, AASHTO T 283 test method was revised in 2003. In the 2003 version, use of gyratory compactor was allowed and changes were made to sample preparation, air void tolerance level, sample conditioning method, and method of testing samples. The major change was a mandatory freeze-thaw cycle to condition samples.

This research examined the application of the current AASHTO T 283 applied to West Virginia mixes. It was concluded that this is not a reliable test method for moisture sensitivity. The 2003 version of the test does not improve the ability of the test to identify moisture sensitive mixes. 


\title{
DEDICATION
}

\author{
THIS THESIS IS DEDICATED TO MY FAMILY \\ WHO HAVE MADE IT POSSIBLE FOR ME TO COMPLETE MY \\ MASTERS DEGREE IN WVU
}




\section{ACKNOWLEDGEMENTS}

I would like to express my gratitude to my advisor, Dr. John Zaniewski, who provided a motivating and enthusiastic atmosphere. It was a great pleasure for me to work under his supervision. I am sincerely thankful for his patience and time when guiding me throughout this research endeavor.

I am thankful to Dr. Ronald Eck and Dr. Udaya Halabe, members of my thesis committee, for their precious time and guidance.

Special thanks to my Lab mates at WVU Asphalt Technology Laboratory, for their support and assistance.

The research sponsorship of the West Virginia Division of Highways is appreciated. The support of the asphalt paving industry in West Virginia also contributed to the success of this research, in particular, the materials supplied by J.F. Allen Company, New Enterprise Stone and Lime, Carl Kelly Paving Inc., and Marathon Ashland Petroleum, LLC.

I am thankful to my Parents, Sister and Aunt, who made me realize the importance of advanced studies. I would like to extend my thanks to my friend Vijay who always helped me with testing. Their love and support have been a source of strength and motivation. 


\section{TABLE OF CONTENTS}

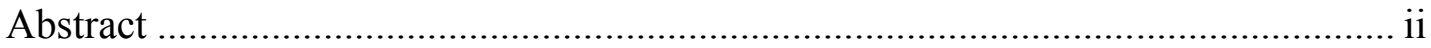

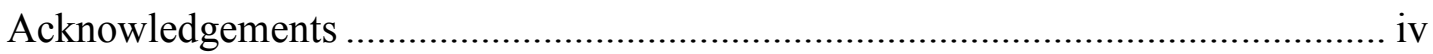

TABLE OF CONTENTS ………………………………................................

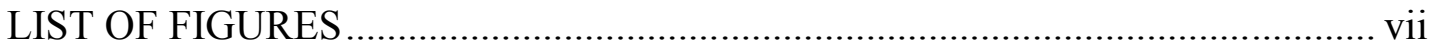

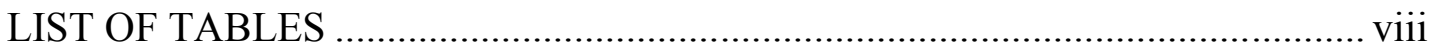

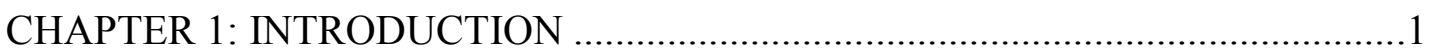

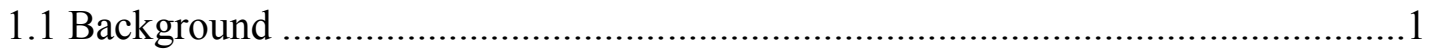

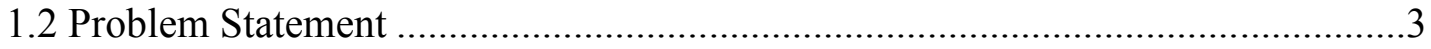

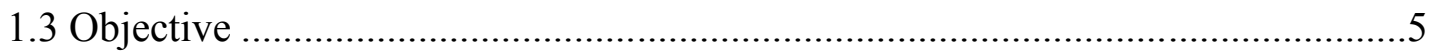

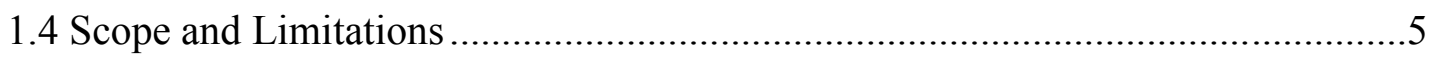

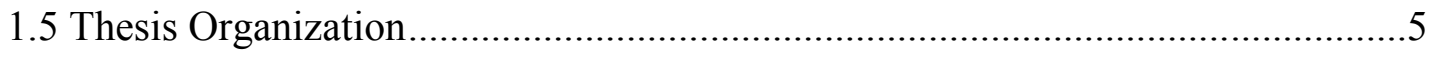

CHAPTER 2: LITERATURE REVIEW ……………….................................

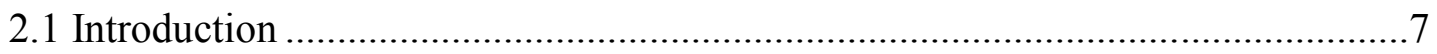

2.2 Stripping Mechanisms .............................................................................

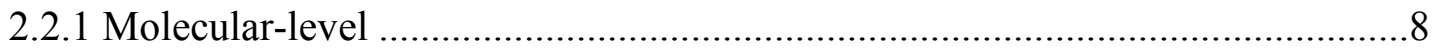

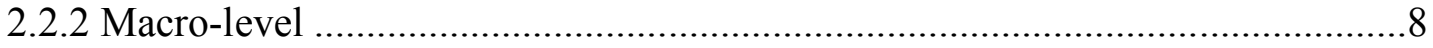

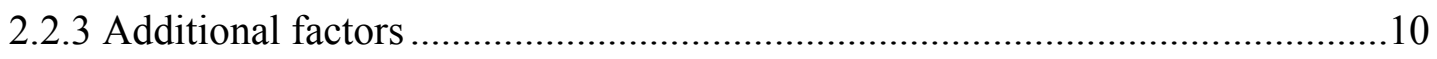

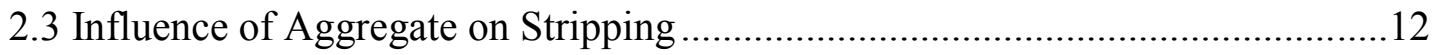

2.4 Engineering and Construction Considerations .....................................................12

2.4.1 Inadequate pavement drainage ……………………....................................13

2.4.2 Inadequate compaction .............................................................................13

2.4.3 Excessive dust coating on aggregate ..............................................................14

2.4.4 Inadequate drying of aggregate …………………........................................14 
2.4.5 Weak and friable aggregate.......................................................................14

2.4.6 Waterproofing membranes and seal coats .......................................................14

2.5 Tests Methods for Moisture Susceptibility …………………............................15

2.6 Evaluation of Moisture Susceptibility Tests ……………..................................18

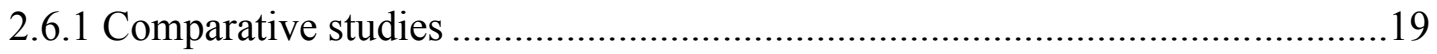

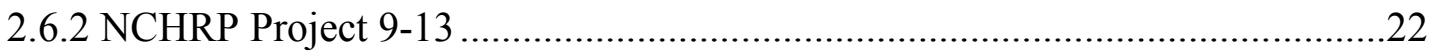

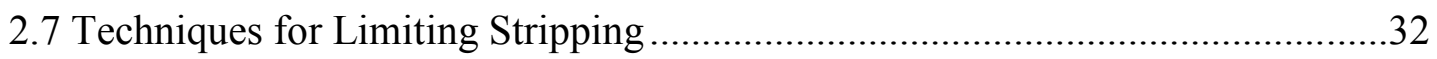

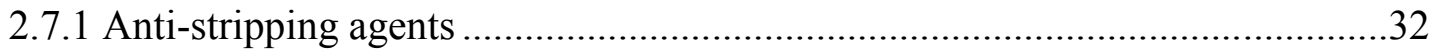

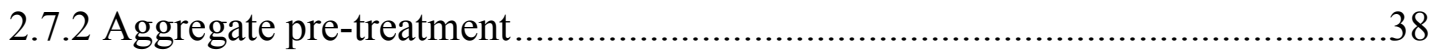

2.8 Identification of Moisture Damage in the Field ....................................................38

2.8.1 Maupin's procedure

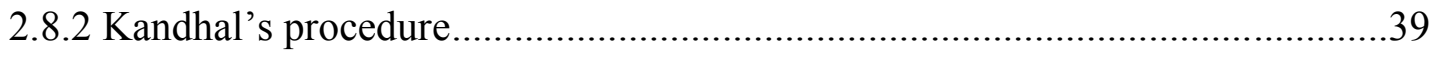

2.8.3 Tunnicliff and Root's procedure ………………............................................41

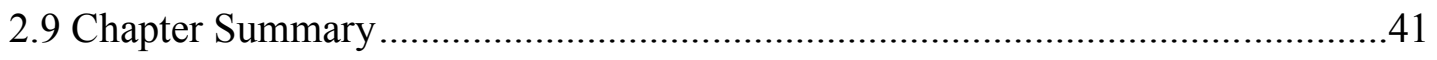

CHAPTER 3: EXPERIMENTAL DESIGN AND TESTING PROCEDURES .........43

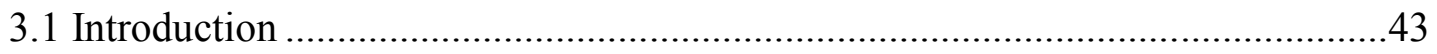

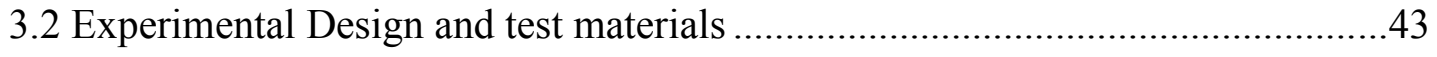

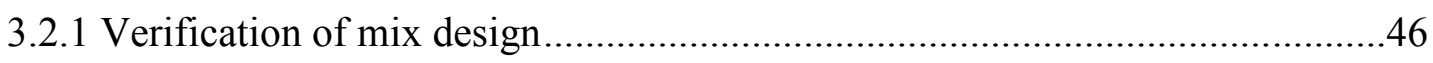

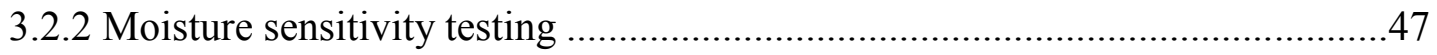

3.2.1 Loose mix aging and compacted mix aging .....................................................50

3.2.2 Sample selection................................................................................50

CHAPTER 4 DATA COLLECTION AND ANALYSIS ...........................................58

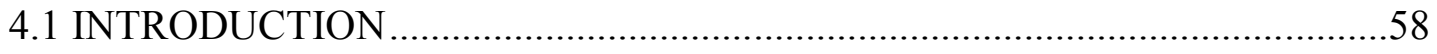

4.2 VOLUMETRIC PROPERTIES ………………………….............................58 


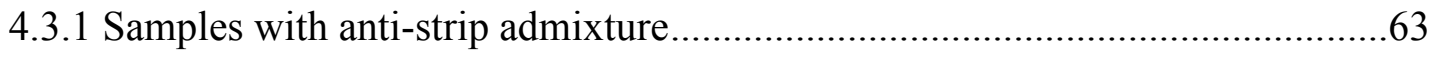

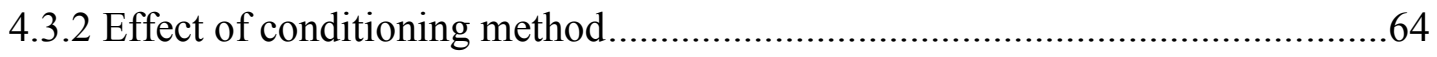

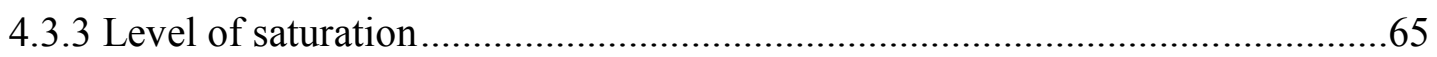

CHAPTER 5: CONCLUSIONS AND RECOMMENDATIONS ..........................66

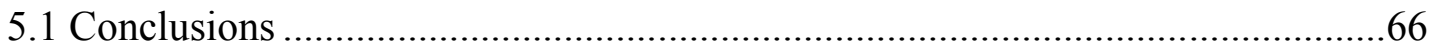

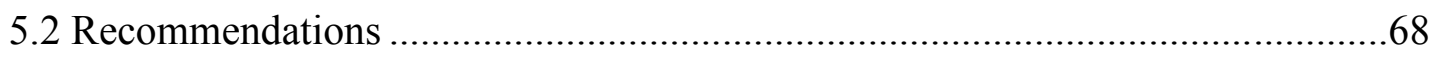

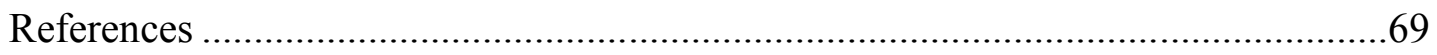

Appendix A - Mositure sensitivity data set ....................................................... 72

\section{LIST OF FIGURES}

Figure 1.1 Failed pavement on I-68 in West Virginia..........................................

Figure 1.2 Generalized flow chart for identifying moisture-related

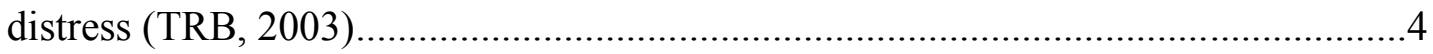

Figure 2.1 Typical appearance of stripping in compacted mix (TRB, 2003)............11

Figure 2.2 Effect of anti-strip agent on surface bonding of aggregate and asphalt

(a) untreated (b) treated (Ksaibati and Conner 2004)

Figure 2.3 Deterioration curve for an asphalt pavement (Maupin, 1999;

Bahia, et al., 1999)

Figure 3.1 Gradation for $9.5 \mathrm{~mm}$ limestone aggregates from J.F. Allen source

Figure 3.2 Gradation for $9.5 \mathrm{~mm}$ limestone aggregates from New Enterprise source

Figure 3.3 Gradation for $19 \mathrm{~mm}$ limestone aggregates from Carl Kelly source

Figure 3.4 Flow chart for the AASHTO T 283 test method.

Figure 3.5 Sample subjected to dry conditioning .51

Figure 3.6 Vacuum apparatus. .52 
Figure 3.7 Sample subjected to wet conditioning

Figure 3.8 IDT Strength test setup and failure plane

Figure 3.9 Measuring tensile strength for the dry subset using Marshall Stability and Flow Machine .56

Figure 3.10 Measuring tensile strength for the saturated no freeze-thaw subset using Marshall Stability and Flow Machine.

Figure 3.11 Measuring tensile strength for the saturated freeze-thaw subset using Marshall Stability and Flow Machine 57

Figure 4.1 Comparison of tensile strength for different sample conditioning (without anti-strip)

Figure 4.2 Comparison of tensile strength ratio for subsets with and without anti-strip.

Figure 4.3 Comparison of tensile strength for different sample conditioning (with anti-strip)

Figure 4.4 Comparison of tensile strength for subsets with and without anti-strip....64

\section{LIST OF TABLES}

Table 2.1 Factors contributing to moisture-related distress (TRB, 2003) .................13

Table 2.2 Summary of AASHTO T 283 test parameters

Table 2.3 NCHRP Project 9-13 experimental plan for tasks 3 and 4 (Epps, et al., 2000)

Table 2.4 ANOVA for complete factorial NCHRP Project 9-13 (Epps, et al., 2000)

Table 3.1 Time schedule for test procedure of AASHTO T 283

Table 4.1 Comparison of volumetric properties .59

Table 4.2 Indirect tensile strength and TSR for all three sources .60

Table 4.3 Comparison of saturation level .65 


\section{CHAPTER 1: INTRODUCTION}

\subsection{BACKGROUND}

The West Virginia Division of Highways (WVDOH) uses the Superpave as the primary mix design method for pavements on high volume roads in the state. In general, the performance of these pavements has met expectations. However, overlay projects on I-68 in 1999 and 2000 developed major distress, such as shown in Figure 1.1, during the 2003-2004 winter. Preliminary investigation examined lack of compaction of longitudinal joints, stripping of the asphalt and deterioration of the aggregate as potential causes of the premature failure. The observation of stripping on this project was unique to the WVDOH as prior to this failure, it was believed that stripping was not a problem in the state. The state did not require the use of a stripping test with the Marshall mix design method. However, in compliance with national standards, the state requires it for mixes designed with the Superpave method. Experience gained with the problems associated with these failed pavements on I 68 lead to this research on issues associated with stripping of pavements in West Virginia.

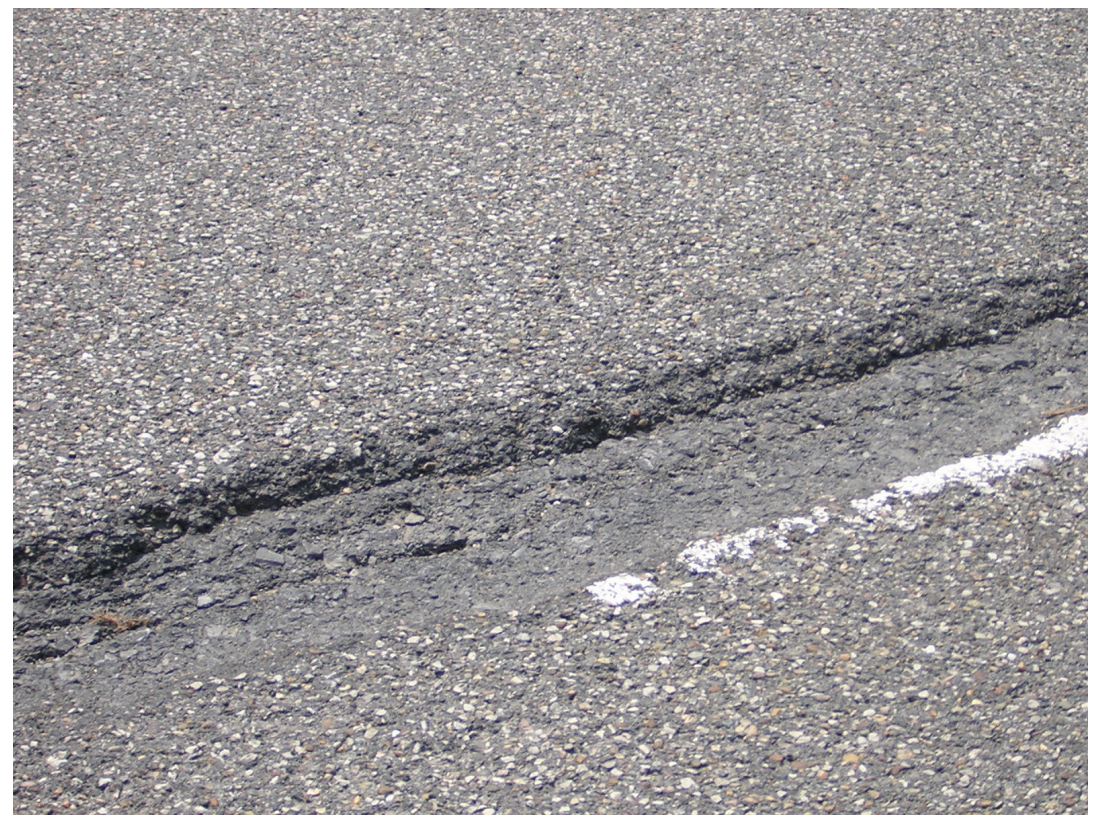

Figure 1.1 Failed pavement on I-68 in West Virginia

Lottman, et al. (1988) found that moisture damage of asphalt concrete pavements was a problem experienced by more than one-half of the State Highway Agencies (SHA) 
in the United States. In a seminar on Moisture Sensitivity of Asphalt Pavements, it was reported (TRB, 2003) that 82 percent of highway agencies require the use of an antistrip additive in hot mix asphalt concrete, HMAC. The WVDOH response to the survey conducted for Moisture Sensitivity of Asphalt Pavements seminar was that stripping was not a problem in the state.

Moisture damage could manifest itself in asphalt pavements either due to stripping or the softening of asphalt, both of which result in loss of ability to resist trafficinduced stresses. Asphalt concrete mix derives its strength from the cohesion of the binder, and the interlocking and frictional resistance of the aggregates. The cohesion of the binder is fully available if a good bond exists between the aggregates and asphalt cement. In the presence of a good bond, failure of the mix should occur within the binder or the aggregates, due to softening or brittle cracking of the binder, and breakdown of the aggregates. If the bond is poor, failure could occur at the aggregate-asphalt interface, thereby leading to premature failure of the mix. This premature failure of the bond is commonly referred to as stripping in asphalt pavements (Kanitpong and Bahia, March 2003). Stripping in general, is defined as the physical separation of the asphalt cement and aggregates due to the loss of adhesion between the asphalt cement and the aggregate surface (Hunter and Ksaibati, 2002). Due to the degradation of material, the most common method for rehabilitating a stripped pavement involves the removal and replacement of the stripped material (Johnson and Freeman, 2002).

Due to the extent of the stripping problem, extensive research has been performed. The mechanisms associated with stripping are complex and no cohesive theory exists that explains the development of stripping. Research has shown that stripping is associated with several factors (Lottman, et al., 1988, Hunter and Ksaibati, 2002, Epps, et al., 2000, and TRB, 2003):

ability of asphalt to bond with aggregate dust coating on aggregate residual moisture in the HMAC during construction moisture penetration into the pavement structure 
traffic loads

freeze-thaw

Since there is no theory to explain the stripping phenomenon, empirical methods are used to evaluate the potential that an asphalt concrete may have a stripping problem. These test methods range from simple qualitative observations of conditioned samples to more elaborate methods of conditioning and testing samples in a qualitative manner. However, due to the empirical nature of the tests, it is necessary to relate the observations from the tests to the performance of the HMAC in the field. The determination of a stripping problem in the field is not straight forward. Figure 1.1 provides a flow chart for evaluating pavement problems that may be associated with stripping. The process begins with the identification of pavement distresses. The symptoms or indicators of stripping include several forms of distress, such as alligator cracking, longitudinal cracking, etc. While these distresses may be a manifestation of a stripping problem, they are not uniquely associated with stripping. Therefore further evaluation of the problem is needed by sampling or coring the pavement. A stripping problem only exists if the samples crumble easily and there is evidence that the asphalt has separated from the aggregate. Otherwise the pavement distress would be associated with a different mechanism.

\subsection{PROBLEM STATEMENT}

Prior to implementing the Superpave mix design method, the WVDOH used the Marshall mix design method. National standards for the Marshall method do not require testing for potential moisture damage problems. Since stripping was not considered to be a problem in the state, the WVDOH did not require testing for it (TRB, 2003). However, the Superpave method requires that mix designers evaluate potential moisture problems using AASHTO Standard Method of Test T283, "Resistance of Compacted Bituminous Mixture to Moisture Induced Damage". So West Virginia requires the use of this test for Superpave mix designs.

The 1989 version of AASHTO T 283, which was applicable when Superpave was implemented, allowed two methods of conditioning the samples; one that required saturation only and one that required both saturation and freezing of the samples. WVDOH specifications were silent as to the conditioning method. This allowed the 
materials designers to select between the two conditioning methods and the practice in the state was to use saturation only method. However, in 2003, the testing protocol of T283 was altered; the option of conditioning with only saturation was removed. This forces the material designers to use the saturation plus freezing procedure which adds significant time, effort and experience to the preparation of mix designs.

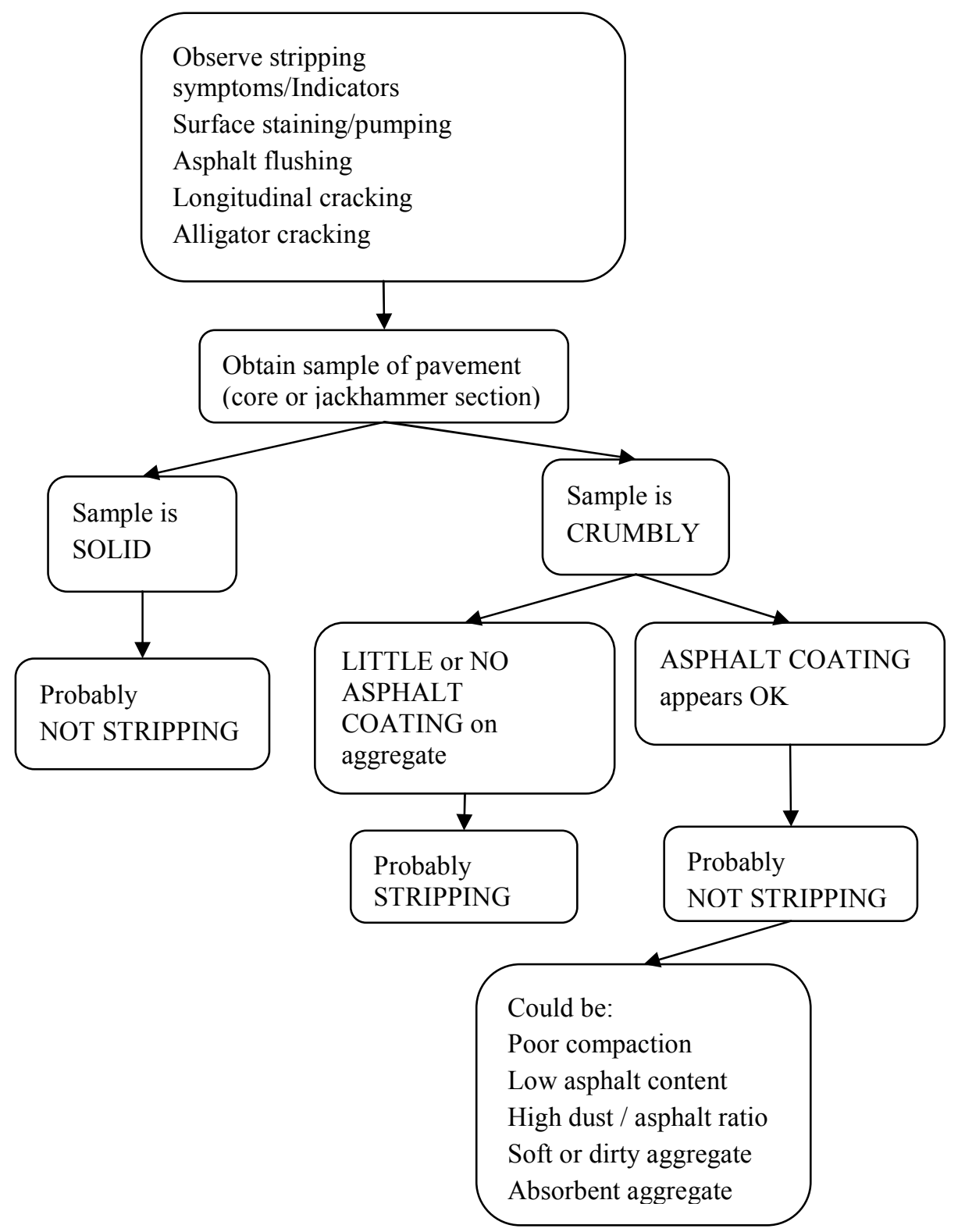

Figure 1.2 Generalized flow chart for identifying moisture-related distress (TRB, 2003) 


\subsection{OBJECTIVE}

The objective of this research project is to evaluate the impact of the change in AASHTO T 283 conditioning procedure on Superpave mix designs in West Virginia. Since it was believed that the conditioning method with freezing is more severe than the saturation only method, it was decided to investigate if antistrip agents would allow mixes which otherwise failed the moisture damage requirement to pass the specification.

\subsection{SCOPE AND LIMITATIONS}

This research focused on the potential implementation by the West Virginia Division of Highways, WVDOH. All materials used during the research were typical of those used in the state. Hence, two Nominal Maximum Aggregate Sizes (NMAS) 9.5 $\mathrm{mm}$ and $19 \mathrm{~mm}$ commonly used by WVDOH were selected for this experiment. Similarly, a PG70-22 binder was selected, which is typically used in West Virginia for Superpave mixes.

The work was limited to the instruments available in the Asphalt Technology Laboratory of West Virginia University, Morgantown. A Marshall Stabilometer, with a split tensile loading head, was used to determine the tensile strength of asphalt mixtures. The loading head has steel strips, with an internal diameter of $150 \mathrm{~mm}$. All samples were compacted with a Superpave Gyratory Compactor (SGC).

\subsection{THESIS ORGANIZATION}

Chapter 2 of this report is a literature review of moisture susceptibility, stripping, existing techniques for limiting moisture effects, anti-stripping additives, test methods for moisture susceptibility, case studies on AASHTO T 283 test method, and various mechanisms of stripping.

Chapter 3 discusses the experimental design and explains the test procedures followed during the process of this research. It describes the materials used for the production of cores, effect of freeze-thaw cycles on the HMA specimens, and how the Marshall Stability and Flow Machine were used for testing moisture susceptibility. 
Chapter 4 includes the data collected throughout this research project and the analysis of the laboratory test results. In this chapter, the tensile strength ratios (TSR) of the conditioned specimens with and without the addition of anti-stripping additives were determined using Marshall Stability machine and the test results can be found in Appendix A.

Chapter 5 presents conclusions from this research and recommendations for further research. 


\section{CHAPTER 2: LITERATURE REVIEW}

\subsection{INTRODUCTION}

Stripping is a major distress occurring in hot mix asphalt (HMA) pavements in the United States and in various parts of the world. Pavement performance is adversely affected by stripping and unforeseen increases in maintenance are often incurred (Lottman, et al., 1988). Environmental factors such as temperature and moisture can have a profound effect on the durability of hot mix asphalt pavements. When critical environmental conditions are coupled with traffic and poor materials, premature failure may occur as a result of stripping of the asphalt binder from the aggregate particles (West, et al., 2004).

\subsection{STRIPPING MECHANISMS}

Moisture-related problems are due to or are accelerated by:

- Adhesive failure - stripping of the asphalt film from the aggregate surface, or

- Cohesion failure-loss of mixture stiffness.

Adhesive failure in aggregates and asphalt occurs at an interface, while cohesive failure occurs directly within asphalt or aggregate surface (Shah, 2003). These mechanisms can be associated with the aggregate, the binder, or the interaction between the two ingredients. When a weakening in the bond between the aggregate and asphalt cement occurs, loss of strength of the HMA can be sudden in some cases where the asphalt and aggregates are influenced by more than one factor or mechanism. Stripping usually begins in the bottom of the HMA layer, and travels upward. A typical situation is a gradual loss of strength over a period of years, which allows rutting and shoving to develop in the wheel path. Many times, stripping is difficult to identify because surface indicators may take years to show. Also, many surface indicators are possible and may include: rutting, shoving, corrugations, raveling, and cracking. It is necessary to look at the cores of the HMA mix to identify stripping. In some cases of stripping, a HMA mix has lost so much adhesion between the aggregate and asphalt that a core cannot be removed in one piece (Hunter and Ksaibati, 2002). 


\subsubsection{Molecular-level}

Stripping of asphalt pavements occurs at the molecular level and is not entirely understood in spite of extensive research. It is thought to be associated with either one or both of the following two phenomena. First, water can interact with asphalt binder to cause a reduction in cohesion with subsequent reduction in stiffness and strength of the mix. Second, and more commonly believed, water can get between the asphalt film and the aggregate, break the adhesive bond, and strip the asphalt binder from the aggregate (Johnson and Freeman, 2002).

The nature of the adhesive bond between the asphalt binder and aggregate is a subject of some debate. Adhesion is defined as that physical property or molecular force by which one body sticks to another of another nature. Several factors affect the adhesion of the asphalt binder to the aggregate, including: interfacial tension between the asphalt binder and the aggregate, chemical composition of the asphalt binder and aggregate, binder viscosity, surface texture of the aggregate, aggregate porosity, aggregate cleanliness, aggregate temperature and moisture content at the time of mixing (Johnson and Freeman, 2002).

Four general theories of adhesion exist to explain the adhesion of asphalt binder to aggregates. These include the Mechanical Interlocking Theory, the Chemical Reaction Theory, the Surface Energy Theory, and the Molecular Orientation Theory. The actual nature of adhesion is not fully explained by any one of these theories, but is partially explained in each theory (Johnson and Freeman, 2002).

\subsubsection{Macro-level}

There are several ways that moisture affects bituminous mixtures. Once moisture accesses the mix, the mix structure is weakened. The mix losses stiffness and it fails under repeated traffic loading. There are five mechanisms for the asphalt film to be stripped from an aggregate surface. These mechanisms may act individually or together. A brief description of each mechanism follows.

\subsubsection{Detachment}

Detachment is the microscopic separation of a binder film from the aggregate surface by a thin layer of water with no obvious break in the binder film. The binder will 
then peel cleanly from the aggregate. The thin film of water probably results from either aggregate that was not completely dried, interstitial pore water which vaporized and condensed on the surface, or possibly water which permeated through the asphalt film to the interface (Johnson and Freeman, 2002).

\subsubsection{Displacement}

Displacement occurs when the binder is removed from the aggregate surface by water. In this type of stripping, as compared to detachment, the free water gets to the aggregate surface through a break in the binder coating. The break may be from incomplete coating during mixing or from binder film rupture (Johnson and Freeman, 2002).

\subsubsection{Spontaneous emulsification}

Spontaneous emulsification occurs when an inverted emulsion of water droplets in asphalt cement forms rather than the converse. Investigators have noted that this process can be exacerbated under traffic on mixtures laden with free water. Fromm (1974) conducted experiments to demonstrate the formation of an emulsion in which he observed that once the emulsion formation penetrated to the substrate, the adhesive bond was broken. Fromm (1974) and many investigators have observed the formation of a brownish color on the surface of asphalt films (approximately 1/8 inch) in severely stripped mixtures as well as on asphalt films submerged in water (Kiggundu and Roberts, 1988).

\subsubsection{Film rupture}

Film rupture is reported to initiate stripping when film fissures occur at sharp aggregate contact, or points due to dust particles on the aggregate surface. The rupture may occur due to construction loads, operating traffic during service conditions, or could be environmentally induced by freeze-thaw cycling. Once a break in the film occurs, moisture has access to the interface and initiates stripping (Kiggundu and Roberts, 1988).

\subsubsection{Pore pressure}

This mechanism precipitates from the presence of water in the pore structure of the HMA locations where segregation is prevalent at layer boundaries when heavy traffic loadings occur and during freeze-thaw cycling. Due to pore pressure, pavement layers 
are known to strip at the interfaces, pavement layers have been observed to disintegrate usually from bottom upward, and in a few instances disintegration within a layer in both directions. In a majority of cases, the binder layers disintegrate first followed by surface layers. Lottman, as cited by Kiggundu and Roberts, (1988) postulated a pore pressure mechanism produced the deterioration of the asphalt (Kiggundu and Roberts, 1988).

Kandhal, et al. (1989) found that water and/or water vapor was enters the pavement overlay from underneath, primarily through the longitudinal and transverse joints cracks in the PCC pavement. Water vapor accumulated in the pavement layers during the day condenses during the night resulting in saturation of the asphalt overlay. With saturation, the pore water pressure developed by differential thermal expansion and cyclic stresses from the traffic ruptures the asphalt-aggregate bond causing stripping.

\subsubsection{Hydraulic scouring}

Hydraulic scouring is caused by the occurrence of a capillary tension/compression phenomenon around a moving heavy traffic wheel on a saturated HMA structure. The asphalt is stripped off the aggregate, producing defects such as surface raveling. In addition, dust is reported to mix with rainwater and, in the presence of traffic, can enhance the abrasion of asphalt films from the aggregate (Kiggundu and Roberts, 1988).

\subsubsection{Additional factors}

Several additional factors have been suggested to also contribute to stripping, including the use of open-graded friction courses, the use of excess anti-strip additives, the use of siliceous aggregates, and the use of aggregates that have relatively high surface potentials, those that impart a high $\mathrm{pH}$ value to water in contact with their surfaces (Johnson and Freeman, 2002).

Weather conditions during construction have been related to stripping behavior. If the weather is cool and wet during construction, moisture damage is more likely to occur. During a pavement's life, environmental factors such as temperature fluctuations, freeze-thaw cycles, and wet-dry cycles have been suggested to influence stripping. All other factors being equal, it is suggested that increased repetitions of traffic loading accelerate stripping (Johnson and Freeman, 2002). 
There are many possible causes of stripping; however, all involve excess moisture in the HMA. There are many ways in which moisture can enter the HMA pavement layers: capillary action from the water table, run off from the road surface, and seepage from surrounding areas are a few examples. If adequate drainage is not present, air voids in the HMA may become saturated with moisture, thereby increasing pressure and weakening the bond (Hunter and Ksaibati, 2002).

Most mix designs specify an air void content of 3 to 5 percent. When the air void content is below 5 percent, HMA materials have been shown to be almost impervious to water. During construction, compaction control is not always good and high air void contents can result. If an air void content is above 8 percent, water can readily seep into the material. Excessive dust coating on an aggregate can inhibit coating by asphalt and provide channels for water to penetrate. Other contributing factors to stripping may include the use of open-graded asphalt friction; coarse, inadequate drying of aggregate; weak aggregate; overlays on deteriorated concrete pavements; waterproofing membranes; and seal coats (Hunter and Ksaibati, 2002). Figure 2.1 shows the effect of moisture damage on the compacted specimens prepared for a moisture susceptibility tests.

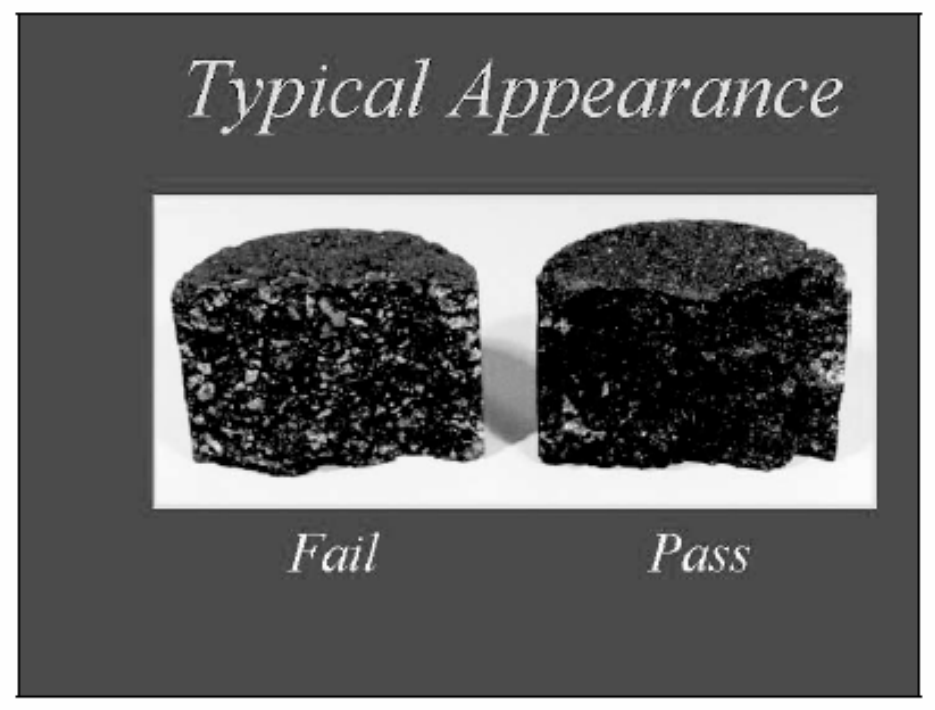

Figure 2.1 Typical appearance of stripping in compacted mix (TRB, 2003) 


\subsection{INFLUENCE OF AGGREGATE ON STRIPPING}

There are number of factors that influence the asphalt-aggregate bond: surface texture, penetration of pores and cracks with asphalt, aggregate angularity, aging of the aggregate surface through environmental effects, adsorbed coatings on the surface of the aggregate, and the nature of dry aggregates versus wet aggregates (TRB, 2003).

Surface texture of the aggregate affects its ability to be properly coated, and a good initial coating is necessary to prevent stripping. Cheng, et al. (2002) demonstrated that the adhesive bond, calculated from basic surface energy measurements of the asphalt and aggregate, between certain granites and asphalt was higher than between limestone aggregate and asphalt when the bond was quantified as energy per unit of surface area. However, when the bond was quantified as energy per unit of aggregate mass, the bond energy was far greater for the calcareous aggregates than for the siliceous. These results agreed well with mechanical mixture testing and clearly showed the importance of the interaction of the physical and the chemical bond. Besides the importance of a good mechanical bond promoted by the surface texture, stripping has been determined to be more severe in angular aggregates because the angularity may promote bond rupture of the binder or mastic, leaving a point of intrusion for the water. Cheng, et al. (2002) substantiated this as they have shown that, regardless of the strength of the bond between the asphalt and aggregate, the bond between water and aggregate is considerably stronger (TRB, 2003).

The coarse and fine aggregate characteristics are important factors related to moisture damage. There is some evidence that moisture damage can be minimal if stripping is restricted only to the coarse aggregate. If the fine aggregate strips, severe damage can occur because the fine aggregate constitutes the basic matrix of the mixture (Pan and White, 1999).

\subsection{ENGINEERING AND CONSTRUCTION CONSIDERATIONS}

Moisture-related distresses are also accelerated by mix design or construction issues, including those given in Table 2.1. The initiation of one or more of the previously described stripping mechanisms is attributable to engineering and/or construction problems. These problems include, but are not necessarily limited to, inadequate 
pavement drainage, inadequate compaction, excessive dust coating on the aggregate, inadequate drying of aggregates, weak and friable aggregates, and the use of waterproofing membranes and seal coats. Each factor will be briefly described below (Johnson and Freeman, 2002).

Table 2.1 Factors contributing to moisture-related distress (TRB, 2003)

\begin{tabular}{|c|c|}
\hline Mix Design & $\begin{array}{l}\text { - Binder and aggregate chemistry } \\
\text { - Binder content } \\
\text { - Air voids } \\
\text { - Additives }\end{array}$ \\
\hline Production & $\begin{array}{l}\text { - Percent aggregate coating and quality of passing the No. } 200 \text { sieve } \\
\text { - Temperature at plant } \\
\text { - Excess aggregate moisture content } \\
\text { - Presence of clay }\end{array}$ \\
\hline Construction & $\begin{array}{l}\text { - Compaction - high in-place air voids } \\
\text { - Permeability—-high values } \\
\text { - Mix segregation } \\
\text { - Changes from mix design to field production (field variability) }\end{array}$ \\
\hline Climate & $\begin{array}{l}\text { - High-rainfall areas } \\
\text { - Freeze-thaw cycles } \\
\text { - Desert issues (steam stripping) }\end{array}$ \\
\hline Other Factors & $\begin{array}{l}\text { - Surface drainage } \\
\text { - Subsurface drainage } \\
\text { - Rehab strategies-chip seals over marginal HMA materials } \\
\text { - High truck traffic }\end{array}$ \\
\hline
\end{tabular}

\subsubsection{Inadequate pavement drainage}

Inadequate surface drainage and/or subsurface drainage allow the water that is necessary for stripping to occur to remain in the pavement system. Water can enter the pavement layers in numerous ways. Surface water can percolate down from the surface, usually through surface cracks. It can also seep in from the sides and bottom from sources such as ditches or high groundwater. Water can also enter the bottom of the pavement system by the upward forces of capillarity or as rising vapor condensation due to water in the subgrade or subbase (Johnson and Freeman, 2002).

\subsubsection{Inadequate compaction}

High air voids present in the asphalt layers allow the movement of water through these pore spaces. Studies have shown that at less than $4 \%$ to $5 \%$ air void content, the 
voids are generally not interconnected and, therefore, impervious to water. While most asphalt mixes are designed to have $3 \%$ to $5 \%$ air voids, many agencies allow a maximum air void content of $8 \%$ at construction assuming that the remaining compaction will occur under 2 to 3 years of traffic. If the pavement remains pervious for an extended period of time, stripping is likely to occur due to ingress of water and hydraulic pore pressures induced by traffic (Johnson and Freeman, 2002).

\subsubsection{Excessive dust coating on aggregate}

The problem created by excessive dust coating on the aggregate is two-fold. First, the presence of dust and clay coatings on the aggregate inhibits intimate contact and complete wetting of the aggregate by the asphalt cement. Because the asphalt is adhered to the dust coating and not the aggregate itself, the binder is easily stripped from the aggregate. Second, the presence of dust particles enhances the action of scouring under the effects of traffic (Johnson and Freeman, 2002).

\subsubsection{Inadequate drying of aggregate}

Aggregate that absorbs or adsorbs water will strip easily if not properly dried. This results from the asphalt being displaced from the aggregate by the thin layer of water already present. A dry aggregate surface will have increased adhesion with the asphalt cement compared to a moist or wet surface (Johnson and Freeman, 2002).

\subsubsection{Weak and friable aggregate}

If weak and friable aggregate is used in an asphalt mix, degradation is possible during rolling and subsequently under heavy traffic. Degradation or delamination exposes uncoated aggregate surfaces, which will readily absorb water and initiate the stripping process (Johnson and Freeman, 2002).

\subsubsection{Waterproofing membranes and seal coats}

If moisture is present beneath the pavement, then sealing the road surface can be detrimental in terms of stripping. A seal coat or membrane, either on or within the pavement layers, acts as a vapor barrier trapping moisture in the asphalt which facilitates stripping (Johnson and Freeman, 2002). 


\subsection{TESTS METHODS FOR MOISTURE SUSCEPTIBILITY}

As demonstrated above, the stripping mechanism is very complex. Consequently, research has focused on the development of empirical tests to identify asphalt concrete mixes that are susceptible to stripping. There are no fundamental engineering tests available to address the stripping problem.

Test methods to evaluate moisture damage have been under development since the 1930's. There are four standard test methods for evaluating the moisture susceptibility of hot mix asphalt concrete, the Boiling Test ASTM D 3625, the Immersion Compression test, AASHTO T 165, and the Modified Lottman procedure, AASHTO T 283 and ASTM D 4867. The primary difference between the AASHTO and ASTM versions of the modified Lottman test is that the ASTM procedure did not include a freeze-thaw conditioning of the samples. AASHTO T 182 is used for evaluating the moisture susceptibility of bituminous mixtures made with emulsions, cut-backs, and semi-solid bituminous binders; since this method is not properly applied to HMAC it is not considered further. In addition to the standard test methods, several procedures have been used on a research basis to evaluate moisture susceptibility; most notably the Hamburg method (Roberts, et al., 1996) and the Environmental Conditioning System (Roberts, et al., 1996) developed during the Strategic Highway Research Program (SHRP). Since the objective of this research is to evaluate methods and procedures used by the WVDOH, only AASHTO T 283 procedure is considered in the following.

The Lottman test has its origins in NCHRP Project 192 with follow-up studies by Tunnicliff and Root. The efforts of Lottman, Tunnicliff and Root were combined into the Modified Lottman procedure published as AASHTO T 283 in 1985 (Hunter and Ksaibati, 2002). There were revisions to T 283 in 1989 and 2003. The SHRP researchers recommended the use of AASHTO T283 to evaluate the water sensitivity of HMA within the Superpave volumetric mixture design system (Shah, 2003). At the time of this recommendation, the 1989 version of the test was in-place. The use of this test method was made by the SHRP asphalt research team even though there was little testing to establish how the use of the Superpave compaction equipment and conditioning methods would affect the results of the test (Epps, et al., 2000). This deficiency in the research 
was recognized by three groups: the SHRP asphalt research team, an NCHRP research project that defined needed Superpave-related research, and the FHWA Asphalt Mixture Technical Working Group. NCHRP Project 9-13, "Evaluation of Water Sensitivity Tests", was developed to address the use of AASHTO T 283 with the Superpave volumetric design method (Epps, et al., 2000). As a result of this research, AASHTO T 283 test method was modified in 2003. The salient features of the 1989 and 2003 versions of the test method are summarized in Table 2.2. Differences in the test methods, identified in the table by bold letters, include:

- The use of the Superpave Gyratory Compactor, SGC, is allowed in the updated test specification. The SGC produces larger samples than the previously used compaction methods.

- The sample preparation process was significantly altered. The temperature used for compaction was changed from a constant $135^{\circ} \mathrm{C}$ to the compaction temperature of the binder as determined from the binder's temperatureviscosity characteristics. This is also the temperature used to compact samples for the Superpave mix design process. The time the compacted samples are stored prior to conditioning was changed from 72 to 96 hours in the 1989 method to $24 \pm 3$ hours. In addition, tolerances of \pm 1 hour was added to the 16 hour curing period and $\pm 10 \mathrm{~min}$. was added to the time to heat the sample to the compaction temperature.

- The evaluation of the samples requires determining the maximum theoretical specific gravity, $\mathrm{G}_{\mathrm{mm}}$, of the mix. The 2003 method requires that the samples used to determine $G_{\mathrm{mm}}$ are conditioned in the same manner as the material used for the compacted samples. The 1989 method was silent on this issue.

- The sample conditioning procedure was also significantly altered. The required minimum degree of saturation was increased from 55 to $70 \%$. The 1989 procedure required distilled water for saturating the samples. This was changed to potable water in the 2003 method. Freezing of the conditioned samples was optional in the 1989 method and is mandatory in the 2003 method. In addition, tolerances were added for the temperature of the water bath for the dry (unconditioned) samples and the for the amount of time the dry samples are in the water bath. The tolerance for the soak time prior to 
Table 2.2 Summary of AASHTO T 283 test parameters

\begin{tabular}{|c|c|c|}
\hline Feature & AASHTO T 283 (1989) & AASHTO T 283 (2003) \\
\hline Sample type & $\begin{array}{l}\text { Pavement cores } \\
\text { Marshall, Hveem, or Corp of Engineers Gyratory }\end{array}$ & $\begin{array}{l}\text { Pavement cores } \\
\text { Marshall, Hveem, or Corp of Engineers Gyratory } \\
\text { Superpave Gyratory Compactor }\end{array}$ \\
\hline Sample preparation & $\begin{array}{l}\text { Mixing temperature not specified } \\
\text { Cool to room temperature for } 2 \pm 0.5 \mathrm{hr} \text {. } \\
\text { Cure at } 60^{\circ} \mathrm{C} \text { for } 16 \mathrm{hrs} \text {. } \\
\text { Heat at } 135^{\circ} \mathrm{C} \text { for } 2 \mathrm{hrs} \\
\text { Compact } \\
\text { Store for } 72 \text { to } 96 \mathrm{hrs} \text { at room temperature }\end{array}$ & $\begin{array}{l}\text { Mixing temperature not specified } \\
\text { Cool to room temperature for } 2 \pm 0.5 \mathrm{hr} \text {. } \\
\text { Cure at } 60^{\circ} \mathrm{C} \text { for } 16 \pm \mathbf{1 ~ h r} \text {. } \\
\text { Heat compaction temperature for } 2 \mathrm{hrs} \pm \mathbf{1 0} \mathrm{min} \text {. } \\
\text { Compact } \\
\text { Store for } \mathbf{2 4} \pm \mathbf{3} \mathbf{~ h r} \text {. at room temperature }\end{array}$ \\
\hline $\begin{array}{l}\text { Evaluate and group } \\
\text { samples }\end{array}$ & $\begin{array}{l}\text { Measure bulk specific gravity } \\
\text { Determine maximum theoretical specific gravity }{ }^{1} \\
\text { Determine air voids, discard sample if air voids are outside } 7 \pm 1 \% \\
\text { Select samples for testing as dry or conditioned such that the average air } \\
\text { voids is approximately equal }\end{array}$ & $\begin{array}{l}\text { Measure bulk specific gravity } \\
\text { Determine maximum theoretical specific gravity } \\
\text { Determine air voids, discard sample if air voids are outside } \mathbf{7} \pm \mathbf{0 . 5 \%} \\
\text { Select samples for testing as dry or conditioned such that the average air } \\
\text { voids is approximately equal }\end{array}$ \\
\hline Sample conditioning & $\begin{array}{l}\text { Dry (control) samples - } \\
\text { Place in plastic bag } \\
\text { Place in water bath } 25^{\circ} \mathrm{C}, 2 \mathrm{hrs} \text {. } \\
\text { Conditioned Samples } \\
\text { Vacuum saturate (distilled water) } 13-67 \mathrm{kPa} \text { for } 5 \text { - } 10 \mathrm{~min} \text {. } \\
\text { Remove vacuum, leave sample in water } 5 \text { - } 10 \mathrm{~min} \text {. } \\
\text { Measure bulk gravity of each sample } \\
\text { Compute degree of saturation, allowable range } 55 \text { to } 80 \% \text {, if less than } 55 \% \\
\text { reapply vacuum saturation. If greater than } 80 \% \text { discard sample. } \\
\text { Freeze (optional) } \\
\qquad \text { Cover samples with plastic film } \\
\qquad \quad \text { Place in plastic bag with } 10 \mathrm{~mL} \text { water } \\
\quad \text { Place in freezer at }-18 \pm 3^{\circ} \mathrm{C} \text { for } 16 \mathrm{hrs} \text {. minimum } \\
\text { Place in } 60 \pm 1^{\circ} \mathrm{C} \text { water bath for } 24 \pm 1 \mathrm{hr} \text {., remove plastic film } \\
\text { Place in } 25 \pm 0.5^{\circ} \mathrm{C} \text { water bath for } 2 \pm 1 \mathrm{hr} \text {. }\end{array}$ & $\begin{array}{l}\text { Dry (control) samples - } \\
\text { Place in plastic bag } \\
\text { Place in water bath } 25 \pm \mathbf{0 . 5} \mathbf{C}^{\circ} \mathbf{C}, 2 \mathrm{hrs.} \pm \mathbf{1 0} \mathbf{~ m i n} \text {. } \\
\text { Conditioned Samples } \\
\text { Vacuum saturate (potable water) } 13-67 \mathrm{kPa} \text { for } 5-10 \mathrm{~min} \text {. } \\
\text { Remove vacuum, leave sample in water } 5 \text { - } 10 \mathrm{~min} \text {. } \\
\text { Measure bulk gravity of each sample } \\
\text { Compute degree of saturation, allowable range } \mathbf{7 0} \text { to } 80 \% \text {, if less than } \mathbf{7 0 \%} \\
\text { reapply vacuum saturation. If greater than } 80 \% \text { discard sample. } \\
\text { Freeze (Mandatory) } \\
\text { Cover samples with plastic film } \\
\text { Place in plastic bag with } 10 \pm \mathbf{0 . 5} \mathrm{mL} \text { water } \\
\text { Place in freezer at }-18 \pm 3^{\circ} \mathrm{C} \text { for } 16 \mathrm{hrs} . \text { minimum } \\
\text { Place in } 60 \pm 1^{\circ} \mathrm{C} \text { water bath for } 24 \pm 1 \mathrm{hr} ., \text { remove plastic film } \\
\text { Place in } 25 \pm 0.5^{\circ} \mathrm{C} \text { water bath for } 2 \mathrm{hr} . \pm \mathbf{1 0} \text { min. }\end{array}$ \\
\hline \multirow[t]{2}{*}{ Test } & $\begin{array}{l}\text { Measure indirect tensile strength, load rate } 50 \mathrm{~mm} / \mathrm{min} \text {, loading strips } \\
\text { optional } \\
\text { Compute tensile strength ratio. }\end{array}$ & $\begin{array}{l}\text { Measure indirect tensile strength, load rate } 50 \mathrm{~mm} / \mathrm{min} \text {, loading strips } \\
\text { mandatory } \\
\text { Compute tensile strength ratio. }\end{array}$ \\
\hline & $\begin{array}{l}{ }^{1} \text { Curing procedure for samples used to determine maximum theoretical } \\
\text { specific gravity not specified. }\end{array}$ & $\begin{array}{l}{ }^{2} \text { Samples used for determining maximum theoretical specific gravity are } \\
\text { cured following procedures for the compacted samples. }\end{array}$ \\
\hline
\end{tabular}


testing of the conditioned samples was changed from \pm 1 hour to \pm 10 minutes.

- The test for the tensile strength in the 2003 method requires steel loading strips, which were optional in the 1989 method.

The results of AASHTO T 283 are expressed in terms of the tensile strength ratio, TSR. This is the ratio of the average tensile strength of the conditioned samples divided by the average tensile strength of the unconditioned samples. Due to the empirical nature of the test, an acceptable level of TSR can only be determined by referencing the results of the test versus field performance of the mixes. Conceptually, the verification of the test limits should be performed whenever the test procedure is altered. Prior to Superpave, there was not a national standard for the acceptance limits for determining moisture damage.

Initially, the ASTM 4863 method, without the freeze-thaw cycle, used a 0.75 TSR minimum acceptance value; this was later increased to 0.85 . Lottman's original recommendation of a minimum criterion of 0.7 was usually specified (Roberts, et al., 1996). A minimum TSR criterion of 0.8 was adopted for Superpave mix design AASHTO T 283 (AASHTO MP-2).

\subsection{EVALUATION OF MOISTURE SUSCEPTIBILITY TESTS}

There is an extensive quantity of literature concerning the evaluation of moisture susceptibility of asphalt concrete. However, the empirical nature of the test method limits the utility of research conducted using one of the variations on the current test specification. The general consensus among the users of moisture damage tests is that the test results are highly variable and validation with field performance is problematical (Roberts, et al., 1996). Despite the recognized problems of AASHTO T 283, it was considered the best available method for evaluating the moisture sensitivity of asphalt concrete mixes. Since AASHTO T 283 was the recommended Superpave test, several researchers have investigated the parameters of this test method and compared it to the results of other methods. NCHRP funded a research program to specifically investigate the test parameters of AASHTO T 283 with a goal of improving the reliability of the test method to identify moisture susceptible mixtures (Epps, et al., 2000). 


\subsubsection{Comparative studies}

Aschenbrener, et al. (1995) tested HMA of known field stripping performance with four moisture susceptibility tests: 1) AASHTO T-283, 2) ASTM D-3625, 3) Environmental Conditioning System, and 4) Hamburg wheel-tracking device. Twenty pavements throughout Colorado with known field performance were selected for evaluation. AASHTO T-283 was successful in delineating between good and poor performing mixes. However, it was not successful in determining the reliability of the marginal mixes. This method is not capable of modeling the extended presence of moisture and corresponding development of the pore pressures from the traffic. Aschenbrener, et al. also indicates that the AASHTO T 283 adopts one level of conditioning ignoring the fact that heavy truck traffic on pavements, conditions more severely than the low truck traffic. ASTM D-3625 was not reliable in predicting mixes because it showed that all mixes failed the design requirements. The Environmental Conditioning System correctly predicted the performance of only one mix. The Hamburg wheel-tracking device correctly predicted the performance of fourteen mixes. The investigation concluded that none of the tests were completely accurate in predicting actual field stripping performance. It was recommended that modifications would be needed to each test prior to successful prediction of pavement performance.

Tandon, et al. (1997) evaluated the ability of the Environmental Conditioning System (ECS) to successfully predict HMA mix stripping potential. Modified Lottman testing was performed on similar specimens for comparison. Three HMA mixes were evaluated: one having a history of stripping and the other two having no stripping history. Mixes were comprised of limestone, sand, and siliceous gravel with an AC-20 (PG 6722) asphalt binder. Results indicated the procedure was unable to identify the performance of any of the three mixes. Additionally, ECS testing proved to be highly variable. Modified Lottman test results were correct in identifying mix performance while having lower variability than the Environmental Conditioning System.

Pan and White (1999) conducted a laboratory study on asphalt mixture moisture sensitivity. Seven mixtures were evaluated including three surface mixes, three binder mixes, and coarse-graded base mixes. Mixes were evaluated using AASHTO T-283 and the PURWheel wheel tracking device. AASHTO T-283 results showed moisture 
conditioning has a significant effect on the stripping potential of the mixes tested. That is, the tensile strength of the mixtures was reduced after the environmental procedures in AASHTO T 283 tests. PURWheel tracking device results indicated temperature and moisture conditions significantly influence stripping severity. The authors suggested a field study be performed to correlate laboratory results with field performance. Results from AASHTO T283 tests for the Limestone, Slag and Dolomite mixtures showed that the TSR of the three control mixtures were all below $80 \%$. Test results also show that the moisture susceptibility of the three mixtures can be improved to meet the Superpave mix design criteria with the addition of anti-stripping agents. However, the results for the limestone base mixes showed that TSR of the specimens after the addition of antistripping agents were still below the minimum Superpave mix design criteria. In general, comparison of the AASHTO T 283 TSR and PURWheel results indicate that the TSR does not reflect a mixture's stripping potential and the application of the $150 \mathrm{~mm}$ specimen for AASHTO T 283 test still needs further evaluation before modification of the current test standards.

Hunter and Ksaibati (2002) evaluated how tensile strength was affected by freezethaw conditioning and whether the Georgia Loaded Wheel Tester (GLWT) could be used to predict moisture susceptibility. Eight asphalt mixtures were evaluated, including granite and limestone aggregates and four asphalt-additive-aging combinations. Results showed the GLWT was not effective in determining moisture susceptibility. Freeze-thaw results showed lower tensile strengths for all conditioned mixes. Tensile strength of the granite mixes decreased more rapidly than limestone mixes. It was recommended that a testing procedure that includes specimen saturation be designed for the GLWT to be effective in measuring moisture susceptibility.

Coplantz and Newcomb (1988) evaluated four variations of water sensitivity tests as follows:

1) Vacuum saturation only

2) High vacuum saturation with single freeze-thaw cycle

3) Low vacuum saturation with single freeze-thaw cycle 
4) Low vacuum saturation with several freeze-thaw cycles

Results indicated that mixes subjected to only vacuum saturation may not show evidence of stripping potential. However, when mixes were subjected to freeze-thaw cycles plus a vacuum saturation, stripping potential was shown. The number of freeze-thaw cycles was directly related to stripping severity, with more freeze-thaw cycles yielding more severe stripping. In addition to freeze-thaw cycles, saturation level influenced the stripping potential, with higher levels of saturation yielding more stripping.

Mahoney and Stephens (1999) compared AASHTO T 283 results with the Connecticut Department of Transportation Modified Test Method. They found that the difference in the degree of saturation was probably the largest factor in the variation in test results. Four of the five materials tested passed the ConnDOT version of T 283 while failing the official AASHTO test. The largest difference in the two methods was the computation of amount of water absorbed by the specimen. The official AASHTO method states the amount of water absorbed into the specimen is calculated by

$$
\text { Water absorbed }=\frac{(\text { VSSD }-\mathrm{SSD})}{\text { Volume of Voids }}
$$

While the ConnDOT version of AASHTO T 283 calculates the amount of water absorbed by the specimen as:

$$
\text { Water absorbed }=\frac{(\text { VSSD }- \text { Dry Weight of Specimen })}{\text { Volume of Voids }} .
$$

Where: VSSD is the vacuum saturated surface dry mass

$\mathrm{SSD}$ is the saturated surface dry mass

The AASHTO procedure results in a higher degree of saturation as the water required to achieve 55 to $80 \%$ saturation is in addition to the amount of water required to reach the saturated surface dry condition. The modified ConnDOT method uses all of the water absorbed by the specimen towards saturation of 55 to $80 \%$. The researchers suggest the increased volume of water in the AASHTO method may be causing the specimen to be damaged excessively when it is frozen thus decreasing the TSR values. Results showed that AASHTO T 283 was more severe than the Connecticut method. The 
authors concluded that both tests have limitations in accurately predicting HMA stripping potential (Mahoney and Stephens, 1999).

Choubane, et al. (2001) evaluated a section of Interstate 75 in Florida for stripping potential by using AASHTO T 283. Six cores from six sites were obtained and tested for TSR two years after construction. Results showed that TSR decreased more for $12.5 \mathrm{~mm}$ mixes than $19.0 \mathrm{~mm}$ mixes. It was concluded that TSR difference between the two mixes was primarily a function of specimen air void content. Choubane, et al. (2001) also evaluated the effect of air void content and degree of saturation on TSR. Aggregates and materials included granite, limestone, and reclaimed asphalt pavement. Asphalt binder was an AC-30 (PG 67-22). Specimens were saturated to 55 and 80 percent. Results showed TSR values decreased as the level of saturation increased. The following recommendations were reported: 1) coarse-graded Superpave mixes should be saturated to more than 90 percent and to include the freeze-thaw cycle when using AASHTO T 283,2 ) a minimum TSR of 80 percent, 3) specimen air void content should be set to $7 \pm$ 0.5 percent, and 4) a minimum requirement for wet indirect tensile strength should be 410 $\mathrm{kPa}(60 \mathrm{psi})$.

\subsubsection{NCHRP Project 9-13}

Given the combination of the concern about the AASHTO T 283 method and the fact that the Superpave mix design method requires it, NCHRP Project 9-13 was performed "to evaluate AASHTO T 283 and to recommend changes to make it compatible with the Superpave system" (Epps, et al., 2000). The parameters studied during this project include:

- Compaction method - Superpave, Marshall and Hveem

- Sample size - 150x95 mm for Superpave and 100x62 mm for Superpave, Marshall and Hveem

- Aging method, loose material - none, 16 hrs. at $60^{\circ} \mathrm{C}, 2 \mathrm{hrs}$. at $135^{\circ} \mathrm{C}$, and 4 hrs. at $135^{\circ} \mathrm{C}$

- Aging method, compacted samples - room temperature, $\mathbf{0}$ to 24 and 72 to 96 hrs.

- Degree of saturation - 55, 75, and 90 percent

- Conditioning methods - Dry (no conditioning), Saturation-No -Freeze-thaw , and Saturation-Freeze-thaw (one cycle) 
- Type of test - indirect tensile and resilient modulus

- Type of aggregate - supplied from 5 states, included three limestone and two alluvial aggregates, selected to represent a range of known moisture sensitivity in field performance. The moisture sensitivity of the aggregates were described as:

Texas and Alabama - not moisture sensitive

Colorado and Nevada - moderate to highly sensitive

Maryland - highly sensitive

The bolded levels in the above list identify the test method parameters which were recommended for inclusion in the revised AASHTO T 283 method. Binder type was not studied as a factor in the experiment. Binders were specific to each mix and included PG 58-28, 64-22, 64-28, and 70-22.

Comparison of the above list with the test method specifications in Table 2.2 demonstrates that many of the test parameters were evaluated during the research, but several test parameters, such as test temperature and loading rate were not evaluated during the experiment. However, the combination of factors and levels shown above is excessive for a complete factorial experiment. Therefore, the research was divided into four tasks to examine the different aspects of the test method.

- Task 1 - influence of resilient modulus test on tensile test results.

- Task 2 - effect of four sample compaction methods and sample size on water sensitivity testing for fixed conditions of aging and conditioning.

- Task 3 - influence of two compaction methods on water sensitivity testing for variable conditions of aging and conditioning.

- Task 4 - influence of two compaction methods on water sensitivity testing for variable curing/aging and conditioning

Tasks 1 and 2 used aging and conditioning procedures which are different from the current AASHTO T 283 procedure. Therefore, they are not germane to the current research project and will not be discussed further.

The factorial for Tasks 3 and 4 is shown in Table 2.3. The " $\mathrm{X}$ " designation in the Table 2.3 identifies the partial factorial experimental plan designed to accomplish the objectives of Task 4. In this task the compaction method - sample size issue was limited to two combinations, Superpave $150 \mathrm{~mm}$ samples and Marshall $100 \mathrm{~mm}$ samples. The 
"E" designation in Table 2.3 indicates the additions made to allow for a complete factorial on a portion of the study, Task 3 . This portion of the study included all combinations of the factors and levels for the test parameters, but was limited to a single aggregate type, Nevada.

Table 2.3 NCHRP Project 9-13 experimental plan for tasks 3 and 4 (Epps, et al., 2000)

\begin{tabular}{|c|c|c|c|c|c|c|c|c|c|c|c|c|c|c|c|c|c|c|c|c|c|c|c|c|c|}
\hline \multirow{4}{*}{\multicolumn{2}{|c|}{$\begin{array}{c}\text { Compaction } \\
\text { \% Saturation } \\
\text { Freeze/Thaw } \\
\text { Compacted Mix Aging } \\
\end{array}$}} & \multicolumn{12}{|c|}{ Gyratory $(150 \times 95 \mathrm{~mm})$} & \multicolumn{12}{|c|}{ Marshall $(100 \times 62 \mathrm{~mm})$} \\
\hline & & \multicolumn{4}{|c|}{55} & \multicolumn{4}{|c|}{75} & \multicolumn{4}{|c|}{90} & \multicolumn{4}{|c|}{55} & \multicolumn{4}{|c|}{75} & \multicolumn{4}{|c|}{90} \\
\hline & & \multicolumn{2}{|c|}{ Yes } & \multicolumn{2}{|c|}{ No } & \multicolumn{2}{|c|}{ Yes } & \multicolumn{2}{|c|}{ No } & \multicolumn{2}{|c|}{ Yes } & \multicolumn{2}{|c|}{ No } & \multicolumn{2}{|c|}{ Yes } & \multicolumn{2}{|c|}{ No } & \multicolumn{2}{|c|}{ Yes } & \multicolumn{2}{|c|}{ No } & \multicolumn{2}{|c|}{ Yes } & \multicolumn{2}{|c|}{ No } \\
\hline & & Y & $\mathrm{N}$ & $\mathrm{Y}$ & $\mathrm{N}$ & Y & $\mathrm{N}$ & $\mathrm{Y}$ & $\mathrm{N}$ & $\mathrm{Y}$ & $\mathrm{N}$ & $\mathrm{Y}$ & $\mathrm{N}$ & $\mathrm{Y}$ & $\mathrm{N}$ & $\mathrm{Y}$ & $\mathrm{N}$ & $\mathrm{Y}$ & $\mathrm{N}$ & $\mathrm{Y}$ & $\mathrm{N}$ & $\mathrm{Y}$ & $\mathrm{N}$ & $\mathrm{Y}$ & $\mathrm{w}$ \\
\hline Aggregate & $\begin{array}{c}\text { Loose Mix } \\
\text { Aging }\end{array}$ & & & & & & & & & & & & & & & & & & & & & & & & \\
\hline \multirow{4}{*}{$\begin{array}{l}\text { Source } 1 \\
\text { Nevada } \\
\text { (N) }\end{array}$} & None & E & $\mathrm{x}$ & $\mathrm{x}$ & E & $\mathrm{x}$ & $\mathrm{x}$ & $\mathrm{x}$ & $\mathrm{x}$ & $\mathrm{x}$ & E & E & $\mathrm{x}$ & E & E & E & E & E & E & E & E & E & E & E & $\mathrm{x}$ \\
\hline & $16 \mathrm{~h} / 60^{\circ} \mathrm{C}$ & E & $\mathrm{x}$ & $\mathrm{x}$ & E & $\mathrm{x}$ & $\mathrm{x}$ & $\mathrm{E}$ & $\mathrm{x}$ & $\mathrm{x}$ & $\mathrm{E}$ & $\mathrm{x}$ & $\mathrm{x}$ & $\mathrm{E}$ & E & $\mathrm{E}$ & E & E & $\mathrm{x}$ & E & E & E & E & $\mathrm{E}$ & $\mathbf{E}$ \\
\hline & $2 \mathrm{~h} / 135^{\circ} \mathrm{C}$ & $\mathrm{x}$ & $\mathrm{x}$ & $x$ & $\mathrm{x}$ & $\mathrm{x}$ & $\mathrm{E}$ & E & $\mathrm{x}$ & E & $\mathrm{x}$ & $\mathrm{x}$ & E & E & E & $\mathrm{x}$ & E & $\mathrm{x}$ & E & E & E & E & E & $\mathrm{E}$ & E \\
\hline & $4 \mathrm{~h} / 135^{\circ} \mathrm{C}$ & $\mathrm{x}$ & E & E & $\mathrm{x}$ & E & $\mathrm{x}$ & $\mathrm{x}$ & E & $\mathrm{x}$ & $\mathrm{x}$ & $\mathrm{x}$ & $\mathrm{x}$ & E & E & $\mathrm{x}$ & E & E & E & E & E & E & $\mathrm{x}$ & E & $\mathbf{E}$ \\
\hline \multirow{4}{*}{$\begin{array}{l}\text { Source 2 } \\
\text { Alabama } \\
\text { (A) }\end{array}$} & None & $\mathrm{x}$ & $\mathrm{x}$ & & $\mathrm{x}$ & $\mathrm{x}$ & & $\mathrm{x}$ & $\mathrm{x}$ & & $\mathrm{x}$ & $\mathrm{x}$ & & $\mathrm{x}$ & & & & & & & $\mathrm{x}$ & & & & \\
\hline & $16 \mathrm{~h} / 60^{\circ} \mathrm{C}$ & $\mathrm{x}$ & & $\mathrm{x}$ & $\mathrm{x}$ & & $\mathrm{x}$ & $\mathrm{x}$ & & $\mathrm{x}$ & $\mathrm{x}$ & & $\mathrm{x}$ & & & & $\mathrm{x}$ & & & & & & & & \\
\hline & $2 \mathrm{~h} / 135^{\circ} \mathrm{C}$ & & $\mathrm{x}$ & $\mathrm{x}$ & & $\mathrm{x}$ & $\mathrm{x}$ & $\mathrm{x}$ & $\mathrm{x}$ & $\mathrm{x}$ & & & $\mathrm{x}$ & & & & & & & & $\mathrm{x}$ & & & & \\
\hline & $4 \mathrm{~h} / 135^{\circ} \mathrm{C}$ & & $\mathrm{x}$ & $\mathrm{x}$ & & $\mathrm{x}$ & & & $\mathrm{x}$ & $\mathrm{x}$ & $\mathrm{x}$ & $\mathrm{x}$ & $\mathrm{x}$ & & & & & & & & & $\mathrm{x}$ & & & \\
\hline \multirow{4}{*}{$\begin{array}{l}\text { Source } 3 \\
\text { Colorado } \\
\text { (C) }\end{array}$} & None & $\mathrm{x}$ & & & $\mathrm{x}$ & & $\mathrm{x}$ & $\mathrm{x}$ & & $\mathrm{x}$ & $\mathrm{x}$ & $\mathrm{x}$ & $\mathrm{x}$ & & & & & & & $\mathrm{x}$ & & & & & \\
\hline & $16 \mathrm{~h} / 60^{\circ} \mathrm{C}$ & $\mathrm{x}$ & $\mathrm{x}$ & & $\mathrm{x}$ & $\mathrm{x}$ & & $\mathrm{x}$ & $\mathrm{x}$ & & $\mathrm{x}$ & $\mathrm{x}$ & & $\mathrm{x}$ & & & & & & & & & & & \\
\hline & $2 \mathrm{~h} / 135^{\circ} \mathrm{C}$ & $\mathrm{x}$ & & $\mathrm{x}$ & $x$ & $x$ & $x$ & & $\mathrm{x}$ & & $\mathrm{x}$ & $\mathrm{x}$ & & & & & & & & & & & $\mathrm{x}$ & & \\
\hline & $4 \mathrm{~h} / \mathrm{i} 35^{\circ} \mathrm{C}$ & & $\mathrm{x}$ & $\mathrm{x}$ & & $\mathrm{x}$ & $\mathrm{x}$ & $\mathrm{x}$ & $\mathrm{x}$ & $\mathrm{x}$ & & & $\mathrm{x}$ & & & & $x$ & & & & & & & & \\
\hline Source 4 & None & $\mathrm{x}$ & $\mathrm{x}$ & $\mathrm{x}$ & & $\mathrm{x}$ & & & $\mathrm{x}$ & & $x$ & $\mathrm{x}$ & & & $\mathrm{x}$ & & & & & & & & & & \\
\hline (M) & $16 \mathrm{~h} / 60^{\circ} \mathrm{C}$ & & $\mathrm{x}$ & $\mathrm{x}$ & $\mathrm{x}$ & $\mathrm{x}$ & $\mathrm{x}$ & $\mathrm{x}$ & & $\mathrm{x}$ & & $\mathrm{x}$ & & & & & & & & & & & & $\mathrm{x}$ & \\
\hline & $2 \mathrm{~h} / 135^{\circ} \mathrm{C}$ & $\mathrm{x}$ & & & $\mathrm{x}$ & & $\mathrm{x}$ & $\mathrm{x}$ & & $\mathrm{x}$ & $\mathrm{x}$ & $\mathrm{x}$ & $\mathrm{x}$ & & $\mathrm{x}$ & & & & & & & & & $\mathrm{x}$ & \\
\hline & $4 \mathrm{~h} / 135^{\circ} \mathrm{C}$ & $\mathrm{x}$ & $\mathrm{x}$ & & $\mathrm{x}$ & $\mathrm{x}$ & & $\mathrm{x}$ & $\mathrm{x}$ & & $\mathrm{x}$ & $\mathrm{x}$ & & & & & & $\mathrm{x}$ & & & $\mathrm{x}$ & & & & \\
\hline Source 5 & None & $\mathrm{x}$ & & & $\mathrm{x}$ & $\mathrm{x}$ & $\mathrm{x}$ & & $\mathrm{x}$ & $\mathrm{x}$ & & $\mathrm{x}$ & & & & & & $\mathrm{x}$ & & & & & & & \\
\hline (T) & $16 \mathrm{~h} / 60^{\circ} \mathrm{C}$ & $\mathrm{x}$ & $\mathrm{x}$ & $\mathrm{x}$ & & $\mathrm{x}$ & & $\mathrm{x}$ & & $\mathrm{x}$ & $\mathrm{x}$ & $\mathrm{x}$ & $\mathrm{x}$ & & & $\mathrm{x}$ & & & & & & $\mathrm{x}$ & & & \\
\hline & $2 \mathrm{~h} / 135^{\circ} \mathrm{C}$ & & $\mathrm{x}$ & $\mathrm{x}$ & $\mathrm{x}$ & $\mathrm{x}$ & $\mathrm{x}$ & $\mathrm{x}$ & & $\mathrm{x}$ & $\mathrm{x}$ & & $\mathrm{x}$ & $\mathrm{x}$ & & & & & & $\mathrm{x}$ & & & & & \\
\hline & $4 \mathrm{~h} / 135^{\circ} \mathrm{C}$ & $\mathrm{x}$ & & $\mathrm{x}$ & $\mathrm{x}$ & & $\mathrm{x}$ & & $\mathrm{x}$ & & $x$ & $\mathrm{x}$ & & & & & & & & & & & & & $\mathrm{x}$ \\
\hline
\end{tabular}

Two techniques were used to evaluate the results of the experiments, analysis of variance, ANOVA, and pair wise comparisons. ANOVA's were performed for both the partial factorial, which included five aggregate sources, but not all combinations of the other factors and levels, and for the full factorial, which was limited to a single aggregate source, but included all the combinations of factors and levels for the test parameters. The ANOVA's were performed to evaluate the significance of the test parameters on all tensile strength results and on the dry, saturated-no-freeze-thaw, and saturated-freezethaw tensile strengths. Table 2.4 shows the ANOVA of the complete factorial, Task 3 , 
for the effect of the test parameters on tensile strength. The factor with the most significant influence, based on the magnitude of the F statistic, on tensile strength was sample conditioning. In addition, the main factors of loose mixture aging, compacted mixture aging, compaction method and saturation level were significant. Several two and three order interactions were also significant. The data were then segregated so ANOVA's could be performed on the influence of the test specification parameters on the tensile strength for each of the conditioning methods. Loose mixture aging and compacted mixture aging was significant factors for all three types of tensile strength, but the relative influence varied. Loose mixture aging was the most significant factor for the dry tensile strength and the saturated-no-freeze-thaw tensile strength. Compacted mixture aging was the most significant factor for the saturated-freeze-thaw tensile strength. Compaction method and saturation level were significant main effects, but of lesser influence than mixture aging.

Table 2.4 ANOVA for complete factorial NCHRP Project 9-13 (Epps, et al., 2000)

\begin{tabular}{|c|c|c|c|c|}
\hline Factor or Interaction & $F$ Value & Rank & $\operatorname{Pr}>F$ & Significant \\
\hline SCOND & 2130.95 & 1 & 0.0001 & $y$ \\
\hline LMA & 156.45 & 2 & 0.0001 & y \\
\hline CMA*SCOND & 77.62 & 3 & 0.0001 & y \\
\hline $\mathrm{COMP}^{*} \mathrm{LMA}^{*} \mathrm{CMA}$ & 56.91 & 4 & 0.0001 & $y$ \\
\hline COMP*SCOND & 51.41 & 5 & 0.0001 & $y$ \\
\hline LMA $=S C O N D$ & 39.97 & 6 & 0.0001 & $y$ \\
\hline $\mathrm{COMP} * \mathrm{CMA} * \mathrm{SCOND}$ & 35.73 & 7 & 0.0001 & y \\
\hline $\mathrm{LMA}^{*} \mathrm{CMA}$ & 28.64 & 8 & 0.0001 & y \\
\hline $\mathrm{LMA} * \mathrm{CMA} * \mathrm{SCOND}$ & 27.40 & 9 & 0.0001 & $y$ \\
\hline COMP*CMA & 26.03 & 10 & 0.0001 & $y$ \\
\hline COMP'LMA & 25.69 & 11 & 0.0001 & $y$ \\
\hline COMP*LMA*SCOND & 24.00 & 12 & 0.0001 & $y$ \\
\hline CMA & 23.92 & 13 & 0.0001 & y \\
\hline $\mathrm{COMP}{ }^{*} \mathrm{LMA}{ }^{*} \mathrm{CMA} * \mathrm{SCOND}$ & 19.10 & 14 & 0.0001 & y \\
\hline COMP*LMA*SATLEV & 7.20 & 15 & 0.0001 & y \\
\hline COMP & 7.03 & 16 & 0.0085 & y \\
\hline COMP*SATLEV & 5.97 & 17 & 0.0029 & y \\
\hline $\mathrm{COMP}^{*} \mathrm{LMA}^{*} \mathrm{CMA}^{*} \mathrm{SATLEV}$ & 5.38 & 18 & 0.0001 & $\mathrm{y}$ \\
\hline SATLEV & 5.26 & 19 & 0.0057 & $y$ \\
\hline CMA*SATLEV & 5.25 & 20 & 0.0058 & y \\
\hline LMA $\odot$ SATLEV & 5.02 & 21 & 0.0001 & y \\
\hline $\mathrm{COMP}^{\bullet} \mathrm{LMA}^{\bullet} \mathrm{CMA}{ }^{*} \mathrm{SATLEV}{ }^{\bullet} \mathrm{SCOND}$ & 5.00 & 22 & 0.0001 & y \\
\hline LMA*SATLEV*SCOND & 4.91 & 23 & 0.0001 & $\mathrm{y}$ \\
\hline SATLEV*SCOND & 4.23 & 24 & 0.0024 & y \\
\hline COMP•SATLEV•SCOND & 3.85 & 25 & 0.0046 & y \\
\hline COMP*CMA*SATLEV ${ }^{*} \mathrm{SCOND}$ & 2.94 & 26 & 0.0208 & $y$ \\
\hline $\mathrm{LMA}^{* \mathrm{CM}}{ }^{*}{ }^{*} \mathrm{SATLEV} * \mathrm{SCOND}$ & 2.32 & 27 & 0.0076 & y \\
\hline $\mathrm{CMA} * \mathrm{SATLEV} * \mathrm{SCOND}$ & 2.23 & 28 & 0.0664 & $\mathrm{n}$ \\
\hline COMP*LMA*SATLEV*SCOND & 2.05 & 29 & 0.0203 & y \\
\hline $\mathrm{LMA} * \mathrm{CMA} * \mathrm{SATLEV}$ & 1.59 & 30 & 0.1488 & $\mathrm{n}$ \\
\hline COMP*CMA*SATLEV & 0.52 & 31 & 0.5973 & $\mathrm{n}$ \\
\hline
\end{tabular}

Notes: COMP—compaction method; LMA - loose mix aging; CMA — compacted mix aging; SATL.EV—-saturation level; SCOND - sample conditioning. 
The partial factorial showed that aggregate source was the most influential factor for all three tensile strength types. Loose and compacted aging were also significant in the partial factorial but the relative influence varied depending on the type of conditioning prior to measuring tensile strength.

All of the ANOVA's performed used tensile strength as the dependent variable. Even though the results of AASHTO T 283 are expressed in terms of the tensile strength ratio, average conditioned tensile strength to average unconditioned tensile strength, none of the statistical analysis considered this variable.

The ANOVA was beneficial for evaluating overall trends in the data. However, due to the experimental design and the fact that many of the two order and higher interactions are significant, it was necessary to do pair wise comparisons of the data to further understand the results of the experimental program. The following considers only the results with respect to the adopted test method.

\subsubsection{Loose mix aging}

Loose mix aging was a significant factor on no conditioned, dry, tensile strength for both the full and partial factorial ANOVA (Epps, et al., 2000). The pair-wise comparison showed dry tensile strength increased in four cases, and was the same in eight cases. However, when only considering $150 \mathrm{~mm}$ Superpave samples that were aged for 0 to $24 \mathrm{hrs}$, parameters for the current AASHTO T 283 procedure, all three samples had the same dry tensile strength.

The ANOVA of the partial and complete factorials also found loose mix aging was also a significant factor on the tensile strength after saturation. The pair-wise comparison indicated an increase in tensile strength with aging in 10 of 36 comparisons and the authors cite this result as support for the conclusion that loose mix aging affects tensile strength of the saturated samples. Of the 36 comparisons samples, half were prepared with the Superpave gyratory compactor; seven of these samples showed a higher strength. Of these samples, nine had the compacted aging procedure currently recommended; only four showed an increase in tensile strength with aging. There were only three possible comparisons of samples prepared to the current AASHTO T 283 procedure; in two cases the tensile strength increased and it was the same in one case. 
The ANOVA of the partial and complete factorials also found loose mix aging was also a significant factor on the tensile strength after saturation plus freeze-thaw. The pair-wise comparison indicated an increase in tensile strength with aging in 3 of 36 comparisons and the authors cite this result as support for the conclusion that loose mix aging affects tensile strength of the saturated plus freeze-thaw samples. Of the 36 comparison samples, half were prepared with the Superpave gyratory compactor; one of these samples showed a higher strength, one showed a lower tensile strength and 16 had the same tensile strength. Of these samples, nine had the compacted aging procedure currently recommended; one showed a decrease in tensile strength and eight had the same tensile strength. There were only three comparisons of samples prepared to the current AASHTO T 283 procedure; all of these had the same tensile strength. There were no pair-wise comparisons of the effect of loose mix aging on tensile strength ratio.

\subsubsection{Compacted mix aging}

Compacted mix aging was a significant factor on no conditioned, dry, tensile strength for both the full and partial factorial ANOVA (Epps, et al., 2000). The pair-wise comparison showed dry tensile strength decreased in one case, and was the same in seven cases. When only considering $150 \mathrm{~mm}$ Superpave samples that were aged for 0 to $24 \mathrm{hrs}$, parameters for the current AASHTO T 283 procedure, the only available comparison indicated the dry tensile strength was not affected by compacted mix aging.

The ANOVA of the partial and complete factorials also found compacted mix aging was also a significant factor on the tensile strength after saturation. The pair-wise comparison indicated an increase in tensile strength with aging in 4 of 24 comparisons and the authors cite this result as support for the conclusion that compacted mix aging affects tensile strength of the saturated samples. Of the 24 comparisons samples, half were prepared with the Superpave gyratory compactor; two of the 12 samples showed a higher strength. Of these samples, three had the loose mix aging procedure currently recommended; all of these samples had the same tensile strength.

The ANOVA of the partial and complete factorials also found compacted mix aging was also a significant factor on the tensile strength after saturation plus freezethaw. The pair-wise comparison indicated a decrease in tensile strength with aging in 
three of 24 comparisons and the authors cite this result as support for the conclusion that compacted mix aging "somewhat" affects tensile strength of the saturated plus freezethaw samples. Of the 24 comparisons samples, half were prepared with the Superpave gyratory compactor; three showed a lower tensile strength and nine had the same tensile strength. Of these samples, three had the loose aging procedure currently recommended; one showed a decrease in tensile strength and two had the same tensile strength. The single comparison of samples prepared to the current AASHTO T 283 procedure had the same tensile strength. There were no pair-wise comparisons of the effect of compacted mix aging on tensile strength ratio.

\subsubsection{Saturation}

The ANOVA of the complete and partial factorial experiments indicated that saturation level was a significant factor on the tensile strength of the saturated and saturated with freeze-thaw samples (Epps, et al., 2000). Saturation level was the least significant main factor in the experiment with the exception of the results for the partial factorial analysis of freeze-thaw samples. For this condition, the only factor with a greater significance was aggregate source.

There were 96 combinations of factors and levels that allowed pair-wise comparisons of the effect of saturation level on tensile strength; the tensile strengths were statistically the same in 94 of these combinations. The pair-wise comparison indicated an increase in no freeze-thaw tensile strength with different levels of saturation ( $75 \%$ vs. 55 $\%$ ) in one of 16 comparisons. When only considering $150 \mathrm{~mm}$ Superpave samples that were aged for 0 to $24 \mathrm{hrs}$, parameters for the current AASHTO T 283 procedure, all three samples had the same no freeze-thaw tensile strength. The pair-wise comparison of the $90 \%$ and $55 \%$ saturated samples indicated a decrease in no freeze-thaw tensile strength in one of 16 comparisons. When considering only the $150 \mathrm{~mm}$ Superpave samples, all samples had the same no freeze-thaw tensile strength. For the samples saturated at $90 \%$ and $75 \%$ levels, the no freeze-thaw tensile strength was same for all the 16 comparisons.

The pair-wise comparison indicated that the freeze-thaw tensile strength for the samples subjected to different levels of saturation, $75 \%$ vs. $55 \%$, was same for all 16 comparisons. Similarly, for the other two combinations of saturation levels (i) $90 \%$ vs. 
$55 \%$, and (ii) $90 \%$ vs. $75 \%$ indicated that the freeze-thaw tensile strength was same for all the 16 comparisons. However, based on partial factorial experiment, it was concluded that saturation level was among the most important factors influencing the freeze-thaw tensile strength of the samples.

\subsubsection{Conditioning}

The ANOVA for the complete factorial demonstrated that sampling conditioning, no conditioning (dry), saturation, and saturation with freeze-thaw was the most significant factor. Sampling conditioning was not included in the ANOVA's for the partial factorial experiment.

The pair-wise statistical comparisons indicated that the saturated tensile strength was lower than the dry tensile strength in 45 of 68 possible comparisons. Examination of the $150 \mathrm{~mm}$ diameter samples compacted with the Superpave Gyratory Compactor showed that the no freeze-thaw tensile strength is statistically same for 3 of 5 available comparisons and in the remaining 2 comparisons it was lower than the dry tensile strength. When the samples were examined based on the two compaction methods, Gyratory and Marshall compaction, 33 of 48 comparisons showed a decrease in saturated tensile strength compared to dry tensile strength. Of the 48 comparison samples, half were prepared with the Superpave gyratory compactor; 17 of the 24 samples showed a lower saturated tensile strength. Of these samples, six had the loose and compacted mix aging procedure currently recommended; all of these samples showed a decrease in saturated tensile strength.

The pair-wise statistical comparisons indicated that the saturated freeze-thaw tensile strength was lower than the dry tensile strength in 52 of 68 possible comparisons. Examination of the $150 \mathrm{~mm}$ diameter samples compacted with the Superpave Gyratory Compactor showed that the saturated freeze-thaw tensile strength is statistically same for 3 of 5 available comparisons and in the remaining 2 comparisons it was lower than the dry tensile strength. When the samples were examined based on the two compaction methods, Gyratory and Marshall compaction, 39 of 48 comparisons show decrease in saturated freeze-thaw tensile strength compared to dry tensile strength. Of the 48 comparison samples, half were prepared with the Superpave gyratory compactor; 20 of 
the 24 samples showed a lower saturated freeze-thaw tensile strength. Of these samples, six had the loose and compacted mix aging procedure currently recommended; all of these samples showed a decrease in saturated freeze-thaw tensile strength.

In 56 of 68 possible comparisons, the strengths for the saturated versus saturated freeze-thaw tensile strengths were the same. This comparison included all four compaction methods. Examination of the $150 \mathrm{~mm}$ diameter samples compacted with the Superpave Gyratory Compactor showed that all five available comparisons had equal tensile strength, regardless of freeze-thaw conditioning.

\subsubsection{Mixture source}

Mixture source was not a factor in the complete factorial experiment. The ANOVA of the partial factorial experiment found mixture source was the most significant factor in the analysis. Mixture source is included in the experiment in order to determine if the overall test method provides meaningful information about the moisture susceptibility of the aggregates and to establish criteria or limits for interpreting the test results. The positive results of the ANOVA of the partial experiment demonstrate the test method is sensitive to mixture source. However, the pair-wise comparisons are needed for the interpretation of the meaning of the ANOVA results. Epps, et al. (2000) report the results of the evaluation of the test method with respect to mixture source as:

Results obtained in this study indicate that the water sensitivities of the mixtures as described by the state DOT's did not satisfactorily match the observed behavior of the mixtures for a number of the data groups in the study.

This conclusion was based on the following specific observations:

- The Maryland aggregates passes the tensile strength criteria based on most of the factors considered in the experiment. However, the Maryland aggregates were classified as water-sensitive base on field experience. Only the samples prepared with the Hveem impact kneading compactor failed the 70 percent acceptance criteria for both no freeze-thaw and freeze-thaw conditioning. In other words, the single aggregate source used in the experiment to represent a moisture sensitive aggregate was found to be not moisture sensitive. 
- The Alabama and Texas aggregates were classified as not water-sensitive based on field performance. However, the Texas mixture failed to reach 70 percent tensile strength ratio for all conditions, and the Alabama mixture exceeded the 70 and 80 percent criteria only for the Marshall samples. So the two aggregate sources included in the experiment to represent materials that are not moisture sensitive were found to be moisture sensitive.

- The Nevada and Colorado mixtures were both described as moderately to highly water-sensitive. The Colorado mixture did not exceed 70 percent for any compaction or conditioning method, so use of an antistrip additive would be recommended. The Nevada aggregate reached 70 percent tensile strength ratio when samples were prepared with the gyratory 150 compactor. This aggregate would need an antistrip admixture under the current limit of 80 percent TSR but would not need an antistrip admixture under the previous limits.

Based on the results of this research, the authors made the following recommendations relative to the test method:

- Loose mixture aging of 16 hours at $60^{\circ} \mathrm{C}$

- Compacted mixture aging was not addressed in the recommendations section of the report. A time of 0 to 24 hours at room temperature was included in their proposed test method

- Saturation level was not addressed in the recommendations section of the report. A range for the saturation level of 55 to 80 percent was included in their proposed test method.

- Sample conditioning was recognized as not being important based on the results, but saturation with freeze-thaw was recommended "to be conservative". Comparison of these recommendations to the outline of the current test method shown in Table 2.1 shows the following:

- The loose mixture aging recommendation was modified to include a variance on of time of $\pm 1 \mathrm{hr}$.

- $\quad$ The compacted mixture aging was implemented as $24 \pm 3 \mathrm{hrs}$.

- The saturation level was restricted to 70 to 80 percent. 
- The saturation with freeze-thaw conditioning was implemented.

It should be noted that although Epps, et al. (2000) conducted an extensive experiment, it was not possible to cover all of the steps and requirements that are specified in AASHTO T 283. Examples of factors not considered in the experiment include mixing and compaction temperature, time between mixing the sample and starting to cure, and air void level.

The authors recommended that states should perform a structured research program to evaluate the implementation of AASHTO T 283. Mixtures should be selected so field performance can be correlated with laboratory test parameters.

\subsection{TECHNIQUES FOR LIMITING STRIPPING}

When subject to moisture, water-sensitive pavements may suffer accelerated damage leading to a reduced pavement life. If asphalt pavement does suffer from water sensitivity, serious distresses may occur. As a result, the asphalt pavement reduces in performance and increases in maintenance costs. To alleviate or control this problem, various liquid or solid anti-stripping additives have been developed, which can be used to promote adhesion between asphalt and aggregate. Anderson and Dukatz, as cited by Hunter and Ksaibati (2002), reviewed the effects of commercially available anti-stripping additives on the physical properties of asphalt cement. Anderson and Dukatz's experimental studies of the physical and compositional properties of asphalt cement with anti-stripping additives demonstrated that anti-stripping additives tend to soften asphalt, reduce temperature susceptibility, and improve the aging characteristics of asphalt cement. Also, Anderson and Dukatz stated that the effect of an anti-stripping additive is asphalt specific (Hunter and Ksaibati, 2002).

\subsubsection{Anti-stripping agents}

The anti-stripping agents may be of two types: liquid and solid anti-stripping agents. Anti-stripping agents may be necessary if a particular mix design has been shown to be susceptible to moisture-induced damage. Liquid anti-stripping agents and lime additives are among the most commonly used types of anti-stripping agents. However, if an additive is used when it is not needed or if it is used incorrectly, adverse affects may 
occur, including an increased economic cost and early maintenance and/or rehabilitation (Hunter and Ksaibati, 2002).

\subsubsection{Liquid anti-stripping agents}

Liquid anti-strip additives have been used effectively and extensively in the United States to reduce the moisture sensitivity of hot-mix asphalt materials. Liquid antistrip agents can affect the engineering properties of the asphalt binder and the engineering properties of the hot mix asphalt mixture. The effectiveness of the liquid anti-strip on the water sensitivity of the hot mix asphalt mixture depends on the physicochemical properties of the asphalt binder and the aggregate, as well as on the amount of liquid anti-strip agent used (TRB, 2003).

Liquid anti-stripping agents are chemical compounds that contain amines. Most anti-stripping agents reduce surface tension between the asphalt and aggregate in a mixture. When surface tension is reduced, increased adhesion of the asphalt to the aggregate is promoted. Thus, most liquid anti-stripping agents are surface-active agents (Hunter and Ksaibati, 2002). Aggregates have a natural affinity for water. As can be seen in Figure 2.2(a), untreated aggregates are much more likely to be damaged by water breaking the asphalt/aggregate bond. Figure 2.2(b) shows how liquid anti-stripping additives allow the asphalt cement to create a strong bond between the asphalt and aggregate which will help reduce the chance of moisture damage. It is important that the liquid anti-stripping agent be heat stable. The simplest method of applying the liquid antistripping additive is to mix it directly with the asphalt cement immediately before its application onto the aggregate. This method is only partially effective because only a small portion of the additive comes into contact with the aggregates (Ksaibati and Conner, 2004).

Liquid amines and liquid phosphate ester are the two types of anti-strip additives used in HMA. Unlike the application of the hydrated lime, the liquid additives can be mixed with large amounts of asphalt and stored for use before mixing. These advantages save time and money by using less material and not affecting the production process greatly. A disadvantage of the liquid surfactants is possible heat degradation. If the 


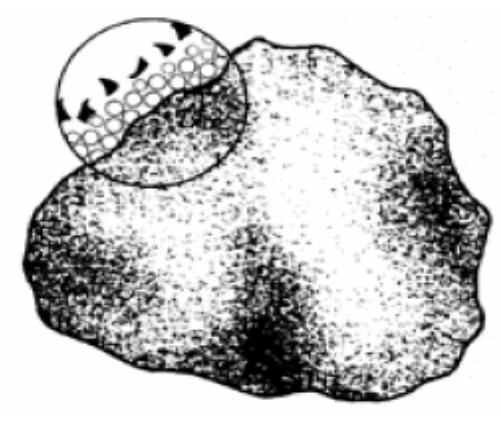

(a)

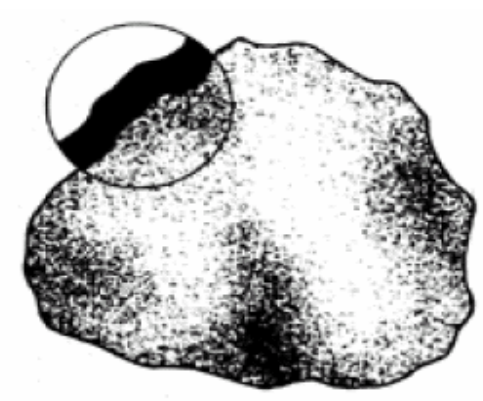

(b)

Figure 2.2 Effect of anti-strip agent on surface bonding of aggregate and asphalt (a) untreated (b) treated (Ksaibati and Conner 2004)

asphalt mixture is held at high temperature for long periods of time, the effectiveness may be reduced. Also, the anti-strip additive has to be added uniformly and mixed consistently throughout the asphalt cement (Tayebali, et al., 2003).

The properties of the combined asphalt binder and liquid anti-strip agent depend on the chemistry of the asphalt binder, the chemistry of the liquid anti-strip, the concentration level of the liquid anti-strip, and the types of carrier or dispersant used with the liquid anti-strip, among other factors. The combined binder and liquid anti-strip properties can also depend on the time and temperature of storage of the asphalt binderliquid anti-strip material (TRB, 2003).

Some of the liquid anti-strip agents use oil-type carriers or dispersants. These dispersants can change the physical properties of the asphalt binders. So they are said to low performance liquid anti-strip agents. High-performance liquid anti-strip agents contain very little dispersants. Testing of liquid anti-strip agents was performed with additives containing diesel oil. The degree of aging of an asphalt binder may also be altered by the presence of liquid anti-strip agents. The viscosity at $140^{\circ} \mathrm{F}$ of the aged asphalts with liquid anti-strip may be lower than that of the control asphalt binder, but the ratio of its viscosity increase (treated sample viscosity after aging to viscosity of treated sample before aging) may be larger. The penetration of the asphalt cement can also be affected by the presence of a liquid anti-strip agent. The magnitude of the penetration change depends on the type of additive, additive concentration, and type and source of 
the asphalt binder. In addition, when high-performance liquids are used, they may exhibit little or no change when measured for SHRP asphalt binder properties (TRB, 2003).

\subsubsection{Lime anti-stripping agents}

The anti-stripping mechanism of lime additives is not well understood. However, lime additives are an accepted method of minimizing moisture susceptibility of a mix. If an aggregate has more fines present, it may be necessary to use more lime additive due to the increased surface area of the aggregate (Hunter and Ksaibati, 2002).

Lime is available in several forms, including high-calcium quick lime, dolomitic quick lime, high-calcium hydrated lime, normal hydrated dolomitic quick lime, and pressure hydrated dolomitic quick lime. Both hydrated lime $\mathrm{Ca}(\mathrm{OH})_{2}$ and quick lime $(\mathrm{CaO})$ are effective at preventing stripping in HMA mixes, although the former is most commonly used. Dolomitic limes have also been used as antistripping additives. However, as a carbonate $\mathrm{CaCO}_{3}$ lime is not as effective (Ksaibati and Conner, 2004).

The common hydrated lime is actually a dry powder, and is added to the aggregate before mixing with the asphalt cement. The main drawback of the application method that hydrated lime requires is that it is difficult to retain an adequate surface coating of lime on the aggregate. Hydrated Lime can also be added to undried aggregate with water content from 3-5 percent. The addition of lime in this manner does, however, reduce HMA production capabilities because additional water needs to be added to prepare the lime and aggregate slurry (Ksaibati and Conner, 2004).

Research has indicated that the amount of hydrated lime needed to improve the moisture sensitivity of hot-mix asphalt is of the order of $1 \%$ to $2 \%$ by dry weight of aggregate. Some mixtures may require lime contents as high as $2.5 \%$ to achieve the desired results (TRB, 2003).

Researchers observed that the addition of hydrated lime to asphalt mixtures improved the adhesive bond between the aggregate and bitumen, substantially reducing the occurrence of stripping. Further research identified chemical reactions that occurred between lime and many bitumens that reduced their affinity for water, in turn reducing the mixture's tendencies to strip. In addition, when aggregates are coated with clays, 
hydrated lime can react pozzolanically to remove the deleterious materials that would otherwise damage the mixture (TRB, 2003).

Hydrated lime helps to mitigate moisture sensitivity of asphalt mixes in mechanical ways as well as chemical. As an extremely fine, active filler (characteristically $50 \%$ smaller than $10 \mu \mathrm{m}$ ), the hydrated lime helps to stiffen the mixture, often increasing the PG rating of the binder by a full grade with the addition of only $1 \%$ lime by weight of the aggregate. By stiffening the mix, the lime increases its resistance to rutting and fatigue cracking, reducing the ability of water to enter the system. In other words, when hydrated lime reacts chemically with bitumens, it often both eliminates components that facilitate the progression of water through the mix and removes compounds that contribute to oxidative aging (TRB, 2003).

\subsubsection{Effect of anti-stripping additives}

Maupin (1999) evaluated anti-stripping agent effectiveness in preventing HMA pavement stripping. Twelve pavements with known field stripping performance were evaluated. Anti-stripping agents included hydrated lime and nine chemical additives. Pavement cores from in service pavements were evaluated using the Root-Tunnicliff test method and by visual examination. Visual examination indicated that eight of the nine projects with chemical additives showed moderate to moderate-severe stripping of coarse aggregate. Six of the nine projects with chemical additives showed moderate to moderate-severe stripping of fine aggregate. Three projects with hydrated lime showed no stripping in the fine or coarse aggregate. Root-Tunnicliff test results indicated only one of twelve projects showed stripping potential. Results from both test methods indicated hydrated lime to be more successful than chemical additives in preventing HMA pavement stripping.

Pan and White (1999) conducted a laboratory study on asphalt mixture moisture sensitivity. Results from AASHTO T 283 tests indicate that moisture conditioning has a significant effect on the stripping potential of the seven mixes tested. That is, the tensile strength of the mixtures was reduced after the environmental procedures in AASHTO T 283 tests. Comparison of the results for the two anti-stripping agents based on TSR indicates that hydrated lime is more effective than the liquid chemical anti-stripping 
agent. Hydrated lime produces a slightly higher tensile strength for the mixtures before and after moisture conditioning. The liquid chemical anti-stripping agent increased the tensile strength for the mixtures after moisture conditioning. In some instances it also reduced the tensile strength for the mixture before moisture conditioning. Currently mixture stripping potential in the Superpave system is evaluated with AASHTO T283 and adopts a minimum TSR of $80 \%$ as design criteria. The reduction of the dry indirect tensile strength by the anti-stripping agent should be considered as a negative modifier effect.

Sebaaly, et al. (2003) evaluated the effectiveness of three different anti-stripping additives: Lime, UP5000 and a liquid additive. In general, the control, the UP5000, and the liquid anti-strip mixtures had the unconditioned strength properties which are similar to the lime treated mixtures. However, when these mixtures were moisture conditioned, their strength fell significantly below the conditioned properties of the lime treated mixtures. The evaluation of in service sections near Brookings, SD indicated that lime is more effective than the liquid anti-strip especially under multiple freeze-thaw cycling which represents the actual field conditions.

Kanitpong and Bahia (2003) evaluated the effect of anti-stripping additives on asphalt mixtures. Based on the results and analysis of the study, anti-stripping additives were not found to change the rheological properties of asphalt binders, and to improve the rutting and fatigue behavior of asphalt binder as measured by the Dynamic Shear Rheometer (DSR). However, both liquid and lime anti-strip additives were found to increase the adhesion of asphalt binder to selected mineral surfaces, especially when the binder bond is exposed to water. Cost estimation of the pavement with anti-stripping additives is very similar to the cost of the pavement without anti-stripping additives when taking into consideration the cost of maintenance every 5 to 6 years of the pavement service life.

Ksaibati and Conner (2004) performed laboratory tests and evaluated the effects of the addition of bottom ash into HMA mixes, testing specimens for tensile strength, and susceptibility to rutting. The data collected in this study showed that, in the absence of lime additive, HMA mixes prepared with granite aggregate reached failure faster than 
those mixes prepared with limestone aggregate. Also multiple freeze-thaw cycling typically showed a rapid strength decrease between the zero cycle (unconditioned specimens) and one freeze-thaw cycle for plant mix specimens of 4in. diameter.

\subsubsection{Aggregate pre-treatment}

Different pre-treatments have been shown to improve the adhesion between asphalt and aggregate. Examples of pretreatment include: heating of aggregate to remove any excess moisture, weathering, washing to remove very fine dust, and crushing. It also has been shown that aggregates pre-coated with asphalt or recycled materials are better at resisting moisture damage than are virgin materials (Hunter and Ksaibati, 2002).

\subsection{IDENTIFICATION OF MOISTURE DAMAGE IN THE FIELD}

Researchers are aware of the need to develop an investigative methodology to identify the moisture damage problem in specific pavement sections. The most commonly recommended procedure is taking cores and splitting them apart to visually evaluate the stripping of asphalt from aggregates. This procedure is arbitrary and could be uneconomical. Also, conclusions based on pavement distresses such as raveling, flushing and rutting could also be erroneous since these distresses could be caused by factors other than stripping. The literature review conducted for this research task identified three procedures that show promise.

\subsubsection{Maupin's procedure}

This procedure uses the development of a deterioration curve of the pavement layer based on the in-situ, remolded, and conditioned tensile strength of the mix (Maupin, 1999). It is based on the concept that as the pavement ages, the stiffness of the mix, (measured with the indirect tensile strength test) increases primarily due to age hardening. If the pavement is affected by moisture damage, the strength of the mix drops after the initial peak as shown in curve 2 on Figure 2.3. To evaluate the present and future strengths of the mix, cores need to be tested for the following conditions:

In-situ strength: Cores taken from the pavement are to be tested for tensile strength directly after removal and as soon as practical. 
Un-stripped strength: Cores are either reheated and remolded to the field air void content or, in cases where it is not possible to remold the mixes due to large aggregate size, cores are dried to constant weight and tested for un-stripped tensile strength.

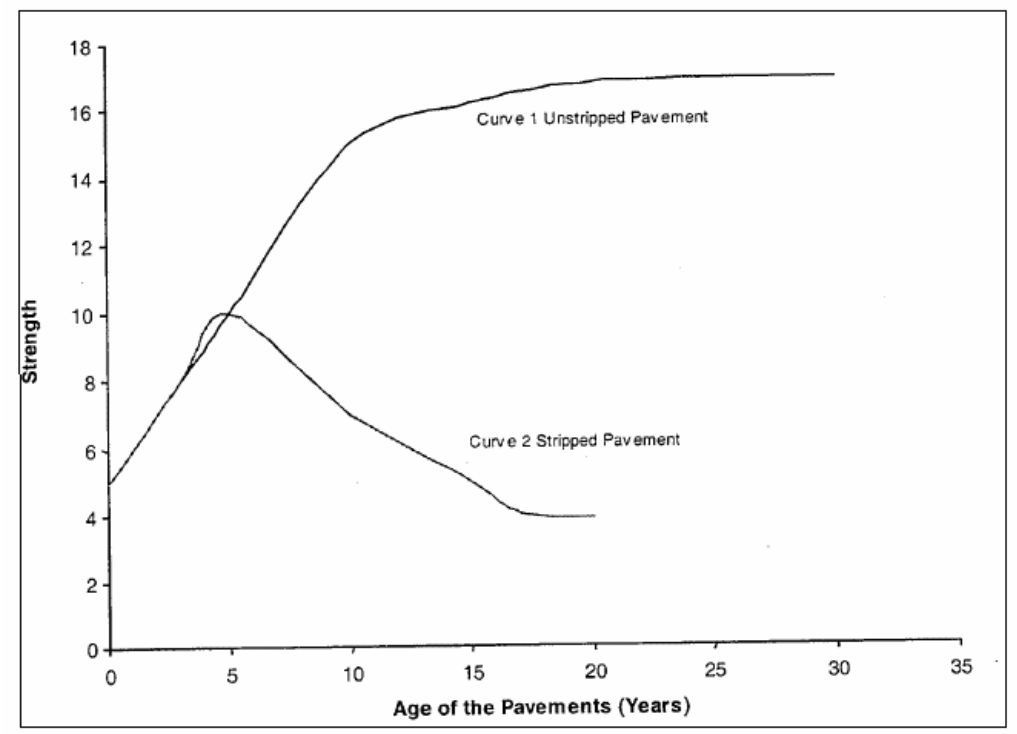

Figure 2.3 Deterioration curve for an asphalt pavement (Maupin, 1999; Bahia, et al., 1999)

Future strength: Cores are conditioned as per NCHRP Report 274 specifications and tested for tensile strength.

Using the in-situ, un-stripped, and the future strength, the deterioration curve is plotted as shown in Figure 2.3. A given pavement layer is said to be a candidate for rehabilitation if the present and future strengths of the pavements is less than 275.8 $\mathrm{kN} / \mathrm{m}^{2}$. This specification is based on Georgia DOT experience. Also, the ratio of present (in-situ), and future (conditioned) strength, to the dry remolded strength must be greater than 0.3 .

\subsubsection{Kandhal's procedure}

Kandhal (1992) suggests an investigative methodology based on forensic experience to identify the stripping problems in a given HMA pavement project. The procedure is accomplished in three phases, (1) sampling phase, (2) testing phase, and (3) analysis phases. 


\subsubsection{Sampling}

Pavement sections of $500 \mathrm{ft}$ are selected to record the distresses. At least seven cores of 4-inch diameter are obtained at random locations. If it is a 4-lane highway, cores from the inside wheel track of slow traffic (outside) lane is obtained. If it is a 2-lane highway, cores from the outside wheel track of the lane is obtained. It is necessary to drill these cores without using water as a coolant so that the in-situ moisture contents can be determined. Cores should be sealed in air-tight containers for determining the in-situ moisture content in the laboratory later. If dry coring cannot be done, then additional pavement layer samples should be obtained adjacent to the wet coring sites using a jack hammer. The HMA chunk samples loosened by the jack hammer from each layer should also be sealed in air-tight containers so that the in-situ moisture content can be determined in the laboratory later.

\subsubsection{Testing}

The in-situ moisture content should be determined by weighing the cores before and after drying to constant weight. The thickness of core is measured. The cores are observed for the evidence of stripping. The HMA layers are separated from the cores and average thickness of each layer is measured. The bulk specific gravity is determined by AASHTO T 166. The indirect tensile strength is determined using AASHTO T283 or ASTM D 4867. The split exposed surfaces of the tested core are examined for stripping. A visual rating of stripping on the exposed surface should be made and documented. The procedure, however, does require some training for consistent interpretation of observations. After cores have been rated, the maximum theoretical specific gravity is determined by AASHTO T209. The extraction test (AASHTO T164) and gradation of extracted aggregate (AASHTO T30) is done to determine the mix composition (asphalt content and gradation).

\subsubsection{Calculations and tabulation}

The effective specific gravity of aggregates should be calculated using their maximum theoretical specific gravity values and their respective asphalt content values. The average effective specific gravity of the aggregate is calculated from these three values. The maximum theoretical specific gravity is calculated using this average 
effective specific gravity and their respective asphalt contents obtained by extraction. The air void content and saturation level is calculated for each core.

The calculated and observed data are tabulated separately for "good" and “distressed" areas. The mean, standard deviation, and 95 percent confidence limits for each parameter are calculated. These values are compared to identify the differences. The air void content and saturation level for each core was determined. The process involved measuring the maximum theoretical specific gravity and asphalt content of three samples per project. The effective specific gravity of the aggregate $\mathrm{G}_{\mathrm{se}}$, was then computed. The average $\mathrm{G}_{\mathrm{se}}$ for the three samples was assumed to apply to all samples for a project. Then, using the asphalt content from the extraction test for each core and $\mathrm{G}_{\mathrm{se}}$, the maximum theoretical specific gravity for the core was computed. This was used with the bulk specific gravity of the core to determine the air voids of the core. The moisture content of the core was then used to compute the level of saturation.

\subsubsection{Tunnicliff and Root's procedure}

The Tunnicliff and Root procedure was developed as a part of NCHRP Report 373 on the field evaluation of anti-stripping additives in asphalt concrete mixtures (Bahia, et al., 1999). To evaluate the performance of the anti-stripping additives over a period of time, the researchers suggested a procedure that involves taking field cores from the pavement periodically and testing them for tensile strength under varying conditions.

\subsection{CHAPTER SUMMARY}

Stripping is a serious problem for many highway agencies. Over the years, many testing procedures have been developed to evaluate moisture susceptibility of HMA mixtures. Two types of testing have been developed: strength and subjective. Of the strength tests, those that use TSR data have been widely tested and accepted. More specifically, the AASHTO T 283 method is recommended as part of the Superpave mix design method.

Although several separate mechanisms have been identified to explain the process of moisture damage in asphalt pavements, it is more likely that most asphalt pavements suffer moisture damage as a result of a synergy of several processes. Researchers point out that certain polar asphalt compounds develop more tenacious and moisture-resistant 
bonds with the aggregate surface than others and that the development of the more tenacious and long-lasting bonds can be promoted by treatment of the asphalt mixtures with additives. Favorable chemical bonding between asphalt and aggregate alone will not optimize the adhesive bond and minimize moisture damage. The bond is part physical, and, therefore, the asphalt must be able to wet and permeate the aggregate surface. This process is dependent on asphalt rheology at mixing temperatures and the nature of the aggregate surface, pore size, pore shape, and aggregate mineralogy.

The complexity of the stripping process has inhibited the development of a fundamental test method. All current methods for testing the moisture susceptibility are empirically based. Although AASHTO T 283 is the recommended procedure it cannot be conclusively stated that this method is reliable for determining the moisture susceptibility of asphalt concrete. Aschenbrener, et al. (1995) criticizes the method for not being capable of modeling the extended presence of moisture and corresponding development of the pore pressures from the traffic. Several authors have presented conflicting results concerning the test method specifications. Hunter and Ksaibati (2002) and Coplantz and Newcomb (1988) concluded freeze-thaw conditioned sample results showed lower tensile strengths than samples which were only saturated. Epps, et al. (2000) recommended the use of saturation plus freeze-thaw conditioning even thought their test results were inconclusive concerning conditioning methods. Mahoney and Stephens (1999)

recommended changes in the method for computing the degree of saturation, but Epps, et al.'s data (2000) showed level of saturation was not an important factor. Choubane, et al. (2001) suggested the degree of saturation should be greater for coarse mixes than for fine mixes. Choubane, et al. (2001) also recommended a minimum requirement for wet indirect tensile strength should be $410 \mathrm{kPa}$ (60 psi). Both Pan and White (1999) and Epps, et al. (2000) recommended field performance studies as part of the implementation of a moisture sensitivity test requirement for the mix design process. Several authors have presented methods to perform field studies to identify stripping problems.

Laboratory and field studies indicate lime is an effective antistrip measure. Liquid anti-strip agents are not as effective as lime and there is some researchers have found no benefit of using liquid anti-strip agents (Maupin, et al., 1999). 


\section{CHAPTER 3: EXPERIMENTAL DESIGN AND TESTING PROCEDURES}

\subsection{INTRODUCTION}

As shown in Table 2.2 the moisture sensitivity test, AASHTO T 283 was changed significantly between the 1989 and the 2003 versions. The change which was anticipated to cause the greatest impact on mix designs in West Virginia was making the freeze-thaw cycle mandatory in the 2003 version. The modifications to AASHTO T 283 were found primarily on the results of NCHRP Project 9-13 (Epps, et al., 2000). In the report for this project it was recommended that all states conduct a structured research program to evaluate the implementation of the moisture sensitivity test. The research reported herein is a preliminary investigation of using AASHTO T 283 as part of the Superpave mix design procedure.

This research focused on the issue of including a freeze-thaw cycle in the conditioning of samples evaluated for moisture sensitivity. The methods and procedures prescribed in the 2003 version of AASHTO T 283 were followed with the exception that some of the samples were only conditioned by saturation rather than by saturation and freeze-thaw.

\subsection{EXPERIMENTAL DESIGN AND TEST MATERIALS}

The evaluation of moisture sensitivity was performed on three mixes. Superpave $9.5 \mathrm{~mm}$ mixes from J.F. Allen and New Enterprise were evaluated. A $19 \mathrm{~mm}$ Superpave mix from Carl Kelly was tested. All aggregates were crushed limestone. The gradation of each mix is shown in Figure 3.1 to 3.3. The aggregates obtained from the suppliers were air dried and sieved using the following set of sieves: $37.5 \mathrm{~mm}, 25 \mathrm{~mm}, 19 \mathrm{~mm}$, $12.5 \mathrm{~mm}, 9.5 \mathrm{~mm}, 4.75 \mathrm{~mm}, 2.36 \mathrm{~mm}, 1.18 \mathrm{~mm}, 0.6 \mathrm{~mm}, 0.3 \mathrm{~mm}$ and $0.075 \mathrm{~mm}$. All aggregates were washed to take off the fines, oven dried and stored in bins. The physical characteristics of each type of aggregate were obtained from suppliers. All mixes were prepared with a PG 70-22 from Marathon Ashland Petroleum LLC. The mixing and compaction temperature ranges were supplied by the manufacturers as 159 to $165^{\circ} \mathrm{C}$ and 148 to $153^{\circ} \mathrm{C}$, respectively. The maximum mixing temperature of $165^{\circ} \mathrm{C}$ and the 
maximum compaction temperature of $153^{\circ} \mathrm{C}$ were selected for the experiment. This is a typical binder used for Superpave mixes in West Virginia.

The effect of using a liquid anti-strip was tested for each mix. The liquid antistrip was provided by New Enterprise. Liquid anti-stripping additive weighing 0.2 to 0.5 percent by binder weight is added to the mix.

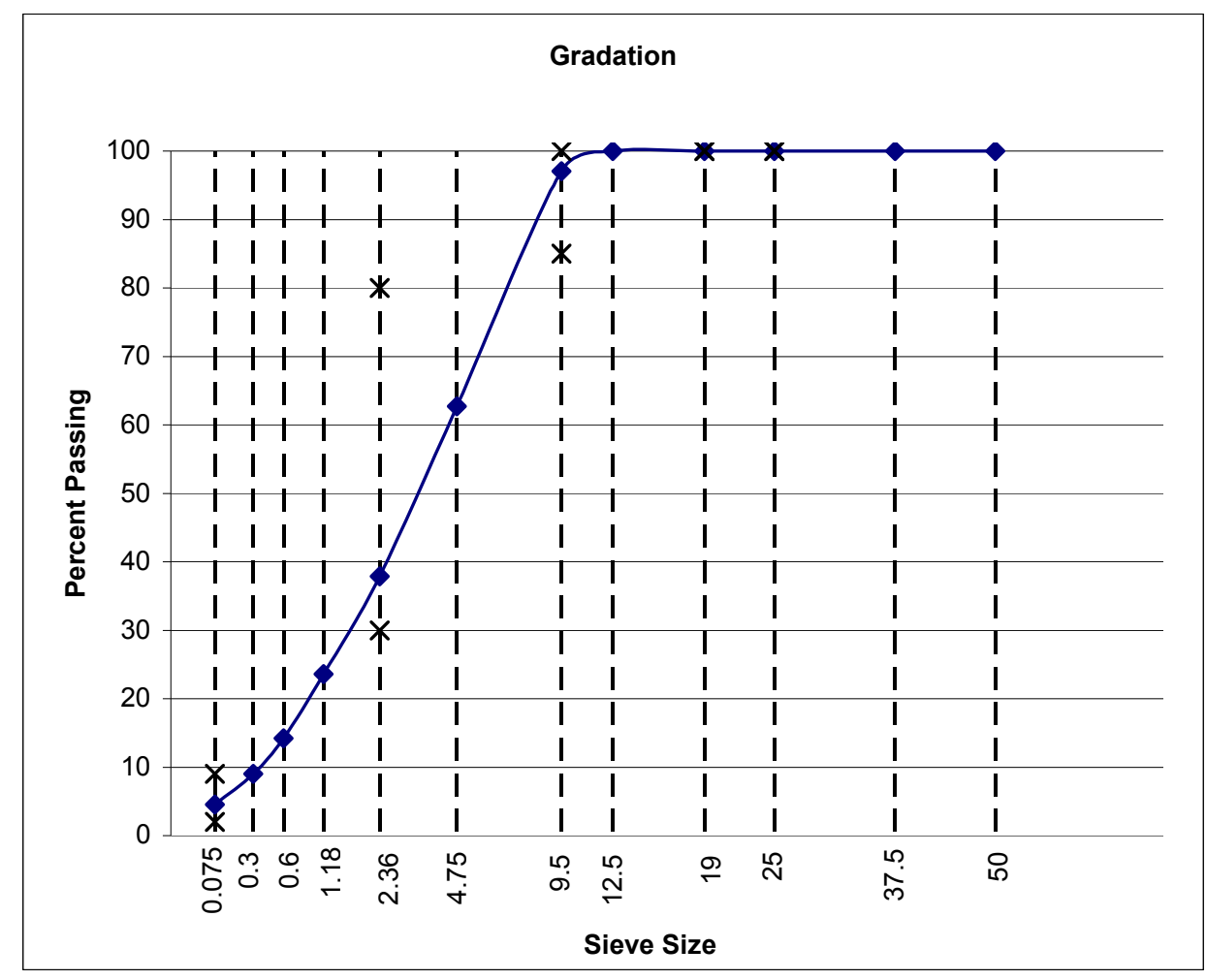

Figure 3.1 Gradation for $9.5 \mathrm{~mm}$ limestone aggregates from J.F. Allen source 


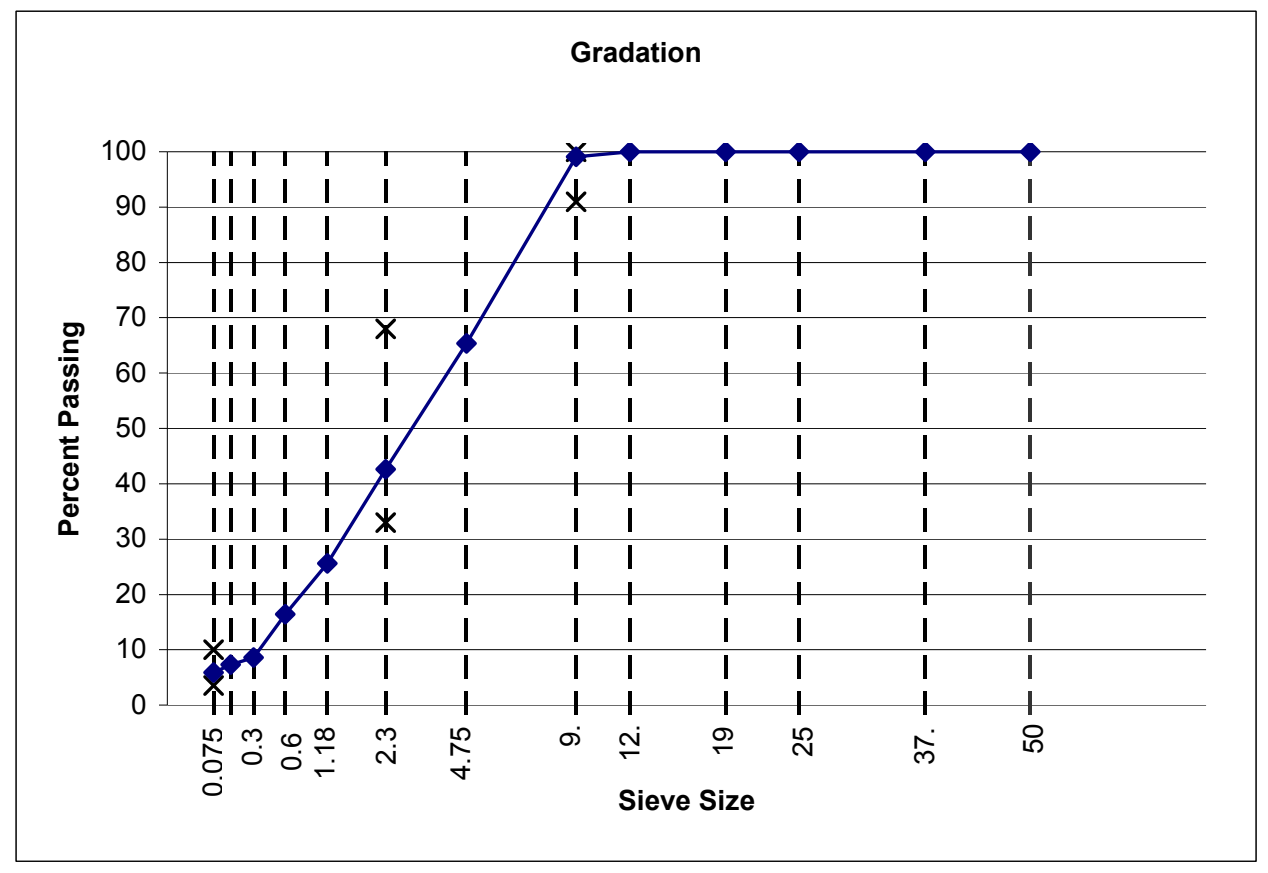

Figure 3.2 Gradation for $9.5 \mathrm{~mm}$ limestone aggregates from New Enterprise source

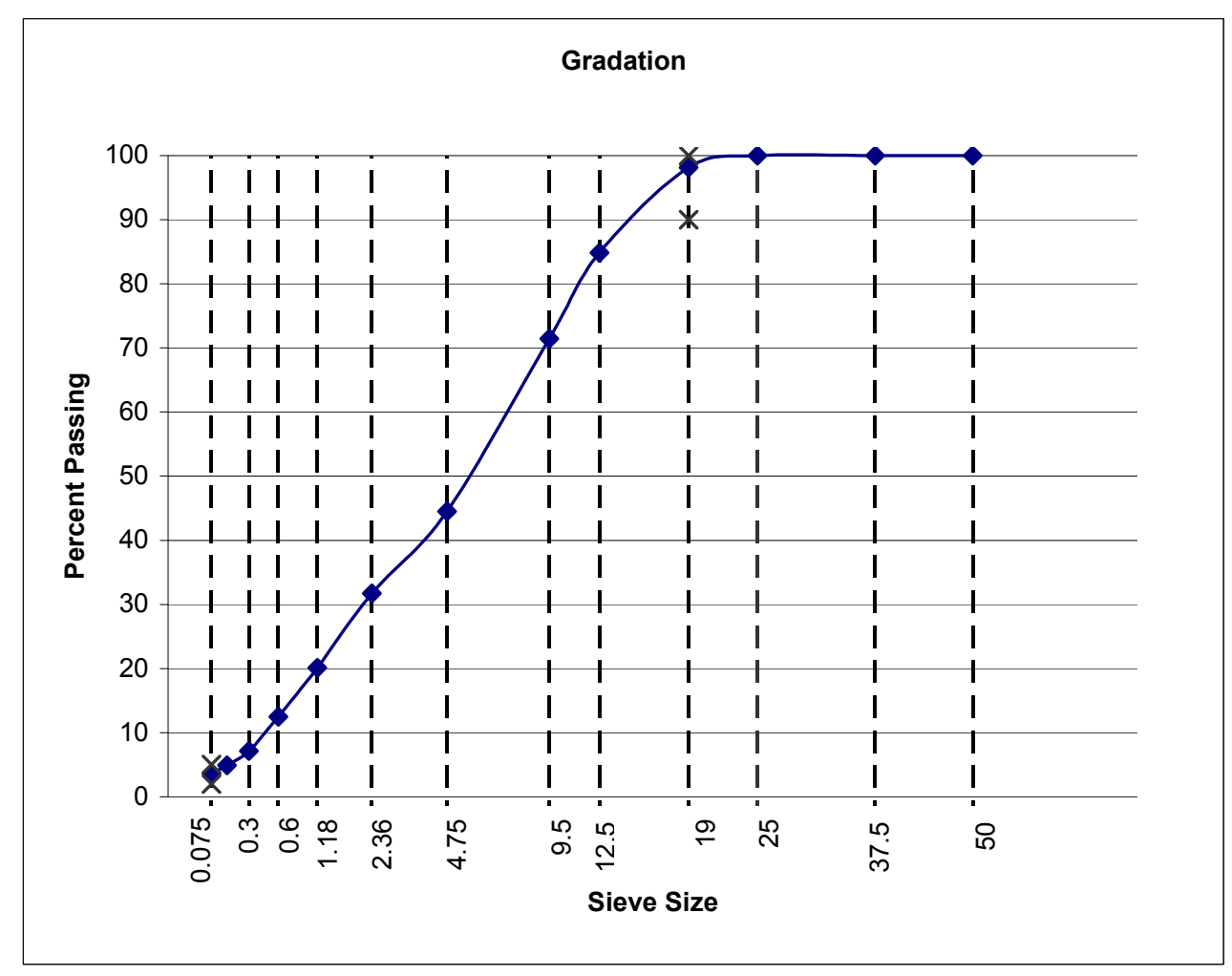

Figure 3.3 Gradation for $19 \mathrm{~mm}$ limestone aggregates from Carl Kelly source 


\subsubsection{Verification of mix design}

Before testing for moisture sensitivity, each mix design was reviewed and verified. The complete mix design package was obtained from the WVDOH. Bulk specific gravity and maximum theoretical gravity were determined using the approximate standard test methods. The verification demonstrated the mixes could be reproduced in the WVU Asphalt Technology Laboratory.

The pills compacted to 100 gyrations were used to verify the mix designs. After compaction, samples were allowed to cool. Weight in air, weight in water and saturated surface dry weight were taken to compute the bulk specific gravity of the mix (AASHTO T166). Using the following set of equations, the maximum theoretical specific gravity and the bulk specific gravity of the mix, the volumetric properties of the asphalt mix were evaluated.

$$
\begin{aligned}
& \% G_{m m, N d e s}=\frac{G_{m b}}{G_{m m}} \\
& G_{s e}=\frac{1-P_{b}}{\frac{1}{G_{m m}}-\frac{P_{b}}{G_{b}}} \\
& P_{b a}=100\left(\frac{G_{s e}-G_{s b}}{G_{s b}\left(G_{s e}\right)} G_{b}\right) \\
& P_{b e}=P_{b}-P_{b a}\left(1-P_{b}\right) \\
& \frac{d}{B}=\frac{\frac{\% P_{\# 200}}{100}}{P_{b e}} \\
& V T M=\left(1-\frac{G_{m b}}{G_{m m}}\right) 100 \\
& V M A=100\left(1-\frac{G_{m b}\left(1-P_{b}\right)}{G_{s b}}\right)
\end{aligned}
$$




$$
V F A=100\left(\frac{V M A-V T M}{V M A}\right)
$$

Where,

$\% \mathrm{G}_{\mathrm{mm}, \mathrm{Ndes}}=$ Percent of maximum specific gravity at design number of revolutions;

$\mathrm{G}_{\mathrm{mb}}=$ Bulk specific gravity;

$\mathrm{G}_{\mathrm{mm}}=$ Maximum specific gravity;

$\mathrm{G}_{\mathrm{se}}=$ Effective specific gravity of aggregate;

$\mathrm{P}_{\mathrm{b}}=$ Percent binder;

$\mathrm{G}_{\mathrm{b}}=$ Specific gravity of the binder;

$\mathrm{P}_{\mathrm{ba}}=$ Percent binder absorbed;

$\mathrm{G}_{\mathrm{sb}}=$ Bulk specific gravity of aggregate;

$\mathrm{P}_{\mathrm{be}}=$ Effective percent binder;

$\% \mathrm{P}_{\# 200}=$ Percent of the aggregate blend passing the \#200 sieve;

$\% \mathrm{G}_{\mathrm{mm} \text {,Nini }}=$ Percent of maximum specific gravity at initial number of revolutions;

$\mathrm{H}_{\mathrm{des}}=$ Height at the design number of revolutions;

$\mathrm{H}_{\text {ini }}=$ Height at the initial number of revolutions;

$\mathrm{VTM}=$ Air voids in compacted mixture;

$\mathrm{VMA}=$ Volume of voids in mineral aggregates; and

$\mathrm{VFA}=$ Voids filled with asphalt

\subsubsection{Moisture sensitivity testing}

Once the mix designs were verified, samples were prepared for the moisture sensitivity testing. The flow of activities was summarized in Figure 3.4. Table 3.1 shows the time schedule of the test procedure of AASHTO T 283 used in the asphalt concrete laboratory in West Virginia University. Each set of moisture sensitivity samples required sufficient material to make nine compaction samples plus a sample for measuring the maximum theoretical specific gravity. Two additional compaction samples were prepared and held in reserve for use as needed. The aggregate and asphalt were heated to the upper temperature of the recommended range for compaction. A pre-weighed quantity of aggregate was placed in the bucket mixer and the required amount of asphalt was weighed in. The samples were mixed in four batches. Three batches contained sufficient material for compacting three samples. For one batch per mix, the quantity of 
material was sufficient for making two compaction samples plus one maximum theoretical specific gravity sample.

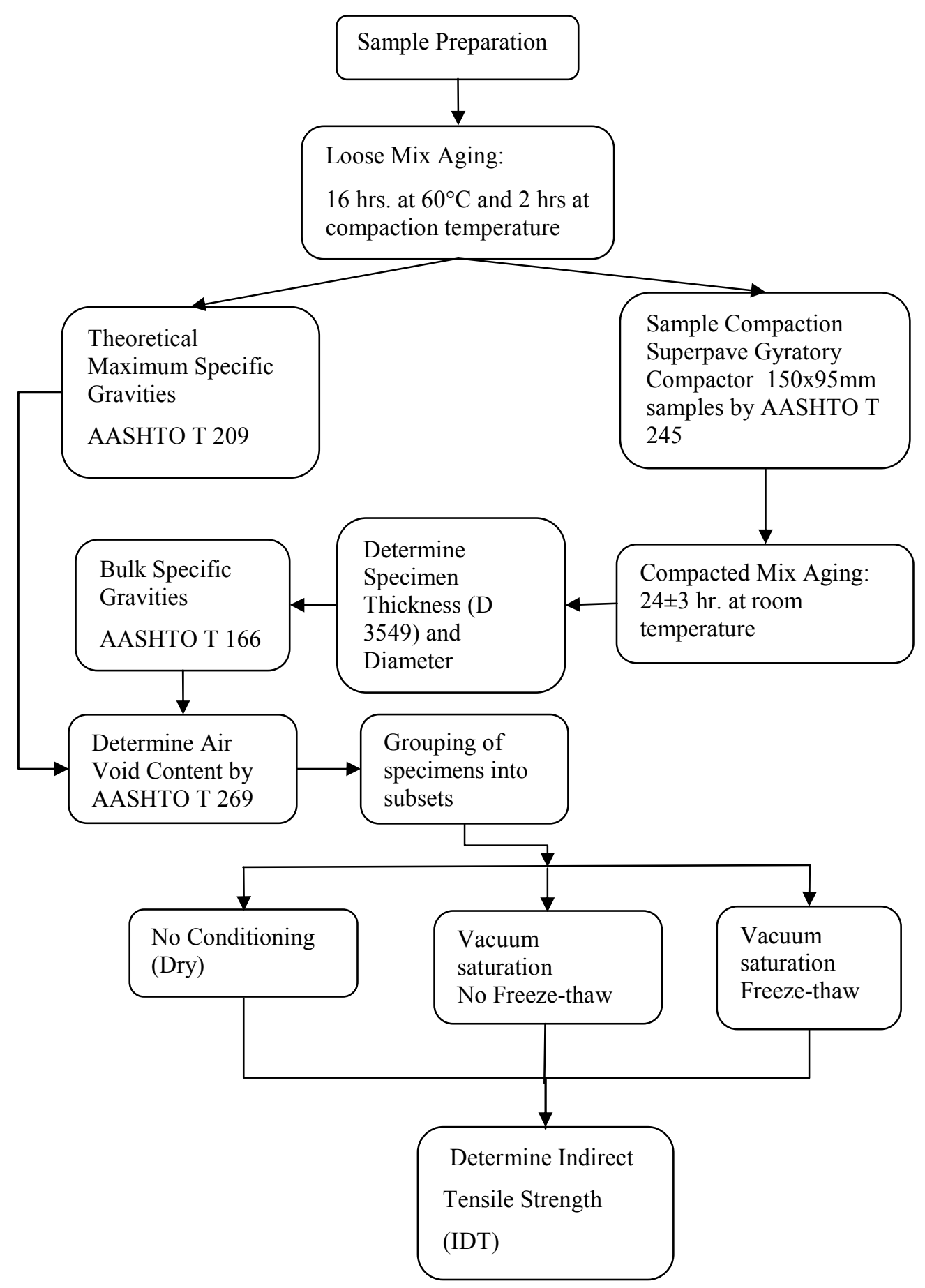

Figure 3.4 Flow chart for the AASHTO T 283 test method 
Table 3.1 Time schedule for test procedure of AASHTO T 283

\begin{tabular}{|c|c|c|c|c|c|c|c|c|c|c|c|c|c|c|c|c|c|}
\hline \multirow{2}{*}{ बิ } & \multirow{2}{*}{$\stackrel{\oplus}{\underline{\xi}}$} & \multirow[t]{2}{*}{ Mix, cool } & \multirow[t]{2}{*}{ Oven 140} & \multirow[t]{2}{*}{ pven 153 } & \multirow[t]{2}{*}{ Compact } & \multirow[t]{2}{*}{$\mathrm{Gmb}$} & \multicolumn{2}{|c|}{ UC } & \multicolumn{4}{|c|}{ C wo/F } & \multicolumn{5}{|c|}{$\mathrm{CF}$} \\
\hline & & & & & & & $\begin{array}{l}\text { WB } \\
77 F\end{array}$ & ST & Vac & \begin{tabular}{|c|}
$\mathrm{WB}$ \\
$140 \mathrm{~F}$ \\
\end{tabular} & $\begin{array}{l}\text { WB } \\
77 \mathrm{~F}\end{array}$ & ST & Vac & Freeze & \begin{tabular}{|c|} 
WB \\
$140 F$ \\
\end{tabular} & $\begin{array}{l}\text { WB } \\
77 \mathrm{~F} \\
\end{array}$ & ST \\
\hline \multirow{3}{*}{ M } & 3 & & & & & & & & & & & & & & & & \\
\hline & 4 & & & & & & & & & & & & & & & & \\
\hline & 5 & & & & & & & & & & & & & & & & \\
\hline \multirow{11}{*}{$\mathrm{T}$} & 8 & & & & & & & & & & & & & & & & \\
\hline & 9 & & & & & & & & & & & & & & & & \\
\hline & 10 & & & & & & & & & & & & & & & & \\
\hline & 11 & & & & & & & & & & & & $\pi$ & & & & \\
\hline & 12 & & & & & & & & & & & & & & & & \\
\hline & 1 & & & & & & & & & & & & 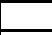 & & & & \\
\hline & 2 & & & & & & & & & & & & & & & & \\
\hline & 3 & & & & & & & & & & & & & & & & \\
\hline & 4 & & & & & & & & & & & & & & & & \\
\hline & 5 & & & & & & & & & & & & & & & & \\
\hline & 6 & & & & & & & & & & & & & & & & \\
\hline \multirow{11}{*}{ W } & 8 & & & & & & & & & & & 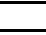 & 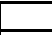 & & 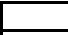 & 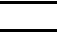 & 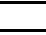 \\
\hline & 9 & & & & & & & & & & & & & & & & \\
\hline & 10 & & & & & & & & & & & & & & & & \\
\hline & 11 & & & & & & & & & & & & & & & & \\
\hline & 12 & & & & & & & & & & & & & & & & \\
\hline & 1 & & & & & & & & & & & & & & & & \\
\hline & 2 & & & & & & & & & & & & & & & & \\
\hline & 3 & & & & & & & & & & & & & & & & \\
\hline & 4 & & & & & & & & & & & & 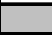 & & & & \\
\hline & 5 & & & & & & & & & & & & & & & & \\
\hline & 6 & & & & & & & & & & & & & & & & \\
\hline \multirow{11}{*}{$\mathrm{R}$} & 8 & & & & & & & & & & & & & & & & \\
\hline & 9 & & & & & & & & & & & & & & & & \\
\hline & 10 & & & & & & & & & & & & & & & & \\
\hline & 11 & & & & & & & & & & & & 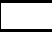 & & & & \\
\hline & 12 & & & & & & & & & & & & & & & & \\
\hline & 1 & & & & & & & & & & & & & & & & \\
\hline & 2 & & & & & & & & & & & & & & & & \\
\hline & 3 & & & & & & & & & & & & & & & & \\
\hline & 4 & & & & & & & & & & & & & & & & \\
\hline & 5 & & & & & & & & & & & & & & & & \\
\hline & 6 & & & & & & & & & & & & & & & & \\
\hline \multirow{11}{*}{$F$} & 8 & & & & & & & & & & & & & & & & \\
\hline & 9 & & & & & & & & & & & & & & & & \\
\hline & 10 & & & & & & & & & & & & & & & & \\
\hline & 11 & & & & & & & & & & & & & & & & \\
\hline & 12 & & & & & & & & & & & & & & & & \\
\hline & 1 & & & & & & & & & & & & & & & & \\
\hline & 2 & & & & & & & & & & & & & & & & \\
\hline & 3 & & & & & & & & & & & & & & & & \\
\hline & 4 & & & & & & & & & & & & & & & & \\
\hline & 5 & & & & & & & & & & & & & & & & \\
\hline & 6 & & & & & & & & & & & & & & & & \\
\hline
\end{tabular}

UC-Unconditioned; $\mathrm{C}$ wo/F-Conditioned without Freezing (saturation only); CF-Conditioned with Freezing; WB-Water Bath; ST-specimens Tested for IDT; Vac-Vacuum saturation.

The J.F. Allen mix was also used to check the sensitivity of TSR to saturation level. Samples were prepared with saturation conditioning of $60 \%$ which meets the 1989 requirement of 55 to 80 percent. The IDT of these samples were used to compute TSR. The results obtained from these samples were compared to the results of samples prepared to the 2003 requirement of 70 to 80 percent saturation. 


\subsubsection{Loose mix aging and compacted mix aging}

Once the samples were mixed, the AASHTO T 283 loose mix aging procedure was followed. The batches were quartered to achieve the required weight for three compacted samples. One batch per mix had sufficient remaining material for determining the maximum theoretical specific gravity.

The loose mix aging process consisted of allowing the mix to cool to room temperature for two hours. The mix was then placed in the oven for $16 \pm 1$ hour at $60^{\circ} \mathrm{C}$. The samples were then transferred to an oven at the compaction temperature and allowed to remain for two hours. The samples used for determining maximum theoretical specific gravity were allowed to cool to room temperature and the AASHTO T 209 method was followed to determine the maximum theoretical specific gravity. The materials for compaction samples were transferred to a pre-heated mold and compacted to the required height. After compaction, the samples were slowly extruded from the mold and allowed to cool at room temperature for $24 \pm 3$ hours. The thickness, diameter and bulk specific gravity (AASHTO T 166) were determined.

\subsubsection{Sample selection}

The void in the total mix, VTM, was determined for each sample. Samples with a VTM outside $7 \pm 0.5$ percent were rejected. Three samples were then selected for each of the conditioning level. The samples were selected such that the average air void content of the each group of the each groups of samples was as close as possible.

\subsubsection{Unconditioned samples}

After the specimens are grouped, the unconditioned (dry) sample was placed in a heavy-duty leak-proof plastic bag. The specimens were then placed in a $25 \pm 0.5^{\circ} \mathrm{C}$ $\left(77 \pm 1^{\circ} \mathrm{F}\right)$ water bath for 2 hours \pm 10 minutes. The specimens were removed from water bath and the indirect-tensile strength was measured. Figure 3.5 shows a sample subjected to dry conditioning. 


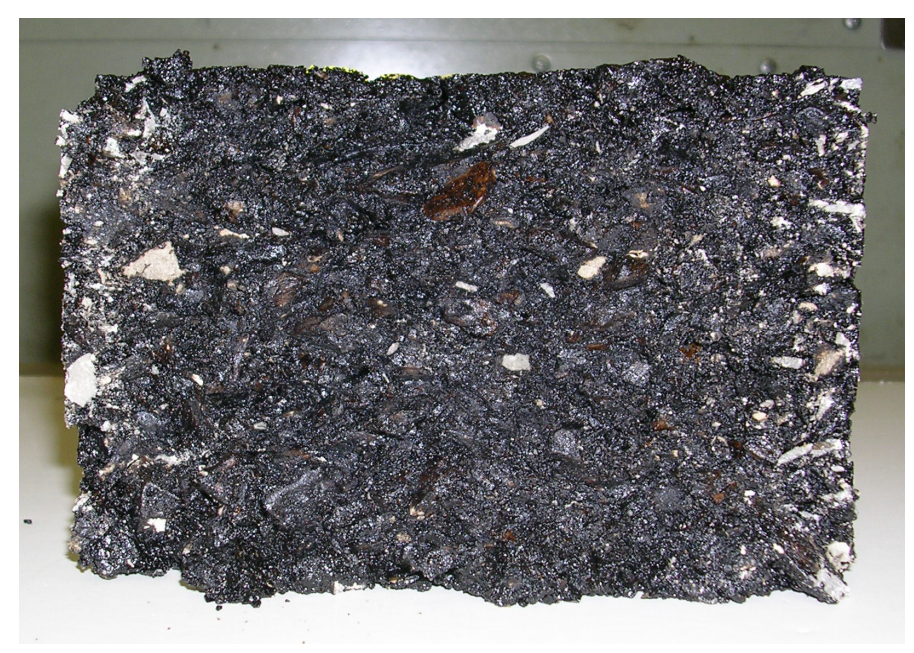

Figure 3.5 Sample subjected to dry conditioning

\subsubsection{Subset conditioned with saturation only}

The second subset consisted of conditioned with saturated only samples. Each sample selected for saturation conditioning only was placed in a vacuum container filled with potable water at room temperature. The sample was vacuum saturated at 13 to $67 \mathrm{kPa}$ absolute pressure (10 to $26 \mathrm{in}$. Hg partial pressure) for approximately 5 to 10 minutes. The vacuum apparatus is shown in Figure 3.6. The vacuum was removed and the specimen was allowed to submerge in water without any disturbance for a short time of 5 to 10 minutes. The degree of saturation was determined for the specimens. If the degree of saturation was greater than the 80 percent, the specimens were discarded. If the degree of saturation was less than 70 percent, then specimens were subjected to vacuum saturation again until the 70 percent saturation was attained. For the sample set used to evaluate the effect of saturation, the process was same except the target saturation level was 60 percent. The degree of saturation ( $\left.\mathrm{S}^{\prime}\right)$ was determined as:

$$
\mathrm{S}^{\prime}=\frac{100 \mathrm{~J}^{\prime}}{\mathrm{V}_{\mathrm{a}}}
$$

where:

$\mathrm{S}^{\prime}=$ degree of saturation, percent

$\mathrm{J}^{\prime}=$ volume of absorbed water, cubic centimeters

$\mathrm{V}_{\mathrm{a}}=$ volume of air voids 
The volume of absorbed water $\left(\mathrm{J}^{\prime}\right)$ was calculated using the following equation:

$$
J^{\prime}=B^{\prime}-A
$$

where:

$\mathrm{B}^{\prime}=$ mass of the saturated, surface-dry specimen after partial vacuum saturation, $\mathrm{g}$

$\mathrm{A}=$ mass of the dry specimen in air, $\mathrm{g}$

The volume of air voids was determined as:

$$
\mathrm{V}_{\mathrm{a}}=\frac{\mathrm{P}_{\mathrm{a}} \mathrm{E}}{100}
$$

where

$\mathrm{V}_{\mathrm{a}}=$ volume of air voids, cubic centimeters,

$\mathrm{P}_{\mathrm{a}}=$ air voids, percent

$\mathrm{E}=$ volume of the specimen, cubic centimeters

The percent air voids in the compacted samples was calculated as follows:

$$
\text { Percent air voids }=100\left(1-\frac{\mathrm{A}}{\mathrm{B}}\right)
$$

Where,

$\mathrm{A}=$ bulk specific gravity $(\mathrm{T}-166)$,

$\mathrm{B}=$ theoretical maximum specific gravity (T-209).

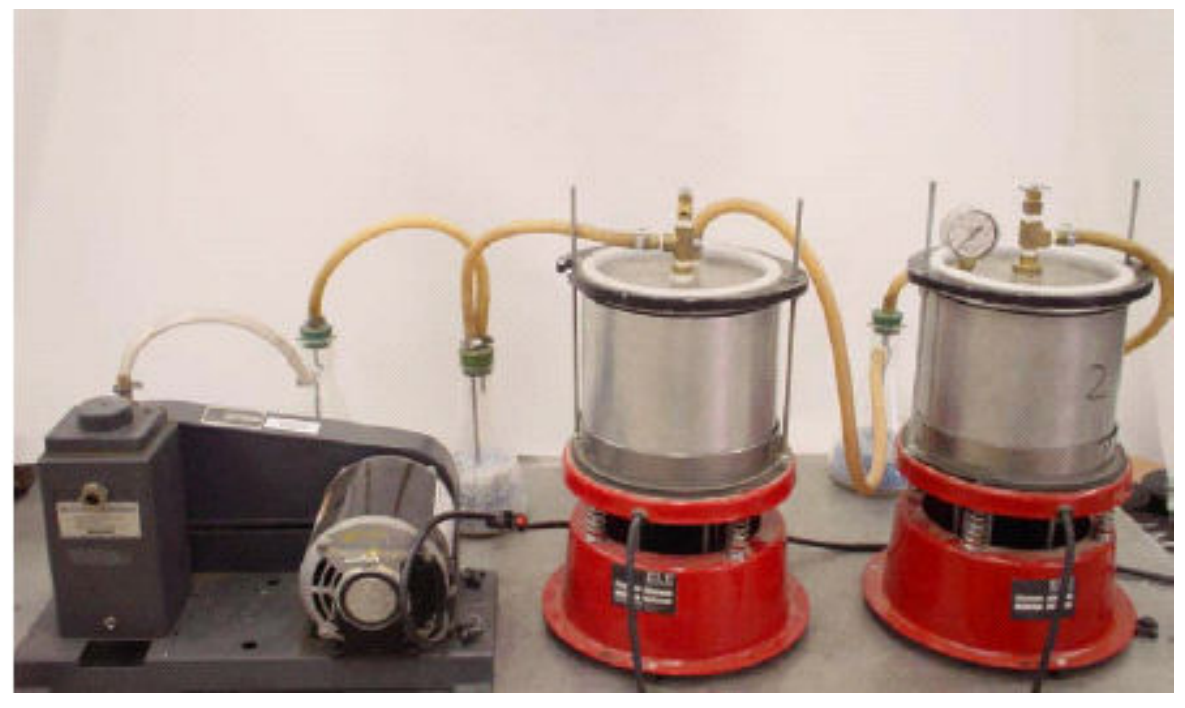

Figure 3.6 Vacuum apparatus 
After vacuum saturation, specimens were placed in a water bath at $60 \pm 1{ }^{\circ} \mathrm{C}$ $\left(140 \pm 2^{\circ} \mathrm{F}\right)$ for $24 \pm 1$ hour. The specimens were then placed in another water bath at $25 \pm 0.5^{\circ} \mathrm{C}\left(77 \pm 1^{\circ} \mathrm{F}\right)$ for 2 hours $\pm 10 \mathrm{~min}$. The specimens were removed from the water bath, and the thickness ( $t^{\prime}$ ) was determined by D3549 method. After the thickness was measured, specimens were tested for indirect tensile strength in the Marshall stability and flow machine. The tensile strength ratio (TSR) was calculated by dividing the average ITS of the conditioned saturated only subset by the average ITS of the unconditioned subset.

\subsubsection{Subset conditioned with saturation plus freeze-thaw cycle}

The third subset was subjected to vacuum saturation followed by the freeze-thaw cycle, and then tested for IDT. The vacuum saturation process was the same as described for conditioned saturation only samples. After vacuum saturation each specimen was wrapped in Saran wrap, placed in a zip-lock bag and $10 \pm 0.5 \mathrm{~mL}$ water was added before the freeze-thaw cycle was performed. The specimens were kept in the freezer at a temperature of $-18 \pm 3^{\circ} \mathrm{C}\left(0 \pm 5^{\circ} \mathrm{F}\right)$ for a minimum of 16 hours. The only difference between conditioned saturation only and conditioned with saturation plus freeze-thaw was that the specimens were subjected to freeze-thaw cycle. After the freeze-thaw cycle, specimens were transferred to the water bath at $60 \pm 1^{\circ} \mathrm{C}\left(140 \pm 2^{\circ} \mathrm{F}\right)$ and the zip lock bag and plastic film were removed from the specimens as soon as it was placed in the water bath. The remaining process was same as described for the second subset. Figure 3.7 shows a sample subjected to wet conditioning followed by a vacuum saturation. 


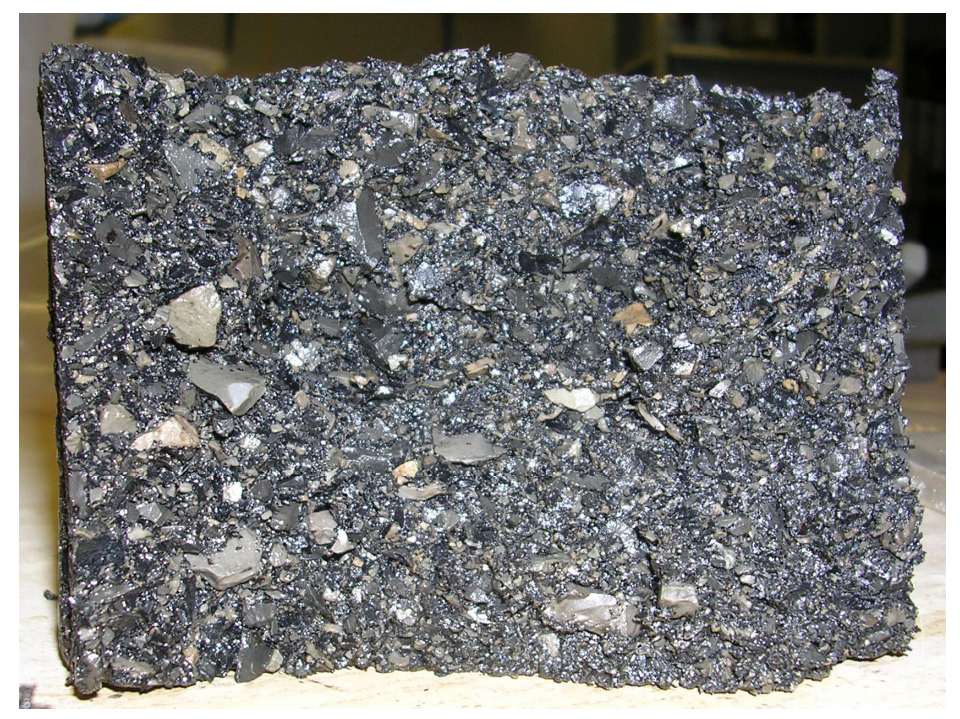

Figure 3.7 Sample subjected to wet conditioning

\subsubsection{Indirect tensile strength test}

The indirect tensile test was performed on a Marshall Stability and flow machine, is shown in Figure 3.8 (a) with steel loading strips that have concave surfaces. Figure 3.8 (b) shows the laboratory test setup for the IDT strength test and the failure plane of specimen.

The specimens were removed from $25 \pm 0.5^{\circ} \mathrm{C}$ water bath, and the thickness $\left(\mathrm{t}^{\prime}\right)$ for the saturated only and saturated plus freeze-thaw samples was measured by the method of D 3549. The specimens were placed between the steel loading strips which were attached to bearing plates of the testing machine. The load was applied to the specimen by the constant head rate, at $50 \mathrm{~mm}$ (2in.) per minute. The maximum compressive force was recorded and the load was continued until a vertical crack appeared on the specimen. Then the specimen was removed from the machine and pulled apart at the crack. The interior surface of the specimen was checked for any cracked or broken aggregates. From the plot of load versus deformation, maximum load carried by the specimen was found, and Equation 3.13 was used to determine the indirect tensile stress at failure. IDT stress for the three specimens was averaged and reported as the IDT strength of each sets. Typical plots of load versus deformation are shown in Figures 3.9 to 3.11. 


$$
S_{t}=\frac{2 P}{\pi d t}
$$

Where,

$\mathrm{S}_{\mathrm{t}}=$ Horizontal tensile stress at center of specimen, psi

$\mathrm{P}=$ Applied load, lbs

$\mathrm{d}=$ Diameter of the specimen, inches

$\mathrm{t}=$ Thickness of the specimen, inches

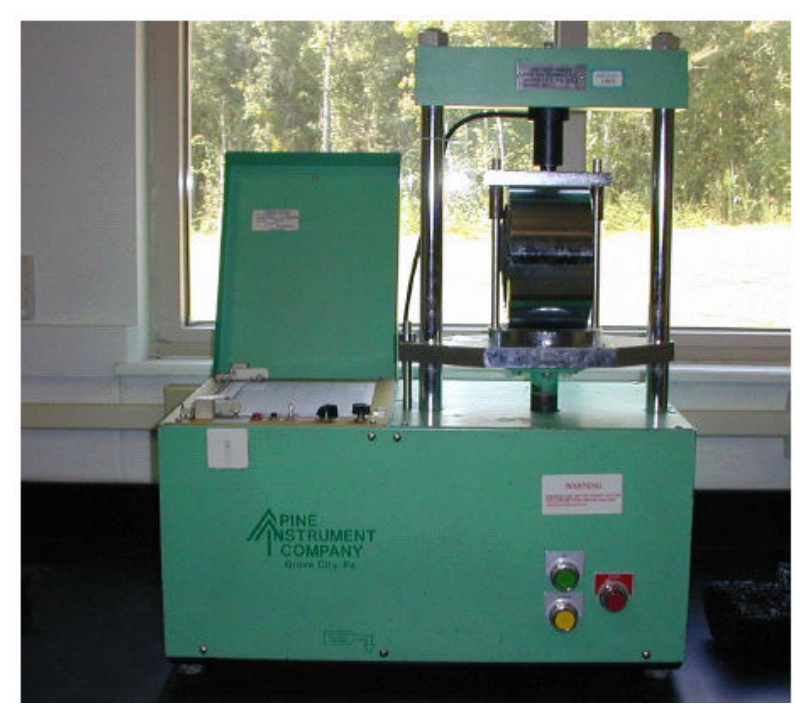

(a)

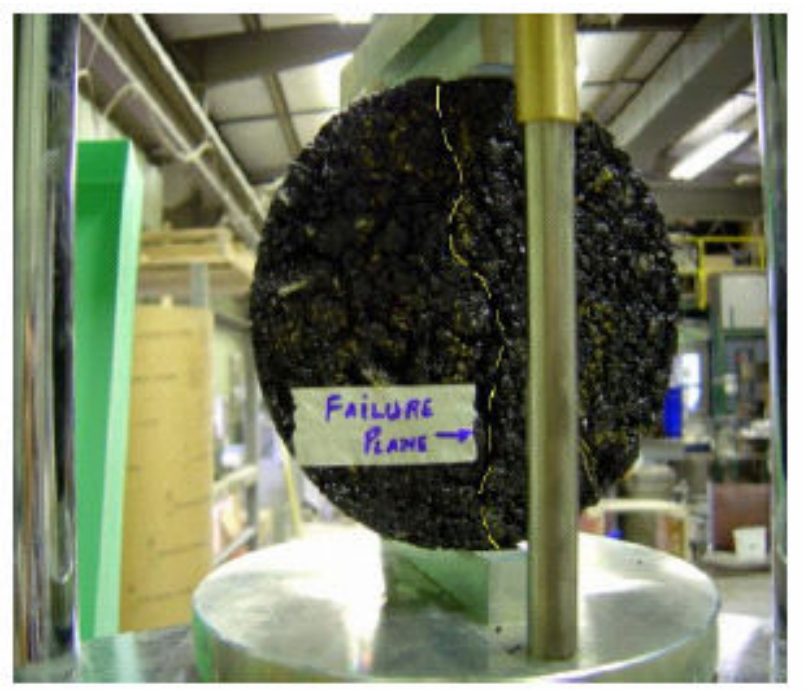

(b)

Figure 3.8 IDT Strength test setup and failure plane

\subsubsection{Tensile strength ratio}

The tensile strength ratio (TSR) was calculated by dividing the average ITS of the conditioned (saturated only or saturated plus freeze-thaw) subset by the average ITS of the unconditioned subset. The TSR was calculated using the following equation:

$$
\text { Tensile Strength Ratio }(\mathrm{TSR})=\frac{\mathrm{T}_{2}}{\mathrm{~T}_{1}}
$$

Where:

$\mathrm{T} 1=$ average tensile strength of dry subset,

$\mathrm{T} 2=$ average tensile strength of conditioned subset. 


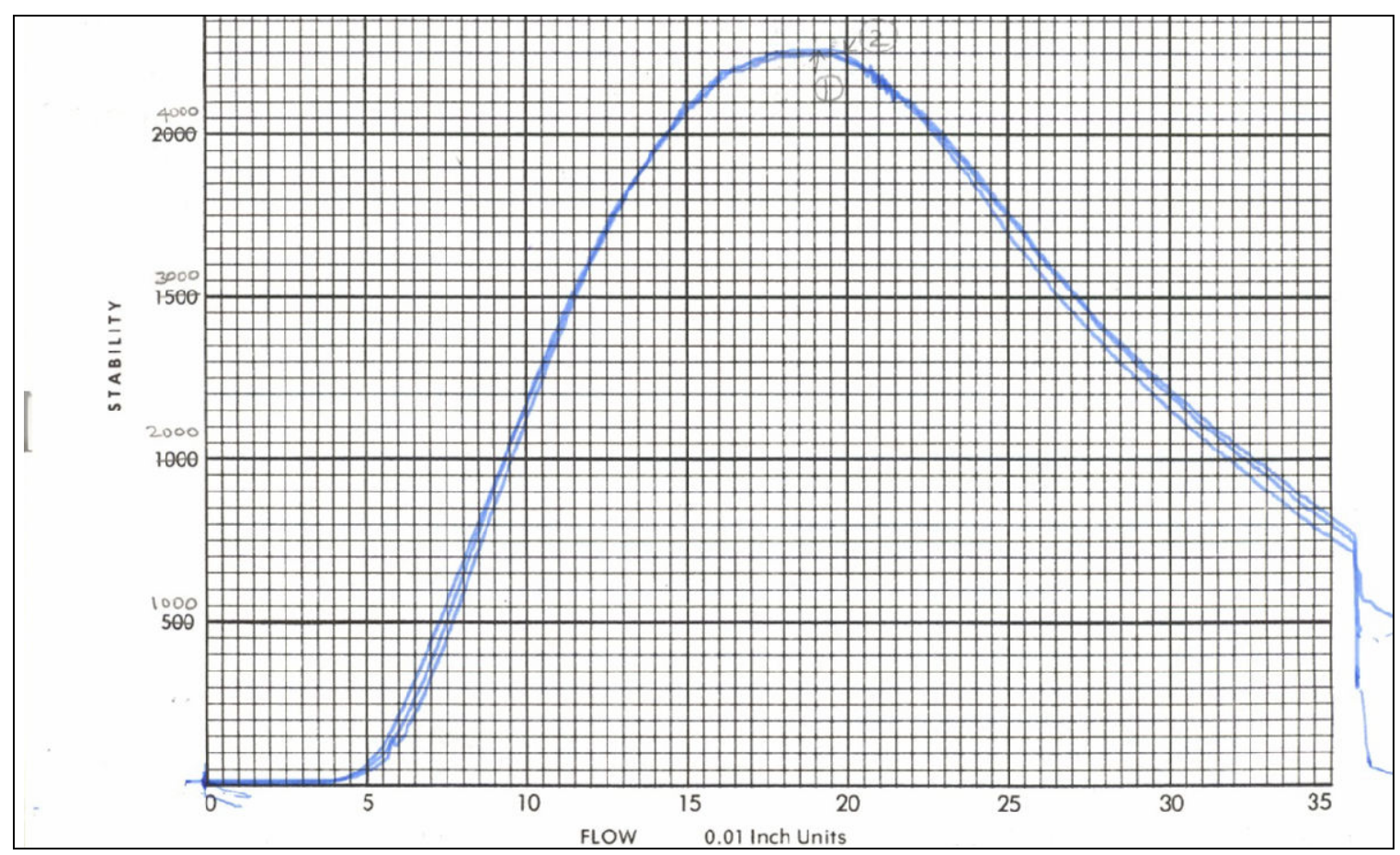

Figure 3.9 Measuring tensile strength for the dry subset using Marshall Stability and Flow Machine

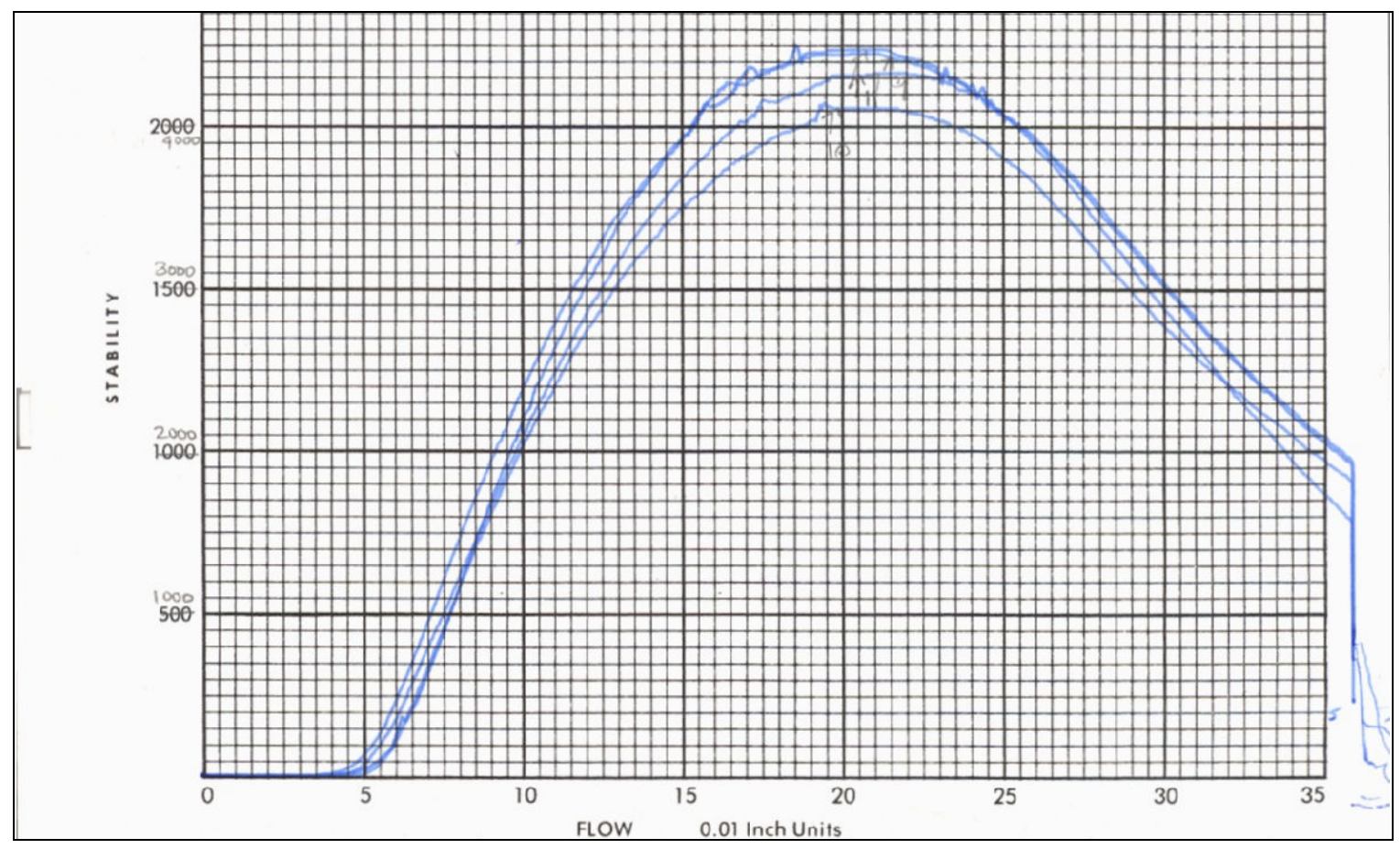

Figure 3.10 Measuring tensile strength for the saturated no freeze-thaw subset using Marshall Stability and Flow Machine 


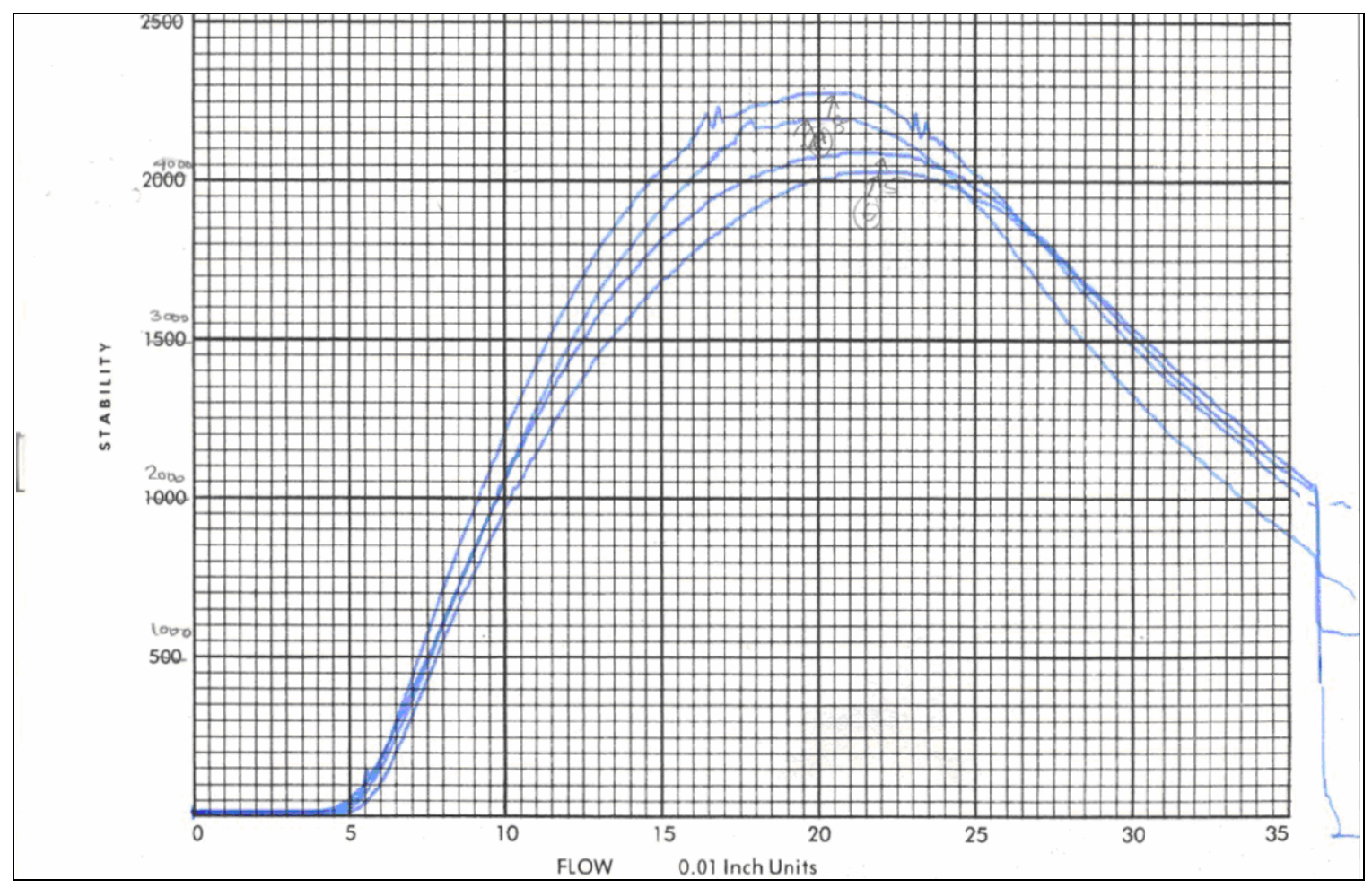

Figure 3.11 Measuring tensile strength for the saturated freeze-thaw subset using Marshall Stability and Flow Machine 


\section{CHAPTER 4 DATA COLLECTION AND ANALYSIS}

\subsection{INTRODUCTION}

This chapter includes a summary of the data generated from the lab testing of samples selected for this project. The data includes volumetric properties and indirect tension test results for the samples produced using Superpave Gyratory Compactor. The samples were conditioned and tested in accordance with the AASHTO T 283 test method. The experiment involved the production of samples from three different sources. The purpose of these tests was to compare the mechanical properties of asphalt mixtures and prediction of stripping potential using AASHTO T 283 test method.

\subsection{VOLUMETRIC PROPERTIES}

Samples were made from $9.5 \mathrm{~mm}$ and $19 \mathrm{~mm}$ NMAS, with original gradation and asphalt content as determined by each contractor's Superpave mix design. The results obtained on checking volumetrics for this asphalt content were compared with results provided by the contractor for the same asphalt content in Table 4.1. For each mix, the material prepared in the WVU Asphalt Technology Laboratory had higher VTM and VMA and lower VFA than was found in the contractors' mix designs. The option of altering the percent binder to lower the VTM was investigated but rejected. The difference in the volumetric parameters was reasonable given the different labs and technicians. It was reasoned that staying with the contractors' selected percent binder would provide meaningful to the results for the WVDOH.

\subsection{TEST RESULTS}

Table 4.2 presents the results of the AASHTO T 283 evaluation of the three West Virginia mixes. The complete data set was presented in Appendix A. Figure 4.1 is a summary of the IDT results for the samples without anti-strip. Unconditioned samples ranged from 91 psi for the New Enterprise mixes to 147 psi for the Carl Kelly mix, with the J.F.Allen mix being 103 psi. These are reasonable values when compared to the results in the literature. Epps, et al. (2000) reported unconditioned tensile strengths ranging from 78.9 psi to 273 psi. 
Table 4.1 Comparison of volumetric properties

\begin{tabular}{|c|c|c|c|c|c|}
\hline Sources & NMAS & $\begin{array}{l}\text { Volumetric } \\
\text { properties }\end{array}$ & Criteria & Contractor & WVU lab \\
\hline \multirow{4}{*}{ JFA } & \multirow{4}{*}{$9.5 \mathrm{~mm}$} & $\mathrm{P}_{\mathrm{b}}, \%$ & - & 5.7 & 5.7 \\
\hline & & VTM, \% & $3.0-5.0$ & 4.0 & 5.0 \\
\hline & & VMA, \% & $15.0 \mathrm{~min}$ & 15.6 & 16.5 \\
\hline & & VFA, $\%$ & $65-75$ & 74.4 & 69.8 \\
\hline \multirow{4}{*}{$\mathrm{NE}$} & \multirow{4}{*}{$9.5 \mathrm{~mm}$} & $\mathrm{P}_{\mathrm{b}}, \%$ & - & 5.7 & 5.7 \\
\hline & & VTM, \% & $3.0-5.0$ & 4.1 & 5.0 \\
\hline & & VMA, \% & $15.0 \mathrm{~min}$ & 15.8 & 16.8 \\
\hline & & VFA, $\%$ & $65-75$ & 74.1 & 69.3 \\
\hline \multirow{4}{*}{ CK } & \multirow{4}{*}{$19 \mathrm{~mm}$} & $\mathrm{P}_{\mathrm{b}}, \%$ & - & 4.7 & 4.7 \\
\hline & & VTM, \% & $3.0-5.0$ & 4.0 & 4.7 \\
\hline & & VMA, \% & $13.0 \mathrm{~min}$ & 13.9 & 15.6 \\
\hline & & VFA, $\%$ & $65-75$ & 71.3 & 69.9 \\
\hline
\end{tabular}

The IDT of the saturated only conditioned samples indicate a large drop-off in tensile strength. The IDT of the saturation samples ranged from 21.5 psi to 58 to 119 for the New Enterprise, J.F.Allen, and Carl Kelly mixes, respectively. These produced respective TSR values of 24, 56, and 81 percent as shown in Table 4.2. Only the Carl Kelly mix passed the Superpave criteria, using the 1989 AASHTO T 283 conditioning method. This was the only $19 \mathrm{~mm}$ mix evaluated, so it cannot be concluded if the positive result was due to the aggregate source or the mix type. 
Table 4.2 Indirect tensile strength and TSR for all three sources

\begin{tabular}{|c|c|c|c|c|c|c|c|c|}
\hline & & ource & & & & & & \\
\hline & & $\mathrm{AS}(\mathrm{mm})$ & 9.5 & 9.5 & 9.5 & 9.5 & 19 & 19 \\
\hline & Anti-str & pping additive & None & Liquid & None & Liquid & None & Liquid \\
\hline & & Avg. Air voids \% & 7.33 & 7.27 & 7.47 & 6.63 & 6.8 & 6.8 \\
\hline & Dry & $\begin{array}{l}\text { Tensile Strength } \\
\text { (psi) }\end{array}$ & 103.0 & 113.67 & 90.89 & 103.25 & 146.6 & 130.5 \\
\hline & & Air Voids $\%$ & 7.37 & 7.23 & 7.43 & 6.6 & 6.9 & 6.8 \\
\hline & $\Gamma$ & Avg. Saturation \% & 75.0 & 74.8 & 76.2 & 70.6 & 72.0 & 70.8 \\
\hline : & (a) $140^{\circ} \mathrm{F}$ & $\begin{array}{l}\text { Tensile Strength } \\
\text { (psi) }\end{array}$ & 58 & 81.0 & 21.5 & 73.35 & 118.8 & 123.0 \\
\hline $\begin{array}{l}8 \\
0 \\
0\end{array}$ & & $\begin{array}{l}\text { Tensile Strength } \\
\text { Ratio }(\%)\end{array}$ & 56.3 & 71.3 & 23.7 & 71.0 & 81.0 & 94.2 \\
\hline$\tilde{n}$ & & Air Voids \% & 7.33 & 7.2 & 7.13 & 6.63 & 6.87 & 6.87 \\
\hline & & Avg. Saturation \% & 73.9 & 72.4 & 73.8 & 72.8 & 71.8 & 70.9 \\
\hline & $\mathrm{F}-\mathrm{T}$ & $\begin{array}{l}\text { Tensile Strength } \\
\text { (psi) }\end{array}$ & 61.0 & 91.0 & 31.85 & 57.18 & 112.6 & 126.3 \\
\hline & & $\begin{array}{l}\text { Tensile Strength } \\
\text { Ratio (\%) }\end{array}$ & 59.2 & 80.1 & 35.0 & 55.4 & 76.8 & 96.8 \\
\hline
\end{tabular}

The IDT of the saturated plus freeze thaw conditioned samples again demonstrates a reduction in the strength when compared to the unconditioned IDT. The IDT of the saturated plus freeze-thaw samples were 32, 61, and 113 psi for the New Enterprise, J.F.Allen, and Carl Kelly mixes, respectively. When compared on a TSR basis the results were 35, 59, and 77 percent, respectively. In this case, all mixes failed the Superpave TSR requirement of 80 percent. 


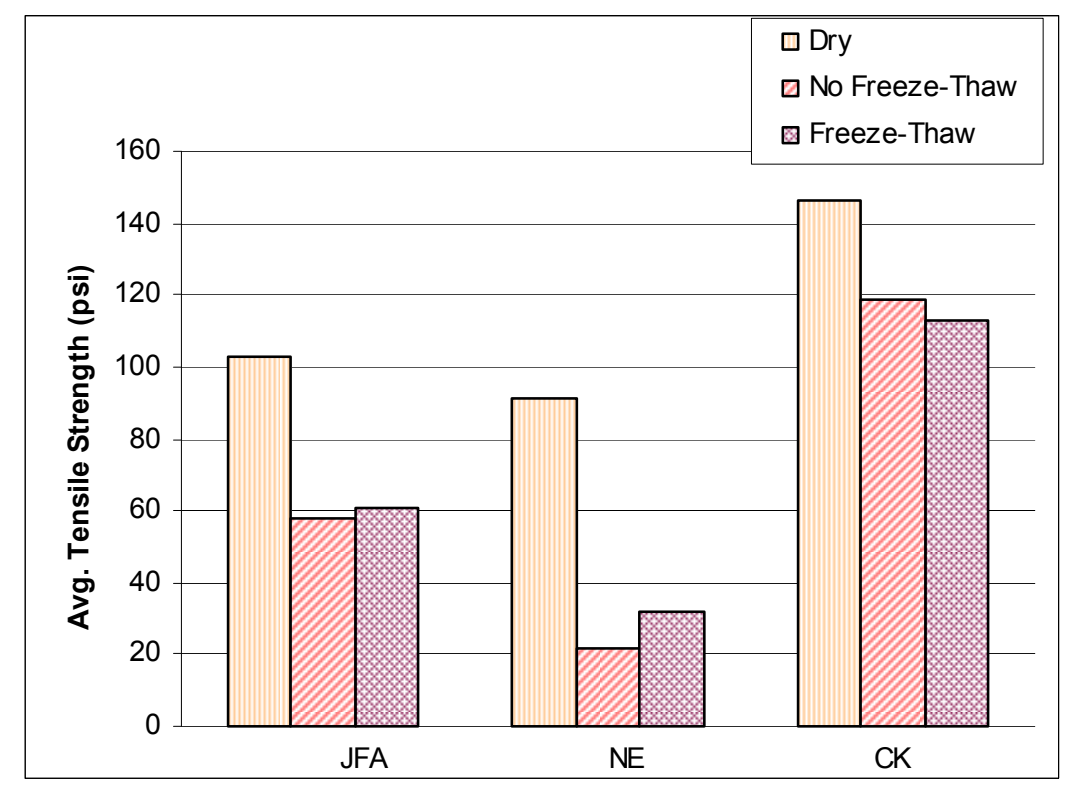

Figure 4.1 Comparison of tensile strength for different sample conditioning (without antistrip)

Figure 4.2 compares the TSR for samples with and without anti-strip for two conditioning methods. The results of the AASHTO T 283 mixes demonstrate that two of the mixes do not meet Superpave requirement when tested under the 1989 conditioning protocol. This is disturbing in two ways. Since these are approved mixes, the contractors' mix design determined that the use of anti-strip admixture was not required. Yet two of the mixes failed the TSR requirement as tested during this research. The New Enterprise mix had a particularly low TSR value. The resources allocated to this research were not sufficient to explore the reasons for this discrepancy. However, the variability in TSR results using the modified Lottman procedure was well documented in the literature (Roberts, et al., 1996). The issue of variability was not addressed in NCHRP 913 (Epps, et al., 2000). There is no precision and bias statement in the AASHTO T 283 test method.

The other area of concern is the lack of correlation between the test results and field performance. Only one mix passed the TSR requirement with the 1989 conditioning method. All three mixes failed when conditioned with the 2003 protocol. 


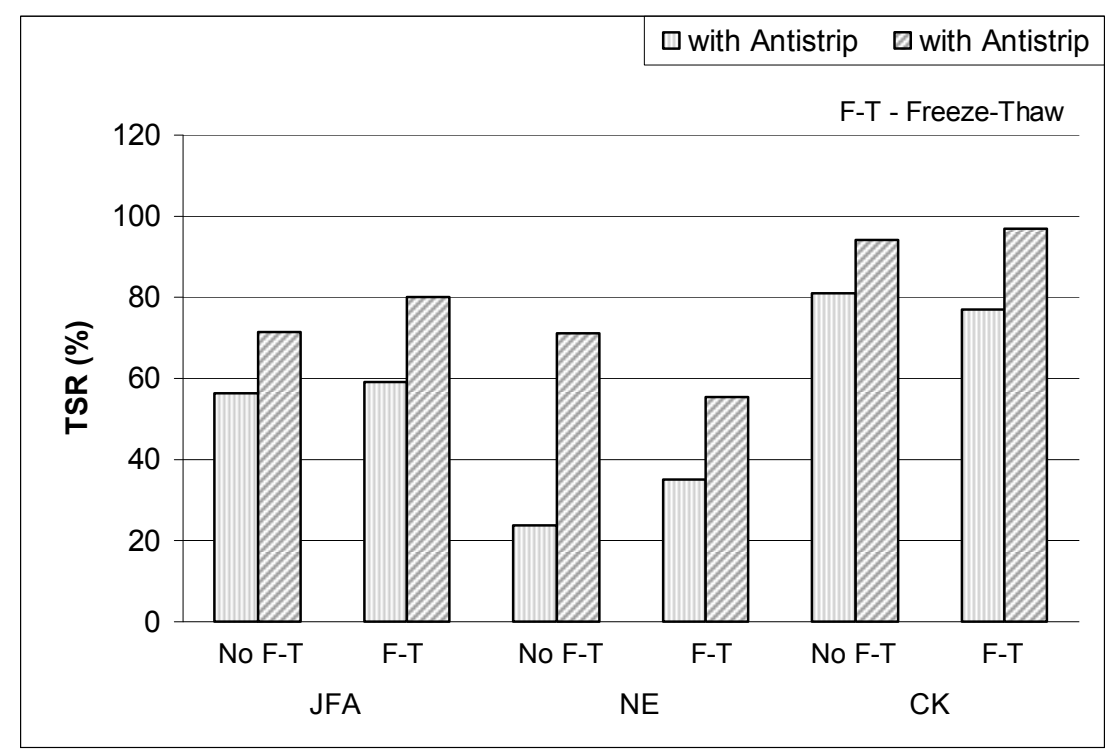

Figure 4.2 Comparison of tensile strength ratio for subsets with and without anti-strip

However, as reported in the literature, there is not a moisture sensitivity problem in West Virginia (TRB, 2003). Either AASHTO T 283 results are not reliable for conditions in West Virginia, or the state may have an unrecognized moisture sensitivity problem. The reliability of T 283 with respect to identifying field performance is an unresolved issue in the literature. Aschenbrener et al (1995) concluded the method could identify between good and poor performing mixes, but marginal mixes could not be reliably detected. Pan and White (1999) concluded the TSR does not reflect a mixture's stripping potential. Epps, et al. (2000), in the NCHRP Project designed to integrate the TSR method with the Superpave mix design method, found an almost inverse correlation between the test results and field performance. In this study, one mix known to be moisture sensitive met the TSR requirement while two materials with good field performance failed to pass the TSR requirement. The two remaining mixes in the NCHRP study were rated as moderate to highly moisture sensitive; one passed and the other failed the current Superpave TSR requirement. The failure of the West Virginia mixes, which are believed to be good performers in the field, to pass the Superpave TSR requirement is consistent with the inverse correlation found in NCHRP 9-13 (Epps, et al. 2000). 


\subsubsection{Samples with anti-strip admixture}

The test results prepared with anti-strip are also presented in Table 4.2. Figure 4.3 shows the IDT results for the samples with anti-strip, for different levels of conditioning. The liquid anti-strip increased the TSR for all mixes and for both conditioning methods. The Carl Kelly material showed an improvement in TSR for the 1989 protocol, but anti-strip would not be recommended since the design requirements were met without anti-strip. The anti-strip allowed the Carl Kelly material to pass the 2003 protocol which failed without the anti-strip. While the IDT of the conditioned samples of materials was improved, the IDT of the unconditioned samples was lower with the anti-strip than without it. This exposes one of the fallacies of the TSR method. Low tensile strengths of unconditioned samples are undesirable but can actually result in a material passing the TSR requirement. The J.F. Allen material with anti-strip failed to pass the TSR requirement for the 1989 protocol, but passed the requirement when tested under the 2003 protocol. The New Enterprise with anti-strip admixture material did not pass the TSR requirement under either protocol.

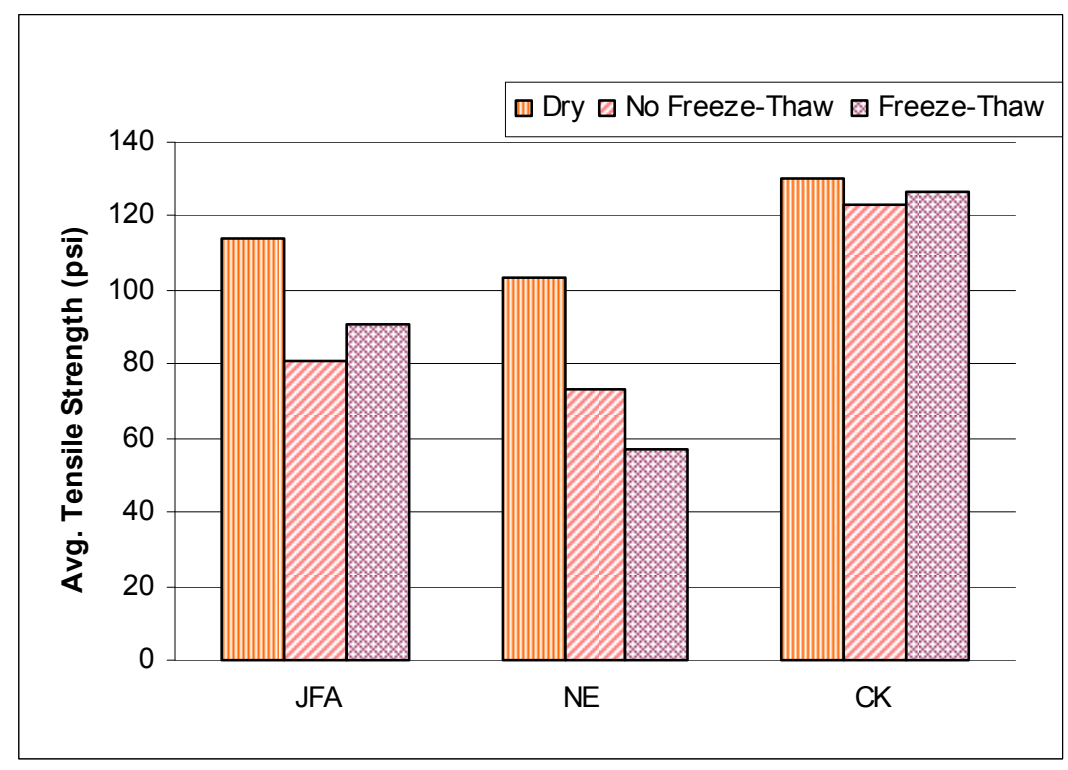

Figure 4.3 Comparison of tensile strength for different sample conditioning (with anti-strip)

The influence of the anti-strip admixture on IDT is summarized in Figure 4.4. In all cases, the IDT of conditioned samples improved with the addition of the admixture. 
In two cases, the IDT of the unconditioned samples improved; in one case the IDT was reduced when the anti-strip was added.

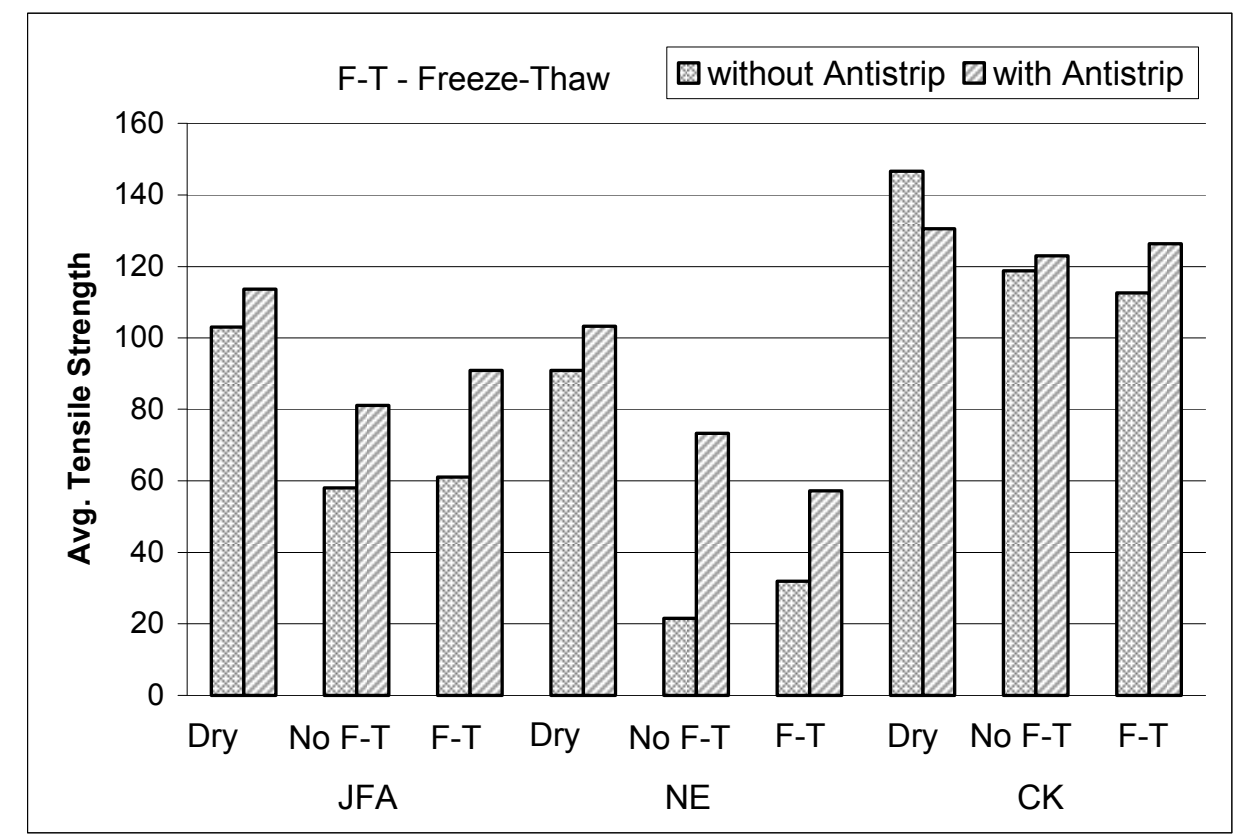

Figure 4.4 Comparison of tensile strength for subsets with and without anti-strip

\subsubsection{Effect of conditioning method}

One of the significant changes between the 1989 and 2003 testing protocols was changing the freeze-thaw conditioning from optional to mandatory. By examination of Table 4.2 and Figure 4.4 it can be determined that IDT decreased for four comparisons and increased for two comparisons when the freeze-thaw cycle was included. These results do not support the hypothesis that the inclusion of a freeze-thaw cycle in the test protocol improves the ability to identify moisture-susceptible mixtures. The number of samples measured during this research is too limited to draw a firm conclusion. However, these test results are consistent with the findings of NCHRP Project 9-13 (Epps, et al., 2000). In the NCHRP research, 56 of 68 possible comparisons showed the IDT was statistically equal between the conditioning protocols. When only the $150 \mathrm{~mm}$ samples compacted with the Superpave gyratory compactor were considered, all five available comparisons had statistically equal strengths. Inclusion of the freeze-thaw cycle in the recommended protocol was an attempt to "make the methodology 
conservative" (Epps, et al., 2000). The researchers acknowledged that sample conditioning was not identified as being important based on the analyses of their data.

\subsubsection{Level of saturation}

The allowable range for the level of saturation was reduced from 55 to 80 percent in the 1989 protocol to 70 to 80 percent in the 2003 protocol. Table 4.3 shows test results obtained for the J.F.Allen material using the two protocols for saturation levels. The IDT of the condition samples are nearly identical, 58 versus 60 psi for the saturation only samples and 61 versus 63 psi for the saturation plus freeze-thaw samples. The differences in the TSR's are somewhat greater due to the differences in the IDT of the unconditioned samples. There was approximately a 10 percent difference in the IDT of the unconditioned samples.

The results of this experiment are consistent with the findings of Epps, et al. (2000). They recommended a range of 55 to 80 percent for level of saturation. The level of saturation range requirement in the 2003 protocol was implemented by the AASHTO committee in an "attempt to reduce test variability" (Myers, 2005)

Table 4.3 Comparison of saturation level

\begin{tabular}{|c|c|c|c|c|}
\hline & & ource & & \\
\hline \multicolumn{3}{|c|}{ NMAS (mm) } & 9.5 & 9.5 \\
\hline \multicolumn{3}{|c|}{ Anti-Stripping additive } & None & None \\
\hline \multirow{10}{*}{$\begin{array}{c}\text { Sample } \\
\text { conditioning }\end{array}$} & \multirow{2}{*}{ Dry } & Avg. Air Voids \% & 7.33 & 7.03 \\
\hline & & Tensile Strength (psi) & 103.0 & 114.67 \\
\hline & \multirow{4}{*}{$\begin{array}{l}\text { No F-T } \\
@ 140^{\circ} \mathrm{F}\end{array}$} & Air Voids \% & 7.37 & 6.93 \\
\hline & & Saturation \% & 75.0 & 61.6 \\
\hline & & Tensile Strength (psi) & 58 & 60.0 \\
\hline & & Tensile Strength Ratio (\%) & 56.3 & 52.3 \\
\hline & \multirow{4}{*}{ F-T } & Air Voids \% & 7.33 & 6.97 \\
\hline & & Saturation \% & 73.9 & 64.33 \\
\hline & & Tensile Strength (psi) & 61.0 & 62.7 \\
\hline & & Tensile Strength Ratio (\%) & 59.2 & 54.7 \\
\hline
\end{tabular}




\section{CHAPTER 5: CONCLUSIONS AND RECOMMENDATIONS}

\subsection{CONCLUSIONS}

The mechanisms associated with stripping are complex and there has been number of theories to explain moisture damage mechanism in asphalt mixtures. Each theory has its merits but is difficult to prove that it alone can explain this complex phenomenon. Research has shown that stripping is associated with several factors. The factors like mix design, construction issues, environmental factors and weather conditions during construction are considered the major contributors of stripping.

There are many test methods for evaluating the moisture susceptibility of HMAC. These test methods are empirically based and the research is focused on the development of a test for identifying moisture susceptibility. These test methods range from simple observations of conditioned samples to more elaborate methods of conditioning and testing samples. Since only empirically based test methods are used to evaluate stripping potential, none of the tests proved to be effective in predicting stripping potential.

AASHTO T283 test method has been recommended to determine moisture susceptibility of HMA mixes until more suitable and reliable tests are developed and validated by SHRP or other agencies (Kandhal, 1992). The general consensus among the users of moisture damage tests is that the test results are highly variable and validation with field performance is problematical (Roberts, et al., 1996).

Despite the recognized problems AASHTO T 283 is the most widely used test method for HMAC moisture sensitivity. Hence, it was adopted as a required step in the Superpave mix design method. Superpave implementation began in the 1990's; at this time, the 1989 version of AASHTO T 283 was in place. However, this version of the test was developed prior to the availability of the Superpave gyratory compactor. In addition, sample condition procedures were different between the Superpave requirements and AASHTO T 283. Several research projects were performed to resolve issues concerning the use of AASHTO T 283 and Superpave. NCHRP Project 9-13 was performed to address this specific problem (Epps, et al., 2000). The results of this project were used to guide the revision of AASHTO T 283 as published in 2003. NCHRP Project 9-13

developed several interesting conclusions concerning the effect of the test parameters on 
the results of the test. Some of the findings were counterintuitive, such as the lack of sensitivity of the test results to degree of saturation and the effect of the freeze-thaw cycle on tensile strength ratio. The AASHTO committee overrode the scientific evidence from NCHRP 9-13 and placed tight restrictions on the degree of saturation and required a freeze-thaw cycle in the conditioning sequence. The NCHRP 9-13 research demonstrated that even with these restrictions, AASHTO T 283 is not a reliable method for evaluating the field performance of HMAC. The researchers recommended states perform a structured research program when implementing AASHTO T 283.

West Virginia, in compliance with the national standards, requires the use of AASHTO T 283 for Superpave mix designs. However, West Virginia reported on a recent survey $(\mathrm{TRB}, 2003)$ that there was not a moisture sensitivity problem in the state. Spurred on by the recent failure on I-68 where stripping may have been a contributing factor, this project was conducted to gain insight into the issue of using AASHTO T 283 in West Virginia.

A limited laboratory program was conducted to evaluate the moisture sensitivity of three mixes approved for use in the state. This limited data set indicated the mixes are moisture sensitive. Only one of the three mixes could be modified to meet the Superpave TSR requirement through the use of a liquid anti-strip. Although only three mixes were evaluated, the results were consistent with NCHRP 9-13 with respect to:

1. Lack of sensitivity of the results to saturation level.

2. Results for samples conditioned with saturation only were similar to results obtained from samples conditioned with saturation plus a freeze-thaw cycle.

3. TSR is not a reliable indicator of field performance

Results obtained in this study indicate that the tensile strength ratio of mixtures did not satisfactorily meet the AASHTO T 283 test method. The aggregates from all three sources have been classified as not water sensitive. However, only one aggregate source passes the 1989 version of AASHTO T 283 test method. All three mixes failed when conditioned with 2003 version of the test method. The resources allocated to this research were not sufficient to explore the reasons for this discrepancy. So either the test 
method is not reliable for conditions in West Virginia or the state may have unrecognized stripping problem.

\subsection{RECOMMENDATIONS}

West Virginia is in a unique position of not recognizing a moisture susceptibility problem in HMAC (TRB, 2003). A mix design from Maryland was included in NCHRP 9-13 because it was a moisture susceptible mix (Epps, et al., 2000). Stripping problems in Pennsylvania have served as case studies in research performed by Kandhal, et al. (1989). Given the proximity of these states, there is a potential that stripping can exist in West Virginia. Research should be performed to verify whether or not there is a stripping problem in the state. If the study verifies the current opinion that moisture damage is not a problem, then the need for continued use of AASHTO T 283 must be questioned.

If the field study identifies a moisture sensitivity problem associated with mix design, then the state should aggressively pursue testing of mixes for moisture sensitivity. Unfortunately, the demonstrated lack of reliability of AASHTO T 283 suggests that an alternative method should be pursued. This would require a significant research effort. Development of a reliable test for moisture sensitivity of HMAC has not been resolved through federal nationwide research programs.

In the interim, the limited data set examined during this research should be expanded to embrace more mix types used throughout the state. If the expanded test program verifies that AASHTO T 283 is not reliable, rejection of the national standard would be justified.

One option which could be considered for immediate implementation would be to return to the 1989 version of AASHTO T 283. The limited data set collected for the West Virginia mixes concurs with the results of NCHRP Report 9-13. The level of saturation restrictions and required freeze-thaw cycle increase the complexity and time required to perform the test. However, they do not improve the reliability of the test with respect to identifying mixes which are moisture susceptible 


\section{REFERENCES}

Aschenbrener T., R. McGennis, and R. Terrel, 1995, Comparison of Several Moisture Susceptibility Tests To Pavements of Known Field Performance, Proceedings of the Association of Asphalt Paving Technologists, Vol. 64 (1995), pp. 162-196.

Bahia, H. and S. Ahmad, December 1999, Evaluation and Correlation of Lab and Field Tensile Strength Ratio (TSR) Procedures and Values in Assessing the Stripping Potential of Asphalt Mixes, The Asphalt Pavement Research Group, University of Wisconsin, Madison, Wisconsin, Report No. WI/SPR-10-99.

Cheng, D., D. N. Little, R. L. Lytton, and J. C. Holste. 2002, Surface Energy Measurement of Asphalt and Its Application to Predicting Fatigue and Healing in Asphalt Mixtures, Transportation Research Record: Journal of the Transportation Research Board, No. 1810, TRB, National Research Council, Washington, D.C., pp. 44-53.

Choubane B., G. Page, and J. Musselman, 2001, Effects of Water Saturation Level on Resistance of Compacted Hot-Mix Asphalt Samples To Moisture-Induced Damage, Transportation Research Record 1723, National Research Council, TRB, Washington, D.C., pp. 97-106.

Coplantz J. and D. Newcomb, 1988, Water Sensitivity Test Methods for Asphalt Concrete Mixtures: A Laboratory Comparison, Transportation Research Record 1171, TRB, National Research Council, Washington, D.C. , pp. 44-50.

Epps J. A., P. E. Sebaaly, J. Penaranda, M. R. Maher, M. B. McCann, A. J. Hand, 2000, Compatibility of a Test for Moisture-Induced Damage with Superpave Volumetric Mix Design, Transportation Research Board, NCHRP Report 444, Washington D.C.

Fromm, H. J., 1974, The Mechanisms of Asphalt Stripping from Aggregate Surfaces, Proc., Association of Asphalt Paving Technologists, Vol. 43, pp. 191-223.

Hunter E. R. and K. Ksaibati, November 2002, Evaluating Moisture Susceptibility of Asphalt Mixes, Department of Civil and Architectural Engineering, University of Wyoming, Laramie, Wyoming.

Johnson D. R. and R. B. Freeman, December 2002, Rehabilitation Techniques for Stripped Asphalt Pavements, Western Transportation Institute, Bozeman, Montana, Report No. FHWA/MT-002-003/8123.

Kandhal P. S., C. W. Lubold, F. L. Roberts, 1989, Water Damage To Asphalt Overlays: Case Histories, Auburn University, Auburn, Alabama, NCAT Report No. 89-1.

Kandhal P. S., May 1992, Moisture susceptibility of HMA mixes: identification of problem and recommended solutions, Auburn University, Alabama, NCAT Report No. 92-1. 
Kanitpong K., and H. U. Bahia, March 2003, Role of Adhesion and Thin Film Tackiness of Asphalt Binders in Moisture Damage of HMA, Association of Asphalt Paving Technologists (AAPT).

Kanitpong K., H. U. Bahia, May 2003, Evaluation of the Extent of HMA Moisture Damage in Wisconsin as it Relates to Pavement Performance, Department of Civil and Environmental Engineering, University of Wisconsin, Madison.

Kiggundu B. M. and F. L. Roberts, September 1988, Stripping in HMA Mixtures: Stateof-The Art And Critical Review of Test Methods, NCAT, Auburn University, Auburn, Alabama, Report No. 88-2.

Ksaibati K. and G. L. Conner, May 2004, et al, Laboratory Evaluation of Bottom Ash Asphalt Mixes, Department of Civil and Architectural Engineering, University of Wyoming, Laramie, Wyoming.

Lottman, R.P., L. White, and D. Frith, 1988, Methods of Predicting and Controlling Moisture Damage in Asphalt Concrete. Transportation Research Record 1171, Washington D.C.

Mahoney J. and J. Stephens, August 1999, Comparison of AASHTO Moisture Sensitivity Test With Connecticut Department of Transportation Modified Test Method, Connecticut Advanced Pavement Laboratory, University of Connecticut, Storrs, Connecticut, Report No. CAPLab 99-1.

Maupin G., 1999, Evaluation of Stripping in Virginia's Pavements, Transportation Research Record 1681, National Research Council, TRB, Washington, D.C., pp. 37-42.

Myers, A.H., Email communications, Asphalt Branch Manager; Kentucky Department of Transportation, AASHTO Committee, Division 2-Bituminous Materials and Mixtures, Frankfort, Kentucky, August 2005.

Pan C. and T. D. White, February 1999, Conditions for Stripping Using Accelerating Testing, Joint Transportation Research Program (JTRP), Purdue University, West Lafayette, Indiana, Report No. FHWA/IN/JTRP-97/13.

Roberts F.L., P.S. Kandhal, E.R. Brown, D.Y. Lee, and T.W. Kennedy, 1996, Hot Mix Asphalt Materials, Mixture Design, and Construction, NAPA Education Foundation, Lanham, Maryland.

Sebaaly P. E., P. Tohme, E. Hitti, K. Stansbury and J. Epps, March 2003, Asphalt Concrete Anti-Stripping Techniques, Pavements/Materials Program, Department of Civil Engineering, University of Nevada, Reno, Nevada, Report No. SD99-10-F.

Shah B.D., August 2003, Evaluation of Moisture Damage within Asphalt Concrete Mixes, Texas A\&M University, College station, Texas. 
Tandon V., N. Vemuri, S. Nazarian, and M. Tahmoressi, 1997, A Comprehensive Evaluation of Environmental Conditioning System, Proceedings of the Association of Asphalt Paving Technologists, Vol. 66 (1997), pp. 187-210.

Tayebali A. A., W. K. Fischer, Y. X. Huang, M. B. Kulkarni, June 2003, Effect of Percentage Baghouse Fines on the Amount and Type of Anti-Stripping Agent Required to Control Moisture Sensitivity, Department of Civil Engineering, North Carolina State University, Raleigh, North Carolina, Report No. FHWA/NC/2003-04.

Transportation Research Board (TRB), February 2003, Moisture Sensitivity of Asphalt Pavements, A National Seminar, San Diego, California.

West R. C., J. Zhang, A. Cooley, July 2004, Evaluation of The Asphalt Pavement Analyzer for Moisture Sensitivity Testing, NCAT, Auburn University, Auburn, Alabama. 


\section{APPENDIX A - MOSITURE SENSITIVITY DATA SET}

Project: JFA $9.5 \mathrm{~mm}$

Additive: None
Compaction Method: Gyratory Compactor

Dosage: None

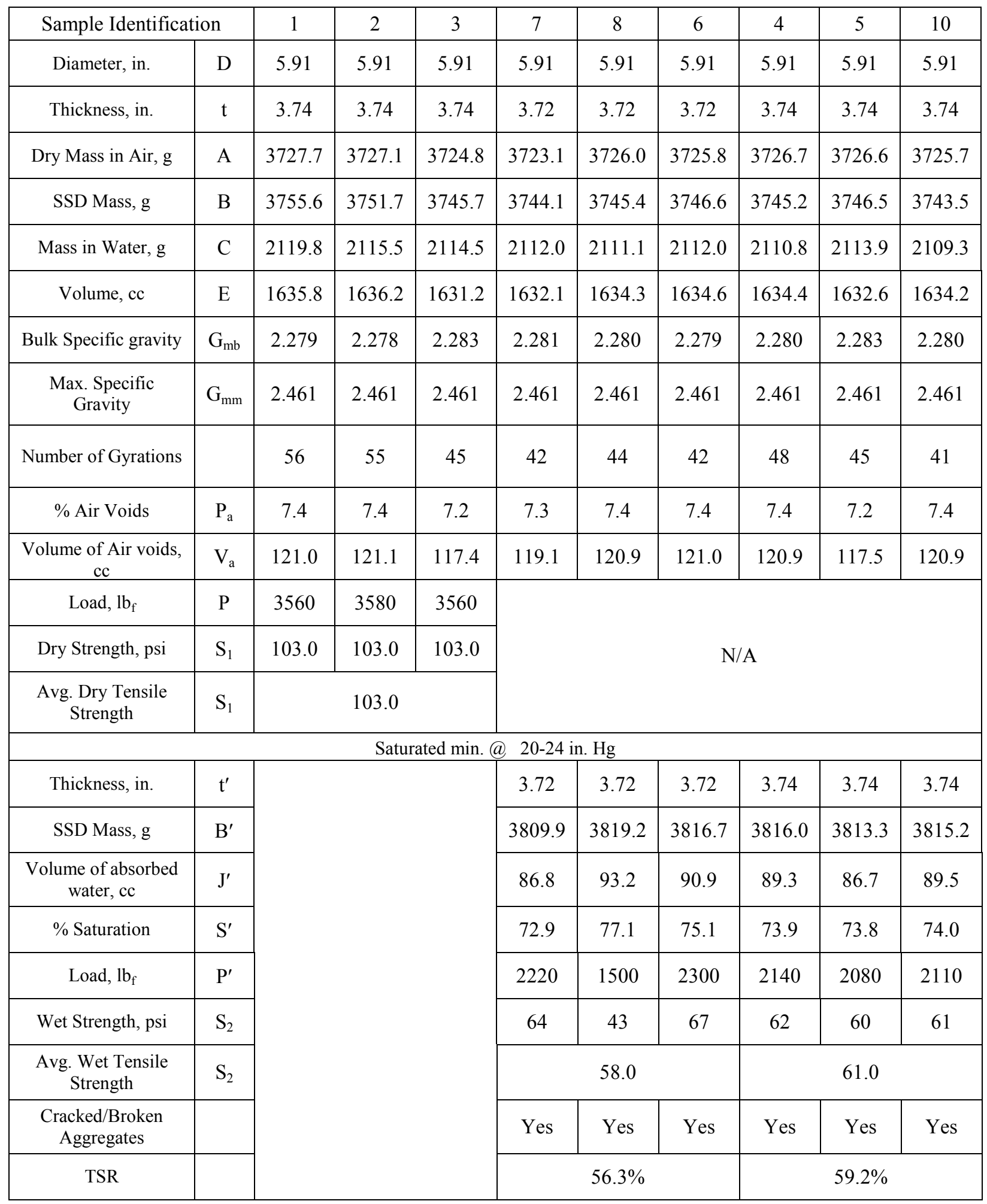


Project: JFA $9.5 \mathrm{~mm}$

Additive: Liquid Anti-Strip
Compaction Method: Gyratory Compactor

Dosage: $0.3 \%$ by Binder Weight

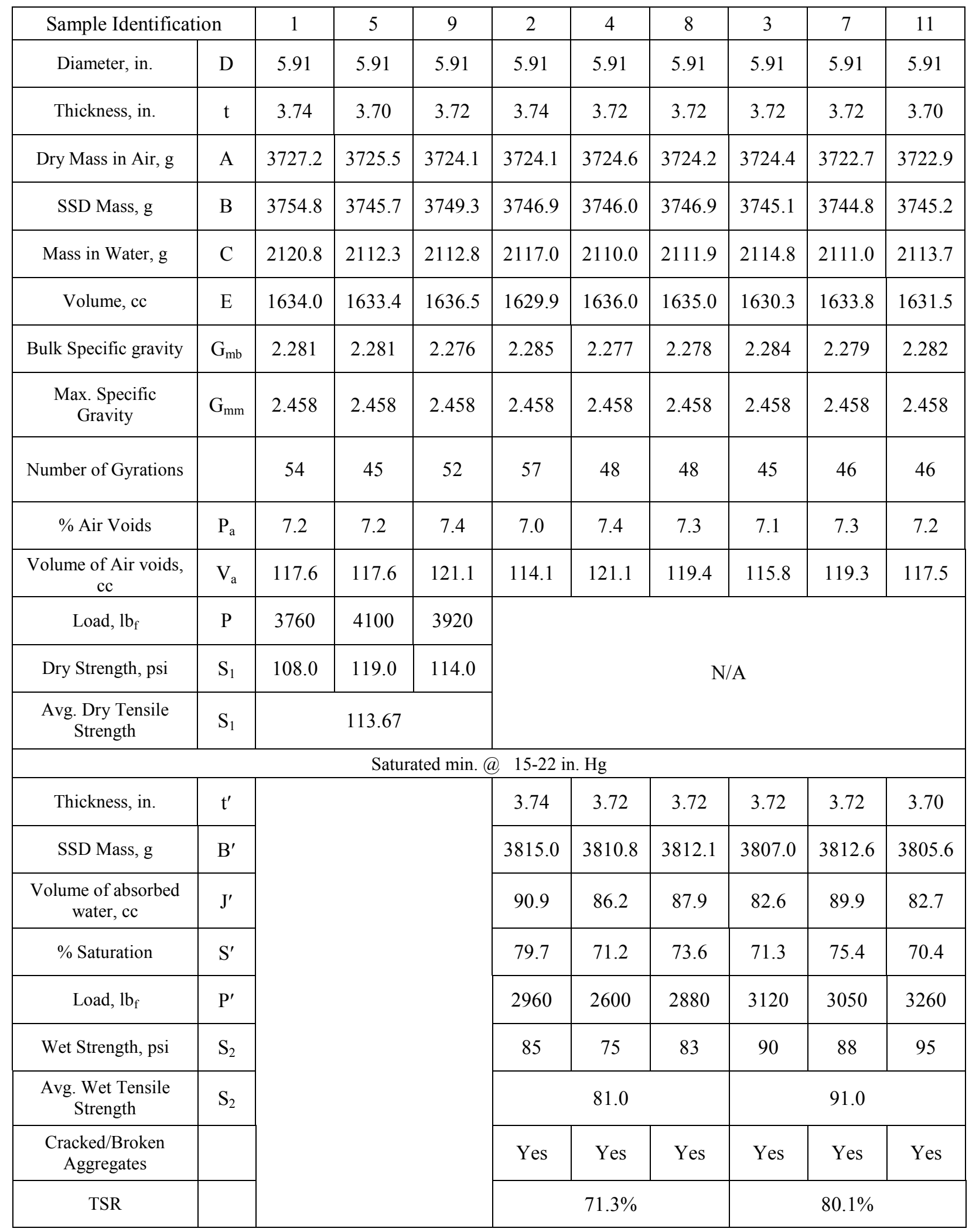


Project: JFA $9.5 \mathrm{~mm}$ at $55 \%$ saturation

Compaction Method: Gyratory Compactor

Additive: None

Dosage: None

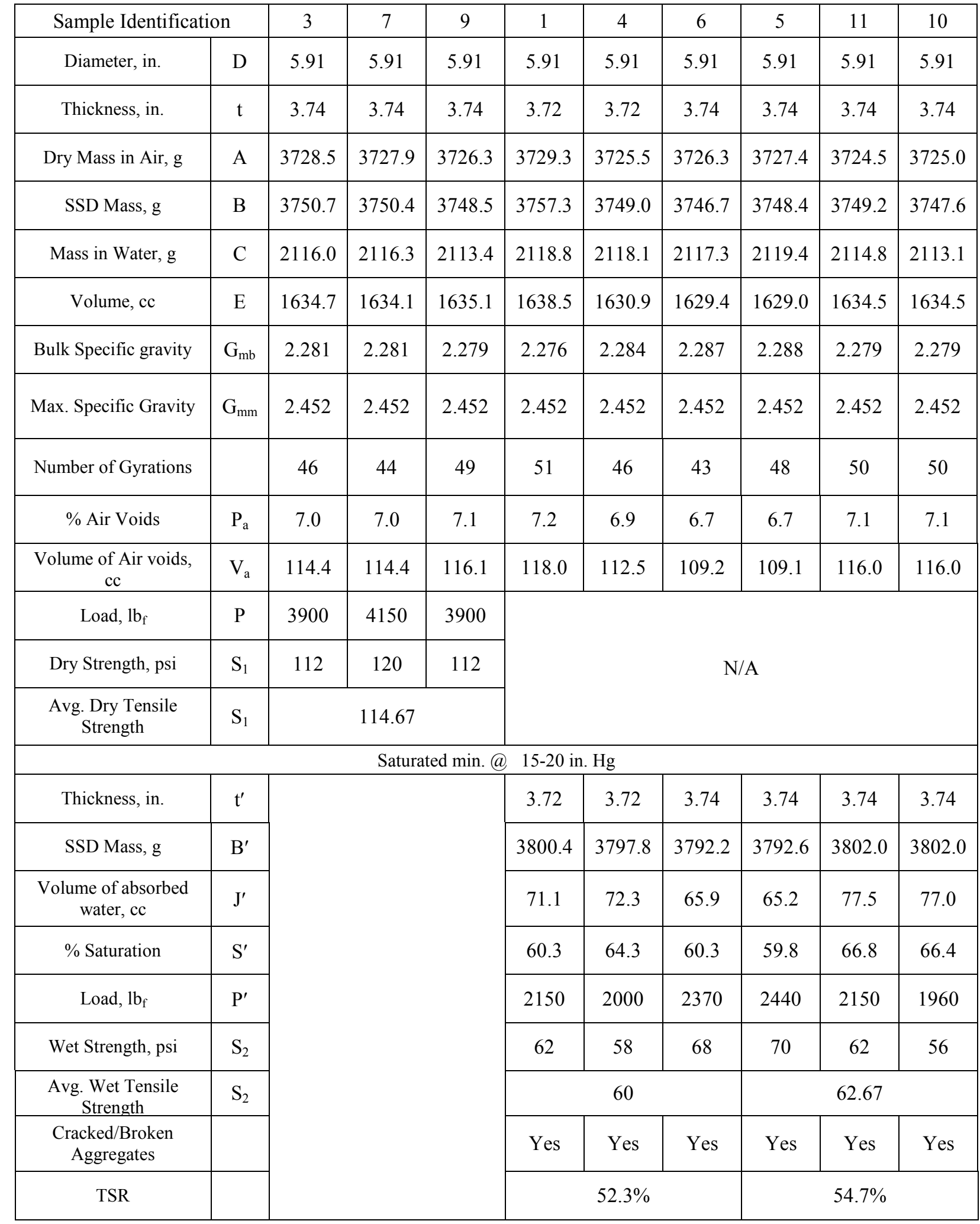


Project: NE $9.5 \mathrm{~mm}$

Additive: None
Compaction Method: Gyratory Compactor

Dosage: None

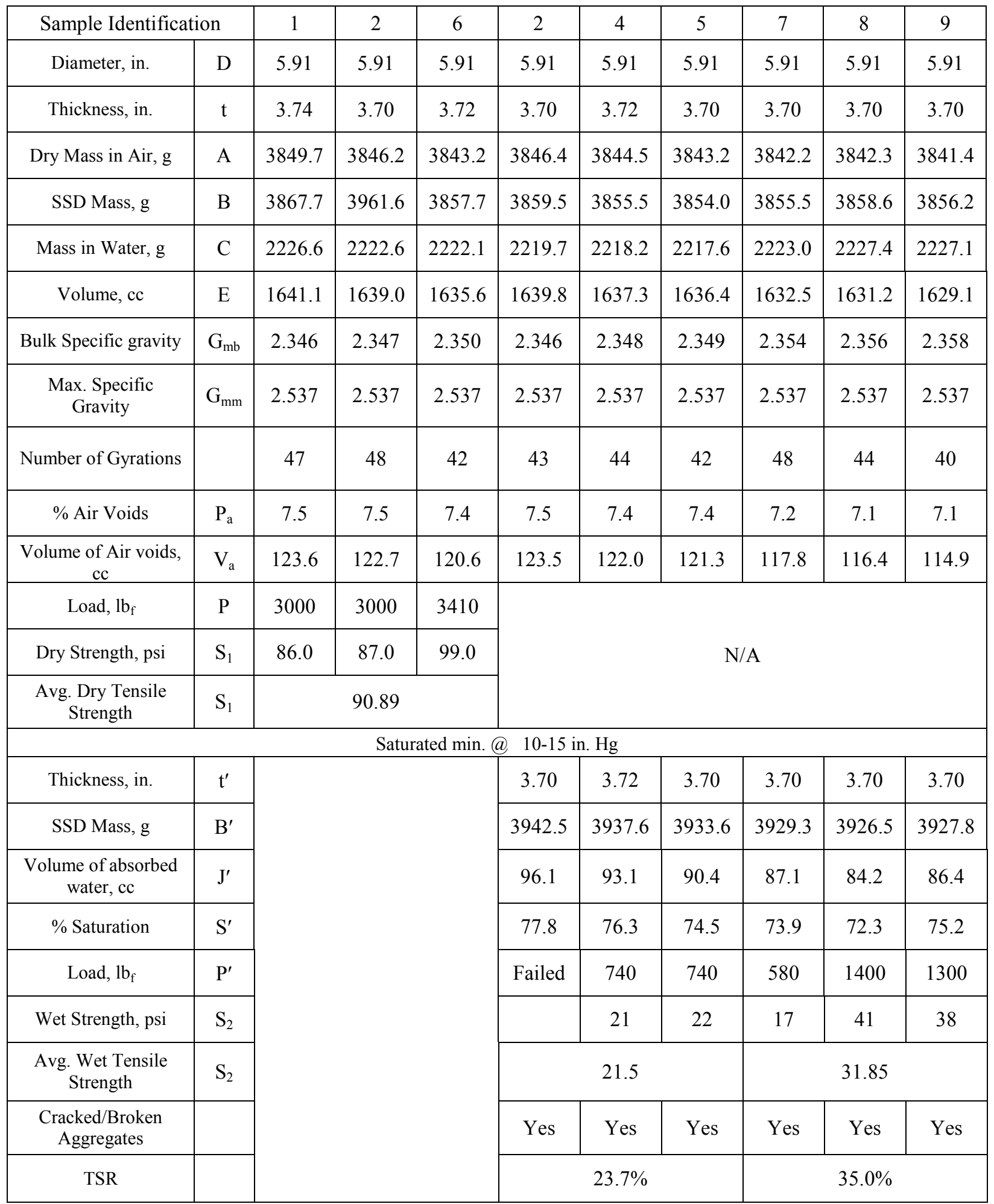


Project: NE $9.5 \mathrm{~mm}$

Additive: Liquid Anti-strip
Compaction Method: Gyratory Compactor

Dosage: $0.5 \%$ by Binder Weight

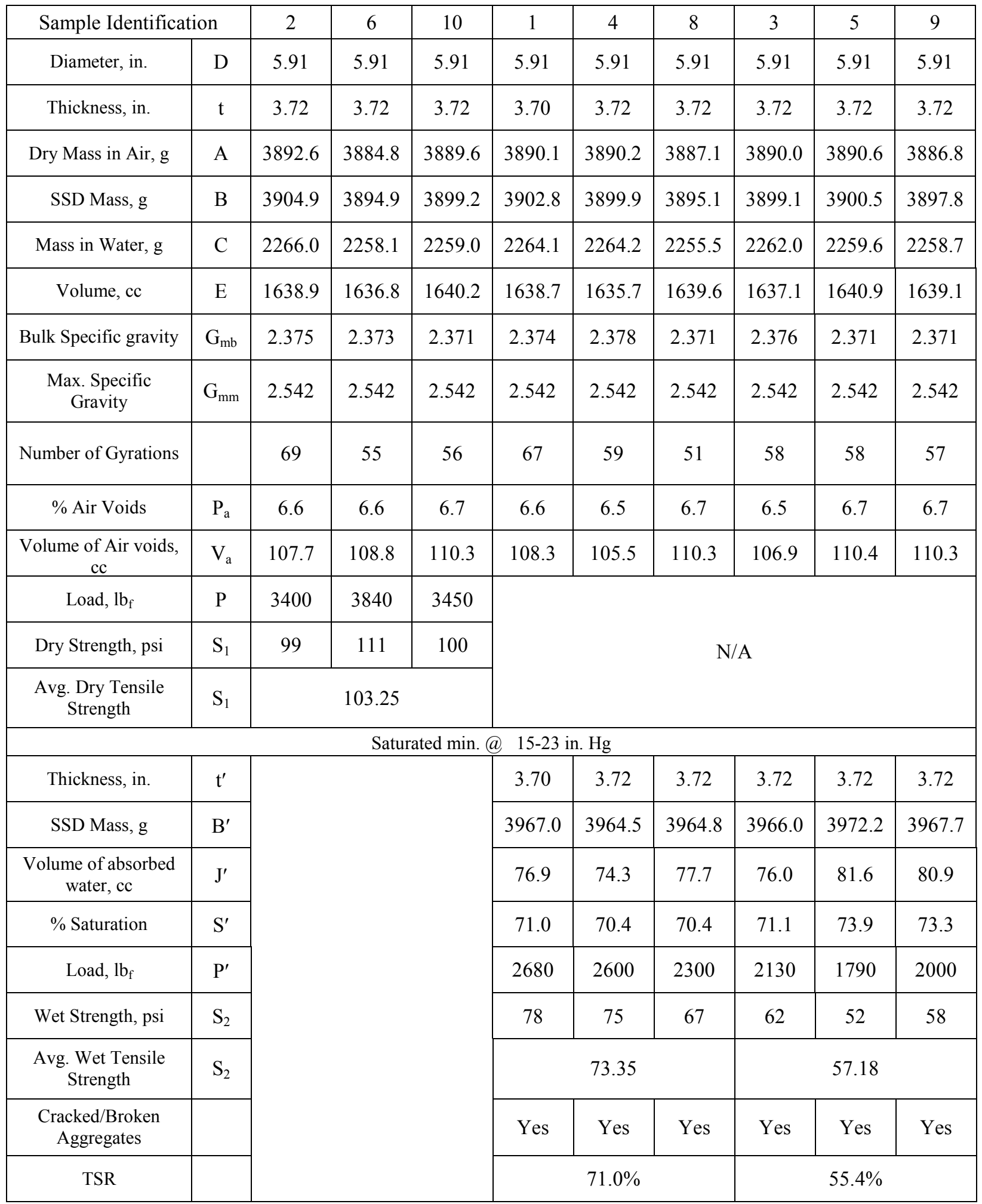


Project: CK 19mm

Additive: None
Compaction Method: Gyratory Compactor

Dosage: None

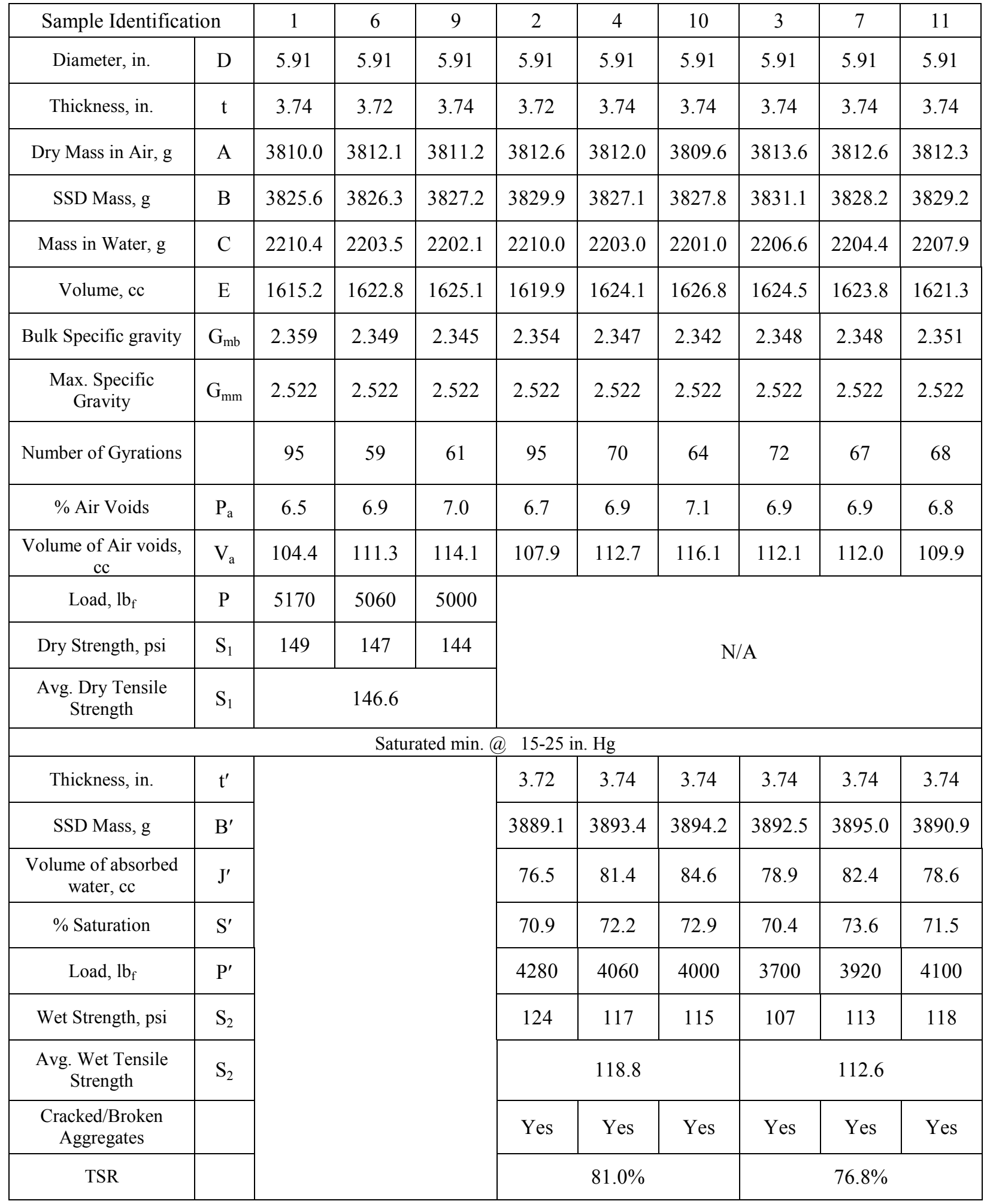


Project: CK 19mm

Additive: Liquid Anti-strip

Additive: Liquid Anti-strip
Compaction Method: Gyratory Compactor

Dosage: $0.5 \%$ by Binder weight

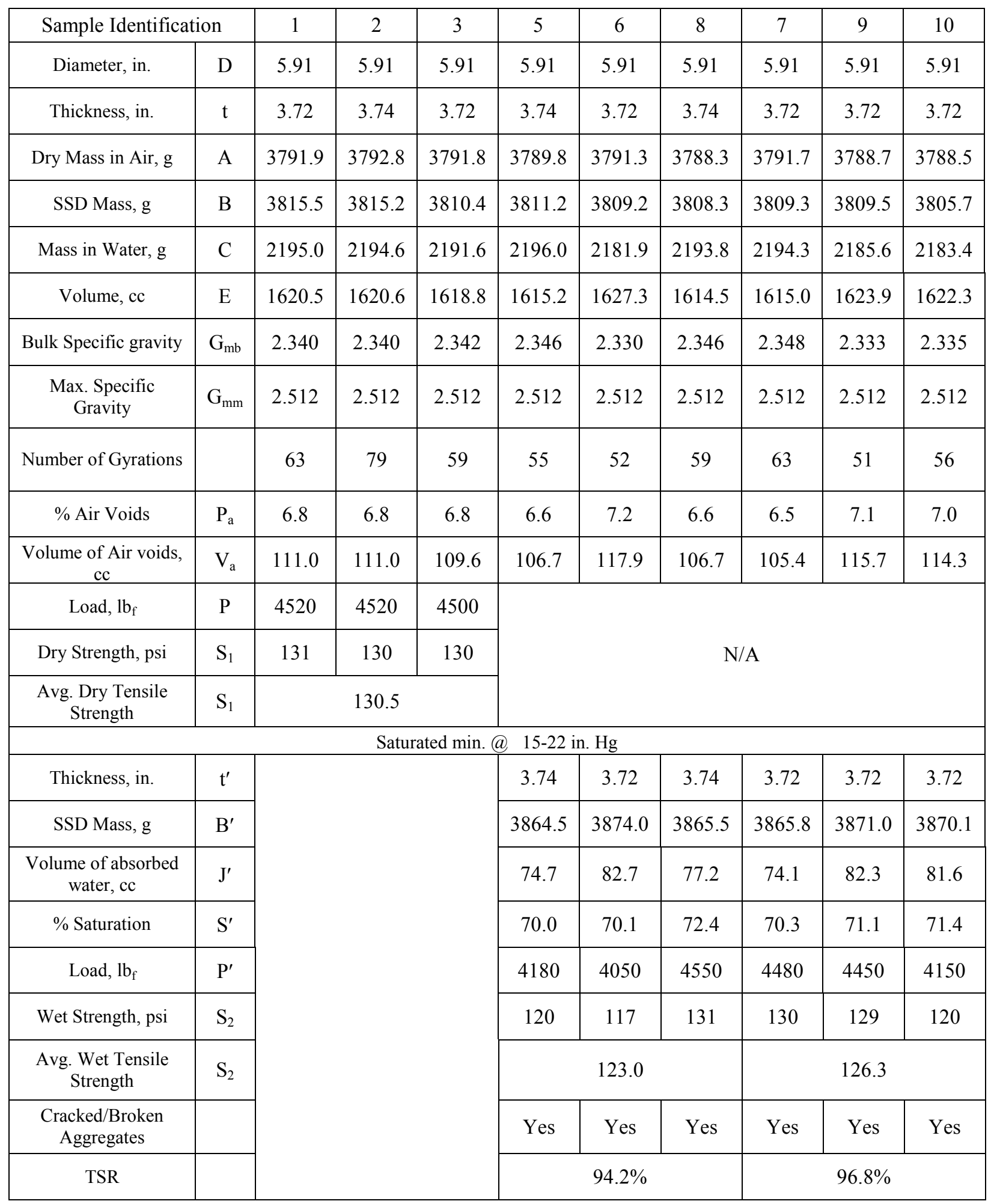

